\title{
Geosmin depuration from fish
}

\author{
Edward Schram
}

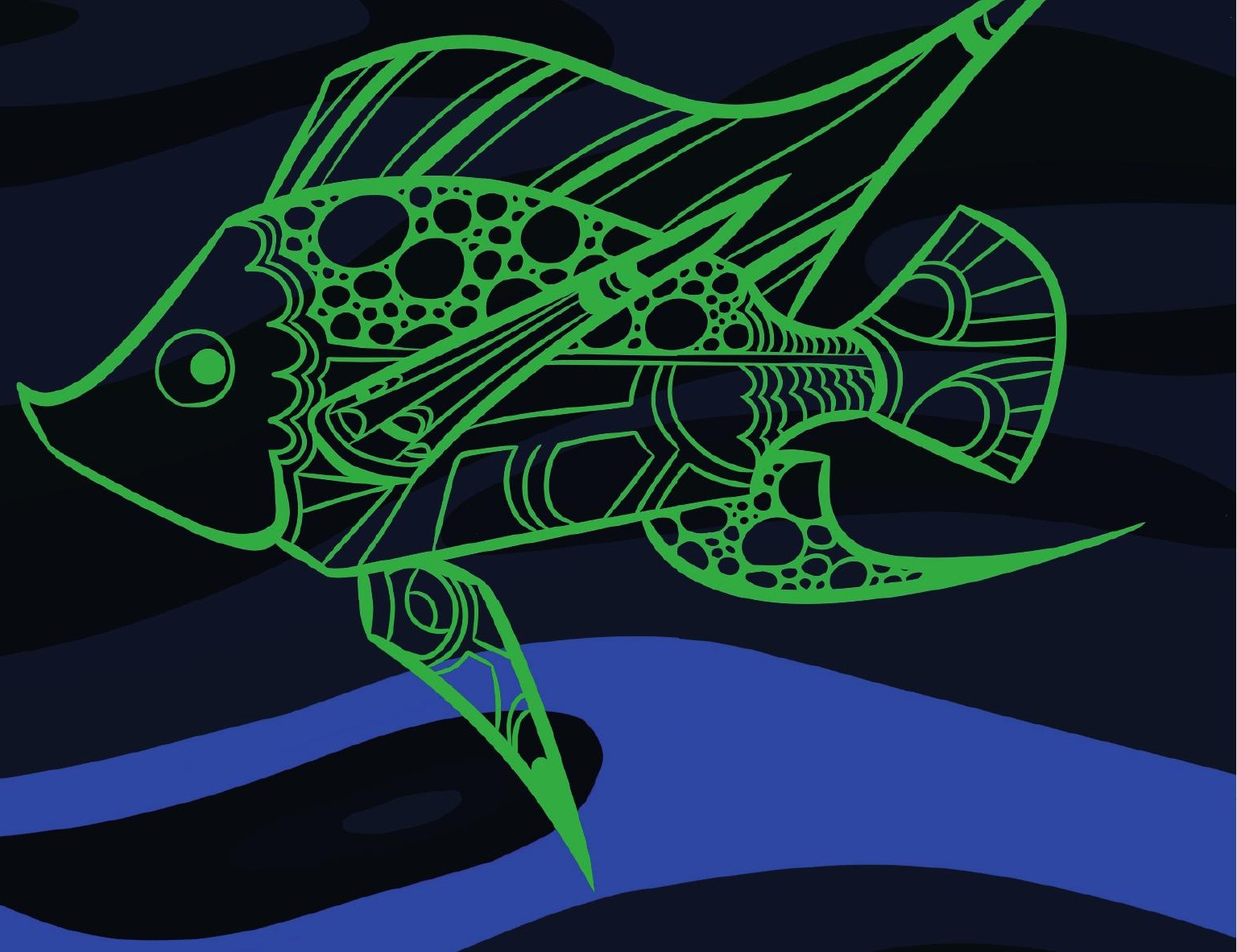




\section{Propositions}

1. In contrast to current scientific consensus, biotransformation of geosmin in fish is probable.

(This thesis)

2. The lipid content of tissues and organs is far less important for the distribution of geosmin in the fish body than suggested by Howgate (2004).

(This thesis)

Howgate, P., 2004. Tainting of farmed fish by geosmin and 2-methyl-iso-borneol: a review of sensory aspects and of uptake/depuration. Aquaculture 234(1-4), 155-181.

3. In contrast to Jobling (1981)'s suggestion, the final temperature preferendum of a fish species cannot be used to determine its optimal growth.

Jobling, M., 1981. Temperature tolerance and the final preferendum - rapid methods for the assessment of optimum growth temperatures. Journal of fish biology 19, 439-455.

4. The claim that the electric field of a pulse trawler causes mass mortality among demersal fish and benthic organisms (anonymous, 2018), is not supported by in situ assessments (Schram and Molenaar, 2019).

Anonymous, 2018. Electric 'pulse' fishing: why it should be banned. http://www.bloomassociation.org/en/wp-content/uploads/2018/01/electric-fishingadvocacy.pdf.

Schram, E., Molenaar, P., 2019. Direct mortality among demersal fish and benthic organisms in the wake of pulse trawling (No. C097/19). Wageningen Marine Research.

5. Independent scientists cannot be activists.

6. It is not always easy to find motivation to solve luxury problems.

Propositions belonging to the thesis, entitled

Geosmin depuration from fish

Edward Schram

Velserbroek, 9 September 2020 



\title{
Geosmin depuration from fish
}

\author{
Edward Schram
}




\section{Thesis committee}

\section{Promotors}

Prof. Dr J.A.J. Verreth

Emeritus Professor of Aquaculture and Fisheries

Wageningen University and Research

Dr J.W. Schrama

Associate Professor, Aquaculture and Fisheries Group

Wageningen University and Research

Prof. Dr A.J. Murk

Professor of Marine Animal Ecology

Wageningen University and Research

\section{Other members}

Prof. Dr J. Komen - Wageningen University and Research Prof. Dr J. van Rijn - Hebrew University of Jerusalem, Israël Prof. Dr J. Martens - Catholic University Leuven, Belgium Prof. Dr J.B. Luten - Wageningen University and Research

The research was conducted under the auspices of the graduate school of WIAS (Wageningen Institute of Animal Sciences). 


\title{
Geosmin depuration from fish
}

\author{
Edward Schram
}

Thesis

submitted in fulfilment of the requirements for the degree of doctor at Wageningen University

by the authority of the Rector Magnificus

Prof. Dr A.P.J. Mol,

in the presence of the

Thesis Committee appointed by the Academic Board

to be defended in public

on Monday 14th of December 2020

at 1.30 p.m. in the Aula 
Edward Schram

Geosmin depuration from fish 148 pages.

PhD thesis, Wageningen University, Wageningen, NL (2020)

With references, with summaries in English

ISBN: 978-94-6395-558-4

DOI: https://doi.org/10.18174/531865 




\section{Abstract}

Off-flavour described as 'earthy-musty' is commonly reported in fish raised in land-based aquaculture systems. Bioconcentration in fish of lipophilic geosmin produced by microbiota is regarded as the most important cause for this off-flavour. Despite that off-flavour in fish is an extensively studied and well documented problem, satisfactory solutions are lacking. The most promising solution on a short notice is the optimization of geosmin removal from fish prior to harvest, i.e., the off-flavour depuration process. This depuration process however is not always effective nor reliable. Hence, further optimization is needed to prevent market entrance of off-flavoured fish. The general objective of this thesis was therefore to improve off-flavour depuration processes, with a focus on geosmin excretion. The experimental work conducted in this thesis leads to the following conclusions regarding the bioconcentration of geosmin in fish:

- Rainbow trout bioconcentrates waterborne geosmin, but in vivo bioconcentration is less than the general fish bioconcentration model for moderately lipophilic compounds predicts based on theoretical rate constants.

- Geosmin distribution within the body of rainbow trout and Nile tilapia is not exclusively governed by the lipid content of tissues/organs.

- Geosmin depuration from European eel is not affected by the water renewal rate of depuration tanks.

- Geosmin depuration from Atlantic salmon is enhanced by increased water renewal rate of depuration tanks.

- Geosmin elimination from European eel does not follow the generally accepted passive diffusion mechanism for excretion of lipophilic chemicals. We assume that geosmin biotransformation by the eel is probable.

- Exercise (swimming) enhances geosmin excretion by European eel and reduces the time required to depurate off-flavours from fish.

- Fed Nile tilapia eliminate geosmin faster from their ovaries compared to starved fish.

- The rate of geosmin elimination from muscle tissue and ovary is similar in Nile tilapia.

This thesis shows that there is more to geosmin bioconcentration in fish than passive partitioning over water and lipid compartments. The physiology underlying the bioconcentration process remains to be fully elucidated. Yet this thesis presents various measures for the optimization of off-flavour depuration processes that can be readily adopted by the aquaculture industry. 



\section{Contents}

$\begin{array}{lll}\text { Chapter } 1 & \text { General introduction } & 11\end{array}$

Chapter 2 Experimental validation of geosmin uptake in rainbow trout, 23

Oncorhynchus mykiss (Waldbaum) suggests biotransformation

Chapter 3 Effects of exercise and temperature on geosmin excretion by 39

European eel (Anguilla anguilla)

Chapter $4 \quad$ Geosmin depuration from European eel (Anguilla anguilla) is not

affected by the water renewal rate of depuration tanks

Chapter 5 Interactive effects of temperature and water exchange of

depuration tanks on geosmin excretion by Atlantic salmon (Salmo salar)

Chapter 6 Effect of feeding during off-flavour depuration on geosmin

excretion by Nile tilapia (Oreochromis niloticus)

Chapter 7 General discussion

Appendices References

Summary

Acknowledgements

About the author

Training and supervision plan 

1. General Introduction 


\subsection{Taints and off-flavours in seafood}

A taint or an off-flavour in food results from the presence of compounds giving the food undesired odour or taste. Strictly speaking taints distinguish from off-flavours based on the origin of the causative chemicals. A taint results from contamination by chemicals from an external source whereas in case of off-flavours the chemicals originate from the food itself (Ridgeway et al., 2010). Many chemicals from various sources that may cause taints have been described (reviewed by Ridgeway et al., 2010; Mottram, 1998; Whitfield, 1998). External sources of taint causing chemicals include packaging, storage, water, cleaning products, microbial products and other foods (cross contamination). Internal sources for off-flavour causing chemicals include for example lipid oxidation products and microbial spoilage products. The distinction between taint and off-flavour is not consistently used and sensory issues with food referred to as off-flavours may actually be taints. In most cases, levels in food of taint causing chemicals are very low and they rarely pose a food safety risk. Yet taints are a major concern for the food industry as it may lead to low quality and low consumer appreciation (Ridgeway et al., 2010).

Also seafood may be affected by taints or off-flavours. In lipid rich products off-flavours are mainly due to organic compounds like amongst others aldehydes, ketones and alcohols produced by lipid auto-oxidation (Labuza \& Dugan, 1971 in McGill et al., 1974). Lean fish like cods can suffer from typical cold storage flavours which is caused by the formation of heptcis-4-enal during frozen storage (McGill et al., 1974). Tainting compounds in aquatic environments originate from anthropogenic pollution as well as natural sources. They may enter aquatic organisms via their diets or via absorption from the water (Whitfield, 1999). Tainting by pollutants includes for example contamination with thiols, anisoles and ketones from pulp mill effluents (Paasivirta et al., 1983) and terpenes from wood processing (Rogers, 1978). Chlorophenols originating e.g. from water chlorination practices can cause typical aseptic taints (Suffet et al., 1996). Oil spills or other water pollution with fossil fuels can cause petroleum like taints in seafood (Motohiro, 1983). Natural dietary taints include iodine like taints in prawns and shrimp that are caused by dietary sources of 2,6-dibromophenol (Whitfield, 1998) and 'rotten' taints in fish caused by consumption of decaying organic matter (Tucker and Van der Ploeg, 1999).

Various microbial products may cause taints in fish. Examples include heptanal produced by Cryptomonas causing a rancid taint and fishy taints caused by dimethylsulfide (DMS) produced by Asterionella (reviewed by Tucker, 2000). A common taint reported in fish is described as 'earthy-musty' and is often, including in this thesis as of this point, strictly speaking incorrectly referred to as 'off-flavour'. The 'earthy-musty' off-flavour is attributed to various compounds (Tucker, 2000; Howgate, 2004) such as haloanisoles and 2-isopropyl-3-methoxypyrazine, 2- 
methylisoborneol (MIB) and geosmin; the latter two being the most important. This thesis reports on the bioconcentration of geosmin in cultured fish.

\subsection{Geosmin}

The irregular sesquiterpene and bicyclic alcohol (4S,4aS,8aR)-4,8a-Dimethyloctahydro-4a(2H)naphthalenol was first named "geosmin" by Gerber and Lechevalier in 1965 (Gerber and Lechevalier, 1965). Geosmin means "earth smell" which is derived from the ancient Greek geo (earth) and osme (smell). Geosmin is a secondary metabolite produced by a wide range of microbiota present in soils and aquatic environments. Actinobacteria, myxobacteria, proteobacteria, cyanobacteria and fungi are all recognized as geosmin producers (Watson, 2003; Darriet et al., 2000; Dickschat et al., 2005; Suurnäkki et al., 2015). However, there are also yet to be identified microorganisms with the capacity to synthesize geosmin (Lukassen et al., 2017). Geosmin biosynthesis and factors affecting its production by microbiota are not yet fully understood (reviewed by Liato and Aïder, 2017). Geosmin is believed to be biologically active in biofilms (Watson, 2003) and play a role in quorum sensing (Schrader and Blevins, 1999 in Liato and Aïder, 2017).

Geosmin has also been suggested to play a role in the urban myth that camels in the desert find water by the smell of it, except that they do not smell water but geosmin. In return, the camels widely disperse the spores of the microbial geosmin producers (Chater, 2015). No need to be a camel to smell geosmin however. Humans can easily smell low levels of geosmin, i.e., the sensory detection limit is very low ( $0.015 \mu \mathrm{g} / \mathrm{l}$ in water, Persson, 1980). In fact most people are familiar with the smell and taste of geosmin: the distinct smell at a florist, the earthy smell of soil, the smell of summer rain after a long period of drought and the earthy taste of beetroots are all caused by geosmin. These smells and taints may be considered, arguably, pleasant but geosmin receives less appreciation when it appears as an 'earthy' tainting compound in food and beverages. Well known examples of problematic geosmin tainting are drinking water (e.g. Watson et al., 2000), wine (Darriet et al., 2000), fruits and vegetables (Liato and Aïder, 2017), wheat grain (Jeleń et al., 2003) and fish (reviewed by Howgate, 2004).

\subsection{Geosmin off-flavour in aquaculture}

Aquaculture is the farming of aquatic organisms including crustaceans, molluscs, plants, algae and fish. Aquaculture dates back to as early as $2500 \mathrm{BC}$ but it is only in the last decades that the aquaculture industry became a very significant global supplier of seafoods next to fisheries. Aquaculture is characterized by its wide variety of cultured species and culture systems. Fish culture systems can be classified by their location (e.g. land-based, lakes, rivers, near shore, off shore), feed sourcing (e.g. naturally produced within the system versus externally sourced formulated diets), housing facilities (e.g. ponds, cages, tanks), water 
management (e.g. stagnant, flow through or recirculating) and intensity of production (low or high yields per unit of surface area or water volume). Systems may be tailored to meet species specific requirements and different systems may be used for different life stages within a production cycle.

Earthy-musty off-flavour issues in aquaculture are in general associated to land-based aquaculture production systems with high nutrient loadings. In practice this means that offflavours are reported in fish produced in pond systems and recirculating aquaculture systems (RAS). Earthy-musty off-flavours in fish are however not restricted to cultured fish; also fish from wild populations may suffer from this problem. Documentation of earthy-musty offflavour in fish from wild populations dates back to 1558 when Conrad Gessner stated that the flesh of tench (Tinca tinca L.) may have a muddy taste (Persson, 1995). The first scientific paper on off-flavoured fish was published in 1910 by Léger (in Persson, 1995), who described muddy off-flavours in rainbow trout (Oncorhynchus mykiss) in relation to the presence of cyanobacteria. Thaysen (1936) linked off-flavour for the first time to the presence of actinomycetes in rivers based on his observations in wild-caught salmon, and suggested the uptake of organic compounds produced by actinomycetes in the fish caused the off-flavour (in Azaria and van Rijn, 2018). The first thorough description of earthy-musty off-flavoured fish originating from aquaculture comes from Aschner et al. (1969). They also associated offflavours to the presence of cyanobacteria, this time in common carp (Cyprinus carpio) farmed in outdoor ponds in Israel. Since then earthy-musty off-flavours have been described for various, widely different farmed aquatic species, geographical regions and aquaculture production systems. Well known examples of earthy-musty off-flavours in aquaculture include channel catfish (Ictalurus punctatus) produced in ponds in the United States (Tucker, 2000), rainbow trout (Oncorhynchus mykiss) produced in ponds (Robin et al., 2006) and European eel (Anguilla anguilla) produced in RAS (own unpublished data). Geosmin and MIB are considered to be responsible for the majority of off-flavour incidences in aquaculture (reviewed by Howgate, 2004). Off-flavour is not a species, rearing system or location specific problem, but rather a potential problem for aquaculture production in ponds, recirculation systems (RAS) and flow through systems. The commonality is the exposure of fish to geosmin and/or MIB produced by microbiota in the systems or present in the system's intake water source.

In aquaculture systems actinomycetes and cyanobacteria are recognized as the main groups of geosmin producing microbiota (Azaria and van Rijn, 2018). Saunders et al. (2011) confirmed the role of cyanobacteria in outdoor pond systems, but also showed that in RAS usually suspected actinomycetes (Guttman and van Rijn, 2008) can only be held responsible for part of the total geosmin production capacity. The largest part of the production capacity was attributed to several groups of currently unidentified bacterial phyla (Saunders et al., 2011; Lukassen et al., 2017). Interestingly, only $0.001-1 \%$ of the entire microbial community of a RAS 
is capable of producing geosmin (Lukassen et al., 2017). Field observations by farmers and a limited farm survey among eel farms in The Netherlands and Germany within the context of a Dutch national project on off-flavour in farmed fish, showed that off-flavour incidence is highly variable, not only among farms but also within farms. At farm level, geosmin concentrations in the rearing water of eel RAS were found to vary over time. Certain farms always had problematic geosmin levels in the rearing water and subsequently always suffered from offflavoured crops, other farms occasionally showed too high levels of geosmin whereas at other farms geosmin levels were never problematic (own unpublished data). This study showed that it is possible to farm fish in RAS without off-flavour issues, but why was not answered. All these farms had an equal design, management and feed, providing no explanation for the variability among farms. Preliminary results of this farm survey also revealed that within a RAS the nitrifying biofilter (be it a trickling filter or a moving bed filter) is likely to be the main source of geosmin as for the high geosmin concentrations measured in biofilms, which is confirmed by other studies (e.g. Houle et al., 2011). Also in marine RAS the nitrifying biofilter was found to harbour the largest quantity of geosmin production capacity (Lukassen et al., 2019).

Earthy-musty off-flavour in farmed fish has been postulated as one of the major economic problems for the aquaculture industry (Engle et al., 1995; Vallod et al., 2007; Robin et al., 2006). For the channel catfish industry in the United States it is estimated that more than $30 \%$ of the potential revenue is lost due to off-flavour (Smith et al., 2008) and various studies estimated that off-flavour adds 0.04 to $0.26 \mathrm{US} \$ / \mathrm{kg}$ fish to the total production costs (in Tucker, 2000). For the European aquaculture industry the economic impact of off-flavour has not been systematically studied. Given the trend towards more closed systems it is clear that the impact of off-flavour will increase rather than decrease in the near future. Economic losses result from consumer rejection of off-flavoured fish. Producers suffer direct losses when they are forced to withdraw fish crops from the market or are forced to sell fish crops at lower prices. Indirect losses are caused by a reduction of market volumes and prices due to low consumer appreciation of aquaculture products. In addition, removing off-flavours from fish crops by depuration procedures prior to market entrance (see below) results in loss of biomass, additional investments and additional operational costs, which may all significantly contribute to costs prices of the farmed fish.

The levels of geosmin and MIB normally observed in off-flavoured fish are not toxic for fish nor human consumers of these off-flavoured fish (Dionigi et al., 1993; Nakajima et al., 1996). As such, earthy-musty off-flavours pose no animal health or food safety risk. It is exclusively a product quality issue. 


\subsection{Mitigation of earth-musty off-flavours in aquaculture}

The chain of events leading to off-flavoured fish (Fig. 1) starts with the microbial production of geosmin and other off-flavour causing chemicals. Once these compounds are released to the water, and this probably requires the disintegration of cells (Jüttner and Waton, 2007), they are quickly absorbed by the exposed fish and concentrated in their lipid tissues (see below). This chain of events allows for different approaches to reduce off-flavour incidence in farmed fish. Three main strategies can be distinguished:

1) Prevention of production: preventing geosmin bioconcentration in fish by preventing its microbial production;

2) Removal from the water: preventing geosmin bioconcentration in fish by removing the chemical from the fish culture water;

3) Removal from the fish: preventing the harvest of off-flavoured fish by facilitating geosmin excretion from fish prior to harvest.

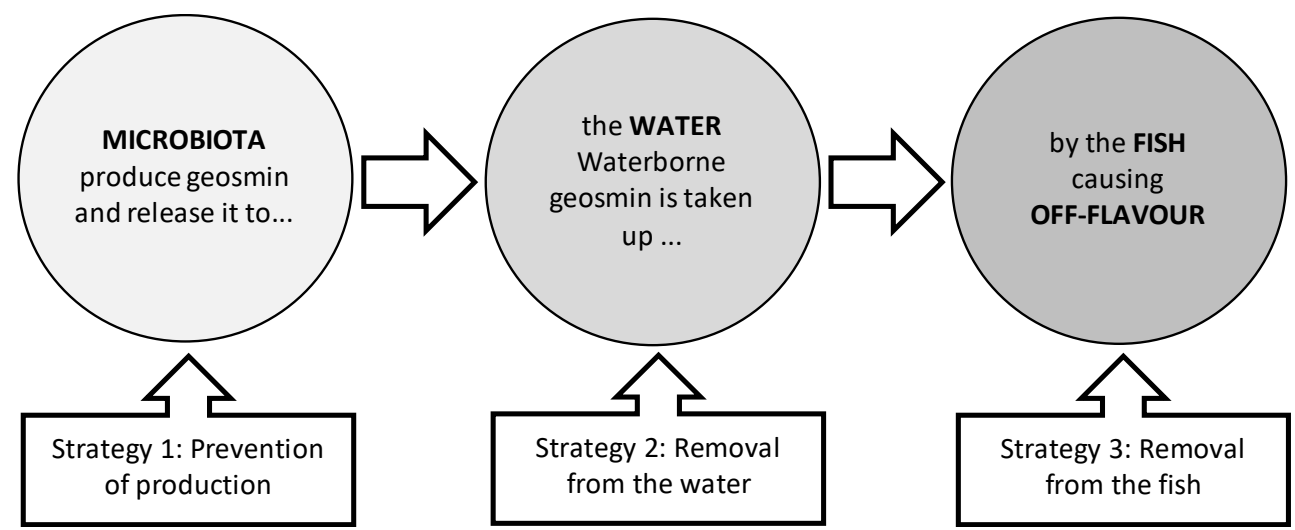

Fig. 1. Chain of events leading to geosmin off-flavours in fish and the three strategies for off-flavour mitigation.

This thesis focuses on the third strategy: removal of geosmin from fish. Geosmin removal can be achieved on the basis of the reversibility of geosmin bioconcentration. The equilibrium between geosmin concentrations in fish and water re-establishes when one of the concentrations changes. Transfer of geosmin contaminated fish to uncontaminated water results in a net geosmin flux from the fish to the water. Fish are no longer off-flavoured in case excretion continues until levels of geosmin and other off-flavour causing chemicals are reduced below their human sensory detection limits. This so called off-flavour depuration procedure is currently (and at the start of this thesis) the only remedy against off-flavour the aquaculture industry uses. The off-flavour depuration process is however not always reliable 
and its results can be variable and unpredictable and off-flavoured fish continue to enter the market. In addition, the process can substantially increase production costs as mentioned above. Clearly the off-flavour depuration process needs to be optimized towards shorter depuration time and higher reliability. A theoretical framework for the uptake and excretion of geosmin has been built on extensive knowledge of bioconcentration of lipophilic compounds in fish and underlying physiological mechanisms (Howgate, 2004). This theoretical framework provides a solid basis for deducing measures to improve geosmin depuration processes, except that it has not been validated experimentally. This thesis therefore addresses the question to which extent the existing theoretical framework correctly describes geosmin uptake and excretion by fish.

\subsection{Theoretical framework for bioconcentration of geosmin in fish}

Bioconcentration of waterborne organic chemicals by fish has been extensively studied for chemical contaminants (reviewed by Streit, 1998). Bioconcentration is the process in which a chemical is absorbed by an organism through it respiratory and dermal surfaces. Intestinal absorption of chemicals from dietary source are not considered (Arnot and Gobas, 2006). The relative importance of chemical uptake via respiratory surfaces, the gills in case of fish, depends on how lipophilic a chemical is. The lipophilic nature of a chemical is often described by the decadic logarithm (logKow) of its octanol/water partition coefficient Kow. For chemicals with logKow values between 3 and 6 exchange between water and fish predominantly takes place via the gills. Bioconcentration of these lipophilic chemicals in fish is considered a passive partitioning process over water and lipid fractions in fish (Gobas and Mackay, 1987). Diffusion of the chemical over the water/blood barrier in the gills is driven by the difference in chemical potential or fugacity between water and lipid fractions in the system. Equilibrium is reached when the fugacities in water and lipid fractions are equal (Howgate, 2004). Distribution of lipophilic chemicals over different tissues within an organism is influenced by the tissue's lipid contents and perfusion (Nichols et al., 1990). Ultimately lipophilic chemicals reach equilibrium in the lipid fraction of different tissues in an organism (Bertelsen et al., 1998; Tietge et al., 1998; Gobas et al., 1999; all in Arnot and Gobas, 2006). The equilibria between tissues within the fish and between the fish and the surrounding water are dynamic, meaning that in equilibrium exchange of chemicals between different compartments (e.g. fish and water) continues but with a net result of zero exchange. Uptake of chemicals through the gills is reversible and the equilibrium will re-establish when the chemical concentration in one of the compartments changes.

Geosmin is moderately lipophilic (logKow $=3.57$ ). On this basis Howgate (2004) proposed that geosmin bioconcentrates in fish according to the generic bioconcentration process for moderately lipophilic compounds described above. Howgate (2004) consequently predicted 
that the difference in affinity for water and lipid ultimately leads to equilibrium concentrations of geosmin that are 400 times higher in a fish with a lipid content of $10 \%$ than in the surrounding water. Howgate (2004) adapted the generally accepted mathematical model for the bioconcentration for moderately lipophilic chemicals in aquatic organisms (reviewed by Arnot and Gobas, 2006) to geosmin bioconcentration. To this end he excluded biotransformation, faecal egestion and growth dilution as these factors were considered to be insignificant for geosmin bioconcentration. The so obtained simplified mathematical model describes geosmin bioconcentration under the assumption of constant geosmin in the water:

$\frac{d C_{F}}{d t}=k_{1} C_{W}-k_{2} C_{F}$

where $\mathrm{dC}_{\mathrm{F}} / \mathrm{dt}$ is the change of the chemical concentration in the fish $C_{F}(\mathrm{~g} / \mathrm{kg})$ over time, $C_{W}$ the constant chemical concentration in the water $(\mathrm{g} / \mathrm{l}), k_{1}$ the first order kinetic rate constant $(1 / d)$ for the uptake from the water and $k_{2}$ the first order kinetic rate constant $(1 / d)$ for excretion to the water. This model, referred to as one-compartment model by Howgate (2004), allows for the prediction of geosmin absorption and excretion by fish exposed to variable (but not varying) geosmin concentrations in water. The uptake $\left(k_{1}\right)$ and elimination $\left(k_{2}\right)$ rate constants depend on factors such as fish species, fish size, lipid content and water temperature. The effect of water temperature acts mainly through the increase in gill ventilation rate to compensate for the decrease in oxygen solubility in water and increase in physiological oxygen demand concurring with temperature increase (Howgate, 2004; Neely, 1979). Experimental data on absorption and elimination of geosmin by fish are scarce. Absorption and excretion rate constants of geosmin were calculated for a reference rainbow trout $\left(750 \mathrm{~g}\right.$, body lipid content $\left.10.0 \% \mathrm{w} / \mathrm{w}, 11^{\circ} \mathrm{C}\right)$ by Howgate $(2004)$ based on equations for $k_{1}$ and $k_{2}$ established by Gobas and Mackay (1987). The obtained rate constants for the reference fish were then calculated by Howgate (2004) into values representing rainbow trout of different body weights (200-1000 g) at different water temperatures ( 5 to $25^{\circ} \mathrm{C}$ ) based on the effects of water temperature and body weight on gill ventilation rate as established by Neely (1979). Howgate's (2004) one-compartment model and the availability rate constants (be it calculated values) allow for the prediction of geosmin levels in fish as a function of water concentrations based on the following equations (Howgate, 2004):

$$
\begin{aligned}
& C_{F(t)}=C_{W} \frac{k_{1}}{k_{2}}\left(1-e^{\left(-k_{2} t\right)}\right) \\
& C_{F(t)}=C_{F(t=0)} e^{\left(-k_{2} t\right)}
\end{aligned}
$$

where is $C_{F(t)}$ the geosmin concentration in the fish as a function of time and $C_{F(t=0)}$ the geosmin concentration in fish at $t=0$. Eq. (1) can be used to calculate the change in concentrations in the fish for a time interval for a given water and initial fish body concentration. Eq.(2) describes the uptake of geosmin by the fish as a function of time and the water concentration. Eq. (3) 
describes the elimination of geosmin from fish to the water when the geosmin concentration in the water is zero. As an example of model predictions Figure 2 presents the uptake of geosmin in rainbow trout during exposure to a constant geosmin concentration in the water of $100 \mathrm{ng} / \mathrm{l}$ for $200 \mathrm{~h}$ followed by excretion after transfer of the fish to geosmin free water (constant $0 \mathrm{ng} / \mathrm{l})$. Uptake $\left(k_{1}=233\right)$ and excretion $\left(k_{2}=0.58\right)$ rate constants for rainbow trout of $200 \mathrm{~g}, 10 \%$ lipids at $15^{\circ} \mathrm{C}$ were used (Howgate, 2004). The initial geosmin concentration in the fish is zero. After $200 \mathrm{~h}$ of exposure the geosmin concentration in the fish approaches equilibrium with the water. The equilibrium concentration in this fish can be predicted as $k_{1} / k_{2}$ $x C_{w}$ which yields $40 \mathrm{ng} / \mathrm{g}$ in this example. Already after seven hours of exposure the geosmin levels in the fish reach the (arbitrary) human sensory detection limit of $6 \mathrm{ng} / \mathrm{g}$. Following the transfer of the contaminated fish to geosmin free water, it takes $78 \mathrm{~h}$ of excretion for the geosmin level in the fish to return to the sensory detection limit. These times are specific for the fish, the exposure conditions and the sensory detection limit chosen for this example. However, the observation that geosmin exposure rapidly results in off-flavoured fish while depurating the off-flavours from the fish takes more time, is generic.

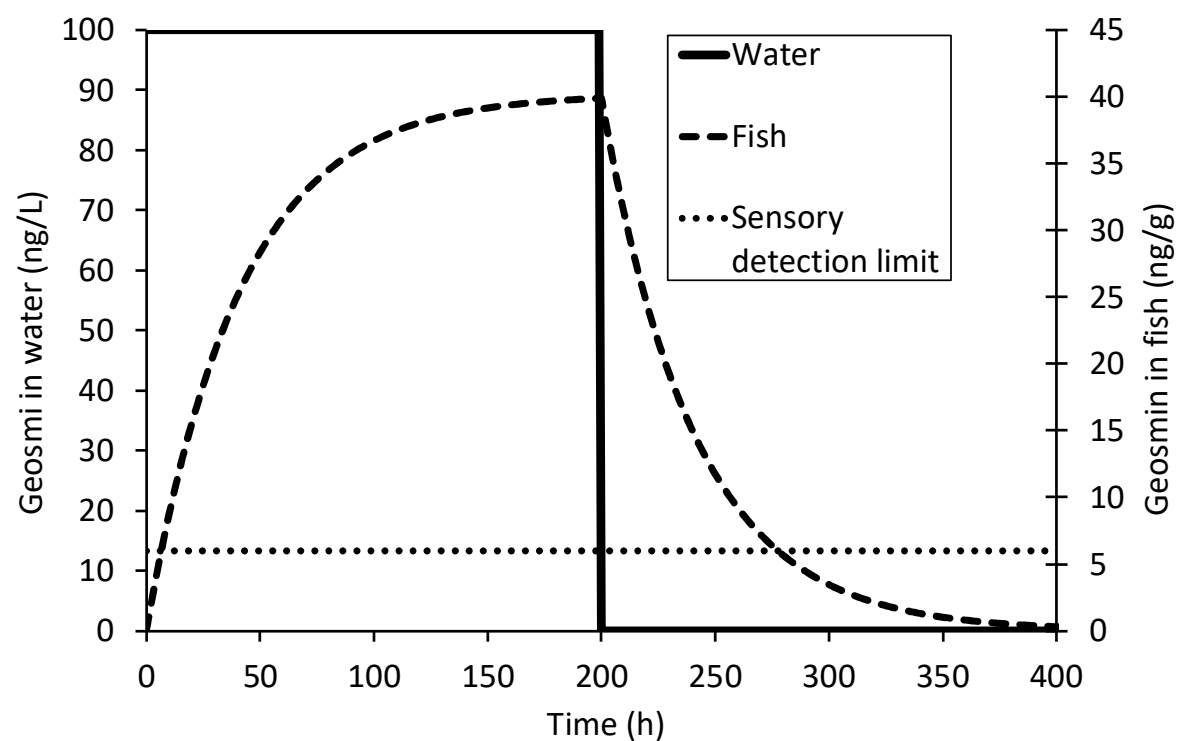

Fig. 2. Development of whole body concentration of geosmin $\left(\mathrm{C}_{\mathrm{F}}\right)$ in rainbow trout $(200 \mathrm{~g}$, $10 \%$ lipids at $15{ }^{\circ} \mathrm{C}, k_{1}=233, k_{2}=0.58$ ) over time following exposure to a water geosmin concentration $\left(C_{W}\right)$ of $100 \mathrm{ng} / \mathrm{l}$ and $0 \mathrm{ng} / \mathrm{l}$.

\subsection{Problem definition and objectives}

Despite that geosmin off-flavour in farmed fish is an extensively studied and well documented problem, satisfactory solutions for the problem are lacking. Optimization of geosmin removal from fish prior to harvest, i.e., off-flavour depuration, is most promising on a short notice compared to the other off-flavour mitigation strategies outlined above. Off-flavour 
depuration systems are generally operated with low water renewal rates to limit water consumption and at temperatures below normal rearing temperatures. Also fish are generally not fed during off-flavour depuration. It seems that the aquaculture industry optimized its offflavour depuration processes towards minimal operational costs, water use, energy use and biomass loss rather than optimal removal of geosmin (and MIB) from fish stocks. Howgate's (2004) theoretical framework for geosmin bioconcentration allows for deducing measures that potentially improve the depuration process. Here, improving includes both a reduction of the required depuration time as well as increased reliability and predictability of the process. The practical objective of this thesis is therefore to improve off-flavour depuration processes. To this end there is a clear need for in-depth studies on absorption, distribution, metabolism and excretion of geosmin by fish, because Howgate's (2004) theoretical framework relies heavily on concepts developed and studied for other lipophilic chemicals that were extrapolated to geosmin on the basis of its lipophilic nature. Only the predominant uptake of geosmin in fish via the gills has been confirmed experimentally (From and Hørlyck, 1984). Predicting fish body concentrations of geosmin related to absorption and excretion provides an important tool. However, whether the one-compartment model, its underlying assumptions and the calculated absorption and excretion rate constants indeed correctly describe geosmin uptake and excretion by fish has not been experimentally validated. It can be deduced from the theoretical framework for geosmin bioconcentration by fish presented by Howgate (2004) that there are two basic mechanisms to speed-up geosmin excretion and thereby reduce the required depuration time: 1 . measures aimed at increasing the rate at which geosmin is excreted by the fish, and 2. measures aimed at increasing the rate at which excreted geosmin is removed from the direct environment of the fish. The first mechanism centres around gill ventilation rate as excretion from blood to water is believed to be water flow limited (Schmieder and Weber, 1992). The second mechanism is based on prevention of re-absorption of excreted geosmin and maintaining the concentration gradient between water and fish; the driving force behind excretion. Howgate's (2004) one-compartment model is not suitable to predict effects of both mechanisms because it assumes constant geosmin concentrations in the water. This concentration is not necessarily constant when it is subject to geosmin absorption and excretion by fish and depuration system management. Therefore an extended model that allows the geosmin concentration in the water to vary over time as a function of these factors is needed to predict effects of measures aimed at improving offflavour depuration from the fish. This leads to the following objectives of this thesis:

1. To experimentally validate Howgate's (2004) one-compartment model for the uptake of geosmin uptake in fish;

2. To experimentally validate the hypothesis that geosmin is distributed over tissues based on the lipid content of tissues; 
3. To extent the one-compartment model such that it can be applied to systems in which geosmin levels vary due to uptake or excretion and system management;

4. To predict the effects of measures aimed at increasing the rate at which fish excrete geosmin, and those aimed at increasing the rate at which geosmin is removed from the depuration tank and their interactions;

5. To experimentally validate the effects of measures aimed at increasing the rate at which fish excrete geosmin, of measures aimed at increasing the rate at which geosmin is removed from the depuration tank and their interactions.

\subsection{Outline of this thesis}

Chapter 2 tested the hypothesis that Howgate's (2004) one-compartment model with calculated uptake and excretion rate constants correctly describes the uptake of geosmin by rainbow trout. To this end a geosmin exposure experiment in stagnant water investigated both the increase of geosmin in the fish and the resulting decline of geosmin in the water over time. Experimental data were compared with model predictions. For this purpose the onecompartment model, which assumes constant geosmin in water, was extended such that it accounted for a declining geosmin concentration in the water as a result of uptake in the fish and biotransformation. Chapter 2 also tested the hypothesis that geosmin tissue distribution is governed by lipid content. To this end geosmin concentrations were measured in the livers and in the liver free carcasses of experimental fish.

Chapter 3 tested the hypothesis that increased exercise and temperature promote geosmin excretion by fish. European eel loaded with geosmin were subjected to passive and forced swimming treatments at two different temperatures to investigate the decline of geosmin in the fish over time. Oxygen consumption was measured in the experiment to test the hypothesis that increased geosmin excretion is associated to increased gill ventilation to handle higher oxygen demands at higher temperatures and due to increased activity.

Chapter 4 tested the hypothesis that increased water exchange of depuration tanks promotes geosmin excretion by fish. The hypothesis is based on the notion that excretion is driven by the concentration gradient between water and fish and that removal of excreted geosmin maintains this gradient and renders it unavailable for re-uptake by the fish. European eel loaded with geosmin were depurated at three levels of tank water exchange. Geosmin was monitored in fish and water over time to be able to relate geosmin decline in the fish and its accumulation in the water to the level of depuration tank water exchange. Experimental data were compared to model predictions for which the one-compartment model was further extended such that it now also accounted for the removal of geosmin from depuration tanks due to continuous water exchange. 
Based on the findings of Chapter 4, a species specific response was suspected. Hence Chapter 5 also tested the hypothesis that increased water exchange of depuration tanks promotes geosmin excretion by fish but in another species: Atlantic salmon. In addition Chapter 5 tested the hypothesis that the two basic mechanisms to promote geosmin excretion interact such that increased excretion by the fish should be accompanied by increased geosmin removal from the direct environment to sort a maximal effect on net excretion and required depuration time. Experimental data were compared to a model prediction of interactive effects, using the extended model developed in Chapter 4.

Chapter 6 tested the hypothesis that feeding fish during off-flavour depuration promotes the excretion of geosmin. This hypothesis is based on two notions. First on the notion that feeding increases physiological oxygen demand in fish and thereby gill ventilation. Second on the suspected role of blood lipids in the transport of geosmin from peripheral tissues to the site of excretion, the gills, combined with reduced blood lipid levels in unfed fish. An experiment investigated the effect of feeding by monitoring the decline of geosmin in the fillets and ovaries of female Nile tilapia that were either fed or starved. Geosmin removal from fillets and ovaries were compared to determine whether required depuration time differs among tissues. This is relevant for the aquaculture production of sturgeon caviar for which female Nile tilapia served as a model. Tissues were also compared to shed additional light on the hypothesis that geosmin tissue distribution is governed by lipid content.

Chapter 7, the general discussion, addresses geosmin exposure in aquaculture systems, the three off-flavour mitigation strategies, the experimental work conducted with a focus on the mechanisms underlying the observed treatment effects and the validity of the current theoretical framework for geosmin bioconcentration. 


\section{Experimental validation of geosmin uptake in rainbow trout, Oncorhynchus mykiss (Waldbaum) suggests biotransformation}

Schram, E., Schrama, J.W., van Kooten, T., Kwadijk, C.J.A.F., Kampen, H., van de Heul, J.W., Verreth, J.A.J., Murk, A.J., 2018. Experimental validation of geosmin uptake in rainbow trout, Oncorhynchus mykiss (Waldbaum) suggests biotransformation. Aquaculture Research 49(2), 668-675. 


\section{Abstract}

The bioconcentration of waterborne geosmin in rainbow trout, Oncorhynchus mykiss (Waldbaum) was assessed. Fifty rainbow trout with a mean (SD) weight of 226.6 (29.0)g and lipid content of $6.2(0.6) \%(w / w)$ were exposed to geosmin in static water for $0,2,4,6,8,12$, 24, 36, 48 and $120 \mathrm{~h}$, with one tank containing five fish for each exposure period. Geosmin concentrations were measured in fish tissue and water samples collected over time. With time the geosmin concentration in the fish increased and decreased in the water. However the total absolute amount of geosmin in the system declined over time which could be explained by induction of biotransformation. This is in accordance with the decreasing lipid normalized geosmin levels in the liver compared to the liver-free carcass. Geosmin distribution within rainbow trout clearly is not exclusively governed by the lipid content of tissues. In vivo geosmin bioconcentration in rainbow trout is slower and the body burden reached is lower than the generally accepted theoretical model predicts. 


\subsection{Introduction}

Off-flavour is the presence of undesired sensory properties in food items. Most common in aquaculture products are earthy-musty off-flavours caused by the presence of the lipophilic chemicals geosmin (4S,4aS,8aR)-4,8a-Dimethyl-1,2,3,4,5,6,7,8-octahydronaphthalen-4a-ol) and 2-methylisoborneol (1,2,7,7-tetramethylbicyclo[2.2.1]heptan-2-ol, MIB) in fish tissues (Howgate, 2004). Geosmin and MIB are secondary metabolites produced by a wide range of microbiota common to land-based aquaculture systems. Actinomycetes and cyanobacteria are considered the most important geosmin and MIB producers in aquaculture systems (reviewed by Krishnani et al., 2008). Off-flavour in farmed fish is one of the most significant economic problems for land-based aquaculture (Vallod et al., 2007, Robin et al., 2006).

Fish rapidly bioconcentrate waterborne lipophilic chemicals in their tissues (reviewed by Streit, 1998). Geosmin and MIB are assumed to be predominantly exchanged between water and fish by passive diffusion via the gills (Howgate, 2004) given their respective octanol/water partition coefficients of 3.57 and 3.31 (Clark et al., 1990). Diffusion of the chemicals is driven by the difference in chemical potential or fugacity between water and lipid fractions in the system. Equilibrium is reached when the fugacities in water and lipid fractions are equal (Howgate, 2004). Distribution of lipophilic chemicals over different tissues within an organism is influenced by the tissue's lipid contents and perfusion (Nichols et al., 1990). Ultimately lipophilic chemicals reach equilibrium in the lipid fraction of different tissues in an organism (Bertelsen et al., 1998; Tietge et al., 1998; Gobas et al., 1999; all in Arnot and Gobas, 2006) and the lipid normalized chemical concentrations are then equal among tissues. Howgate (2004) presented a one-compartment model to describe the time-kinetics of geosmin and MIB bioconcentration in fish, including theoretical uptake and excretion rate constants for rainbow trout. In this model uptake and depuration are the two dominant processes in geosmin and MIB bioconcentration. Biotransformation, growth dilution and faecal egestion are assumed to be insignificant and therefore not included in the model. Howgate's (2004) model, the assumptions and theoretical rate constants have not been validated experimentally.

The first goal of the present study was to assess the accuracy of model-predicted geosmin bioconcentration in rainbow trout based on Howgate's (2004) theoretical rate constants. We hypothesized that experimental geosmin bioconcentration equals model-predicted bioconcentration. The second goal was to verify the assumption that uptake and depuration are the two dominant processes in geosmin bioconcentration. We predicted the uptake by the fish of geosmin from the water following first order kinetics. The geosmin removal from the water then equals the accumulation of geosmin in the fish. The third goal was to verify the assumption that within the fish geosmin is distributed according to the lipid content of tissues. We hypothesized that lipid-normalized geosmin concentrations in the whole fish and the liver are equal. To test these hypotheses we exposed rainbow trout, Oncorhynchus mykiss 
(Waldbaum) to waterborne geosmin for 0 up to $120 \mathrm{~h}$ in air-tight tanks with static water and monitored geosmin levels over time in water, whole fish, liver and head space air of the tanks.

\subsection{Materials and methods}

\section{Bioconcentration experiment}

The bioconcentration experiment was performed in 180 I polyester tanks with static water. The design of the geosmin exposure tanks aimed to minimize and quantify any geosmin losses via volatilisation and adsorption to the tank and its auxiliary equipment (system losses). To this end each tank was covered by a $6 \mathrm{~mm}$ thick glass cover sheet and sealed air-tight to the tank by Duct tape. The glass covers were equipped with a circular hatch (diameter $150 \mathrm{~mm}$ ) to allow for introduction of fish. The hatches were covered by glass sheets ( $200 \times 200 \mathrm{~mm})$ during the experiment.

Head space was minimized by maximum filling of the tanks with water. Teflon tubing was used where contact with tank water was inevitable (aeration, water sampling). Tubing (in and outflowing air, water sampling) entered the tank via air-tight transits. Each tank was equipped with an air-pump set at an air inflow of $300 \mathrm{ml} / \mathrm{h}$ for oxygen supply. Air was extracted from each tank by a central vacuum pump at a flow rate slightly above that of the incoming air to create an under-pressured head space in the tank. For each tank extracted air was washed over a glass gas washing bottle filled with 1 I methanol to collect any volatilized geosmin.

One day before the start of the bioconcentration experiment, a single batch of 1900 I local tap water was spiked with $8143 \mu \mathrm{l}$ of a $70 \mu \mathrm{g} / \mathrm{ml}$ geosmin (Sigma Aldrich) stock solution in acetone and mixed well, resulting in a nominal geosmin concentration of $308 \mathrm{ng} / \mathrm{l}$. Four hours before the start of the experiment, nine exposure tanks were filled with $170 \mathrm{l}$ of the geosmin solution. According to preliminary model predictions (see below) an initial geosmin level in the water above $300 \mathrm{ng} / \mathrm{l}$ should result in geosmin levels in water and fish above analytical detection limits at all sampling points. Fifty rainbow trout with a mean (SD) weight of 226.6 (29.0)g and a mean (SD) lipid content of $6.2(0.6) \%(w / w)$ were randomly split into ten groups of five fish. One group served as $\mathrm{t}=0$ fish sample. The other nine groups were randomly divided over nine exposure tanks at $t=0$. Fish were exposed to geosmin for ca. 2, 4, 6, 8, 12, 24, 36, 48 and 120 $\mathrm{h}$ with one tank for each exposure time prior to sampling.

A control treatment without fish was not included in the experiment as the stability of the geosmin concentration in the water of the exposure tanks had already been established in a preliminary stability study. The stability study was conducted in accordance with the OECD guideline for bioconcentration studies in fish (OECD, 2012), using two of the 9 identical exposure tanks filled with 170 I water spiked with geosmin. Tank water was aerated as described for the bioconcentration experiment. Water samples for geosmin analysis were 
collected from both tanks at $\mathrm{t}=0$ and $\mathrm{t}=120 \mathrm{~h}$. Geosmin concentrations were 160 and $155 \mathrm{ng} / \mathrm{l}$ and $\mathrm{t}=0$ and 160 and $150 \mathrm{ng} / \mathrm{l}$ at $\mathrm{t}=120 \mathrm{~h}$, which demonstrates that $97 \%$ to $100 \%$ of the geosmin concentration measured at $\mathrm{t}=0$ remains in the exposure tanks during $120 \mathrm{~h}$.

Water samples for geosmin analysis (250 $\mathrm{ml}$ in glass containers) were collected from each geosmin exposure tank at $\mathrm{t}=0$ and just before fish sampling and stored at $4{ }^{\circ} \mathrm{C}$. Upon fish sampling approximately $99 \%$ of the water volume was quickly drained from the exposure tank. Fish were euthanized by adding $3 \mathrm{ml} / \mathrm{l}$ phenoxy ethanol to the remaining tank water and then removed from the tank. Livers were dissected, pooled per tank and stored in glass containers at $-80^{\circ} \mathrm{C}$. Liver-free carcasses (the entire fish except for the liver) were pooled per tank, homogenized using a refrigerated mincer (DRC C10, PSV Group, Genainville, France) and stored at $-80^{\circ} \mathrm{C}$ in glass containers. Total biomass per tank was measured at $\mathrm{t}=0$; individual fish weight was measured upon fish sampling (Mettler PM40).

Dissolved oxygen concentration, and water temperature (Hach Lange Multimeter) were measured in each tank at $\mathrm{t}=0$ and upon fish sampling. Overall mean (SD) dissolved oxygen concentration was $5.5(0.9) \mathrm{mg} / \mathrm{l}$. Overall mean (SD) water temperature was $18.8(0.3)^{\circ} \mathrm{C}$.

Gas washing bottles were sampled upon fish sampling. Immediately after each fish sampling, the tank, air-stone, glass cover sheet and tubing were rinsed with $50 \mathrm{ml}$ methanol to wash off any adsorbed geosmin. All methanol samples were stored in glass bottles at $4{ }^{\circ} \mathrm{C}$ prior to geosmin concentration measurement.

The treatment of the fish was in accordance with Dutch law concerning animal welfare, as approved by the ethical committee for animal experimentation of Wageningen UR Livestock Research.

\section{Geosmin and lipid analysis}

Liver-free carcass samples and liver samples were thawed overnight at $4{ }^{\circ} \mathrm{C}$. From each sample a subsample of approximately $1 \mathrm{~g}$ was taken. To each subsample $100 \mu \mathrm{l}$ of internal standard solution (D5-geosmin in water, $1 \mu \mathrm{g} / \mathrm{ml}$, Sigma Aldrich) was added. Samples were extracted by accelerated solvent extraction (ASE, Dionex, Amsterdam, The Netherlands) at $40^{\circ} \mathrm{C}$ using a 15:85 (v/v) pentane-dichloromethane mixture. After extraction, $1 \mathrm{ml}$ of hexane was added to the extract. Extracts were concentrated to $1 \mathrm{ml}$ by gently evaporating the pentanedichloromethane mixture (Rotavap, Heidolph) and stored in $2 \mathrm{ml}$ amber coloured glass vials at $-20^{\circ} \mathrm{C}$ until geosmin concentration measurement.

To each water sample $(250 \mathrm{ml}) 100 \mu$ of internal standard solution (D5-geosmin in water, 1 $\mu \mathrm{g} / \mathrm{ml}$ ) was added. Methanol samples originating from the gas washing bottles and the rinsing of equipment were diluted approximately 20 times in demineralized water and subsequently treated the same as the water samples. Water samples were extracted via an extraction cartridge (Sep-Pak ${ }^{\circledast}$ Vac 6cc $(1 \mathrm{~g})$ Certified tC18) which were then eluted with $5 \mathrm{ml}$ diethyl 
ether. Water was removed from the collected diethyl ether by addition of dried sodium sulphate. Diethyl ether samples were then separated from the sodium sulphate by manually transferring the liquid to another glass tube. The sodium sulphate was washed three times with $5 \mathrm{ml}$ diethyl ether to ensure full transfer of geosmin. The extracts were concentrated to $1 \mathrm{ml}$ under a gentle nitrogen gas flow and stored in an amber coloured glass vial at $-20^{\circ} \mathrm{C}$ until geosmin measurement.

Geosmin concentrations were measured on a Shimadzu GCMS2010 (GC) coupled to a GCMSQP2010 Ultra (MS) detector (Shimadzu, 's Hertogenbosch, The Netherlands) as described in detail in Schram et al. (2016). The method for geosmin concentration measurement was validated in low fat $(6 \% \mathrm{w} / \mathrm{w})$ fish samples according to NEN 7777 (anonymous, 2011) and established a limit of detection of $6.1 \mathrm{ng} / \mathrm{g}$, a recovery of 93.5 to $99.2 \%$ and an extended uncertainty $(U)$ of $27.8 \%$. The $95 \%$ confidence interval of measured geosmin concentration equals the measured value $\pm U / 2$.

Lipid content of the liver-free carcass samples and liver samples was determined using the gravimetric method according to Bligh and Dyer (1959) modified by De Boer (1988).

\section{Calculations and statistics}

The total amounts of geosmin in the system compartments (liver-free carcass, liver, water and gas washing bottles) were calculated for each sampling point by multiplying the measured geosmin concentrations with the respective masses or volumes.

Bioconcentration can be described mathematically by an organism-water two compartment model:

$\frac{d C_{F}}{d t}=k_{1} C_{W}-\left(k_{2}+k_{E}+k_{M}+k_{G}\right) C_{F}$

where $C_{F}$ is the chemical concentration in the fish $(\mathrm{g} / \mathrm{kg}), C_{W}$ the chemical concentration in the water $(\mathrm{g} / \mathrm{l}), k_{1}, k_{2}, k_{E}, k_{M}$, and $k_{G}$ the rate constants (1/d) for the uptake from the water $k_{1}$, elimination to the water $k_{2}$, faecal egestion $k_{E}$, metabolic biotransformation $k_{M}$ and growth dilution $k_{G}$. The sum of $k_{2}, k_{E}, k_{M}$, and $k_{G}$ represents the total elimination or depuration rate constant $k_{T}$ (Arnot and Gobas, 2006). As the fish in our study were starved prior to the experiment and not fed during the experiment, we excluded the rate constants for faecal egestion and growth dilution from the model. In contrast to Howgate (2004) we do not rule out biotransformation of geosmin and thus maintain the metabolic biotransformation rate constant $k_{M}$ in the model. Equation 1 then simplifies to:

$\frac{d C_{B}}{d t}=k_{1} C_{W}-k_{2} C_{B}-k_{M} C_{F}$

In experimental settings the chemical concentration of lipophilic compounds in the water declines over time due to the uptake of chemicals by organisms (Arnot and Gobas, 2006). Since our experimental system had static water and a high biomass to water volume ratio, we 
predicted a declining geosmin concentration in the water over time due to uptake in the fish. To account for a decline of the geosmin concentration in the water in the current experiment, we extended the bioconcentration model by allowing $C_{W}$ to vary over time, which is described by:

$\frac{d C_{W}}{d t}=z k_{2} C_{F}-z k_{1} C_{W}$

where the first term describes the increase in concentration as a result of depuration from fish and the second term is the change rate of the concentration in the water as a result of uptake by fish. The parameter $\mathrm{z}$ is the ratio of fish biomass to water volume, which is used to account for the different masses. We assume that fish and water have an identical density of one. We solved the system formed by equations 2 and 3 analytically using Mathematica 9.0 (Wolfram Research, Champaign, Illinois, USA) to yield equations for $C_{F}(t)$ and $C_{W}(t)$ :

$$
\begin{aligned}
& C_{F(t)}=\frac{1}{2 D} e^{-\frac{1}{2} t\left(k_{2}+k_{M}+k_{1} z+D\right)}\left(k_{2} C_{F O}+k_{M} C_{F O}-2 k_{1} C_{W O}-k_{2} C_{F O} e^{t D}-k_{M} C_{F O} e^{t D}+2 k_{1} C_{W O} e^{t D}-\right. \\
& \left.k_{1} C_{F O} z+k_{1} C_{F O} e^{t D} z+C_{F O} D+C_{F O} e^{t D} D\right) \\
& C_{W(t)}=\frac{1}{2 D} e^{-\frac{1}{2} t\left(k_{2}+k_{M}+k_{1} z+D\right)}\left(-k_{2} C_{W O} k_{M} C_{W O}+k_{2} C_{W O} e^{t D}+\right. \\
& \left.\quad k_{M} C_{W O} e^{t D}-2 k_{2} C_{F O} z+k_{1} C_{W O} z+2 k_{2} C_{F O} e^{t D} z-k_{1} C_{W O} e^{t D} z+C_{W O} D+C_{W O} e^{t D} D\right)
\end{aligned}
$$

Where $D=\sqrt{-4 k_{1} k_{M} z+\left(k_{2}+k_{M}+k_{1} z\right)^{2}}, C_{F O}$ is the chemical concentration in the fish $(\mathrm{g} / \mathrm{kg})$ at $\mathrm{t}=0, C_{w_{0}}$ the chemical concentration in the water $(\mathrm{g} / \mathrm{l})$ at $\mathrm{t}=0$ and $\mathrm{t}$ is time (days).

Experimental rate constants for uptake $\left(k_{1}\right)$, depuration $\left(k_{2}\right)$ and biotransformation $\left(k_{M}\right)$ were estimated by fitting the equations for $C_{F}(t)$ and $C_{W}(t)$ to respectively the observed geosmin concentrations in the fish and the water by non-linear regression analysis. The liver-free carcass samples were used to represent the geosmin concentration in the intact fish $C_{F}$, which is appropriate given the minimal contribution of the liver ( 1.5\%) to the total mass and geosmin content of the intact fish. Theoretical uptake $\left(k_{1}\right)$ and depuration $\left(k_{2}\right)$ rate constants representative for the experimental fish were calculated according to Howgate (2004), taking into account mean fish body weight, fish lipid content and water temperature in the experiment. As Howgate (2004) does not consider geosmin biotransformation, the theoretical metabolic biotransformation rate constant $k_{M}$ was set at zero.

The equations for $C_{F}(t)$ and $C_{W}(t)$ were used to predict the development over time of the geosmin concentrations in fish and water, using the experimentally determined (experiment based prediction) and theoretical (theory based prediction) rate constants. For hypothesistesting the $95 \%$ confidence intervals of the experimental estimates for the rate constants were compared. Rate constants were considered significantly different at $p<0.05$ when $95 \%$ confidence intervals showed no overlap. Geosmin concentrations in liver-free carcass samples and liver samples were normalized for lipid content by dividing the measured geosmin 
concentration by its lipid content. The geosmin concentrations in the lipid fractions of the liver-free carcass and the liver were predicted to increase with exposure time (Howgate, 2004; OECD, 2012). The measured geosmin concentrations were related to natural logarithm transformed exposure times by linear regression analysis. We hypothesized that geosmin is distributed over the liver-free carcass and the liver according to their lipid contents and reaches equilibrium in the lipid fractions, in which case the ratio between the lipid normalized geosmin content of the liver and the liver-free carcass $R$ equals 1 . To assess the development of this ratio towards 1 with increasing exposure time, the lipid-normalized liver:liver-free carcass ratio was related to exposure time $t$ using Eq. 6 .

$R=R_{0} \times e^{(-k t)}+A$

where $R_{0}$ equals the ratio between the lipid normalized geosmin content of the liver at $\mathrm{t}=0$, $k$ a term for the change of the ration over time and $A$ the asymptote. The model parameters were estimated by non-linear regression analysis. All statistical procedures were performed in SAS 9.1.

\subsection{Results}

\section{Geosmin in water and fish}

Geosmin concentrations, volumes and masses of system components, and the total amounts of geosmin in the various system components are presented per exposure time in Table 1 . The total amount of geosmin in the water declined over time while in the fish the total amount of geosmin increased (Table 1). The total amount of geosmin in the system declined over time and the loss of geosmin from the system exceeded geosmin accumulated in the fish (Table 1). During the first $12 \mathrm{~h}$ of the experiment no geosmin was detected in the gas washing bottles, and this increased from $<0.1$ at $t=24 \mathrm{~h}$ to $860 \mathrm{ng}$ at $\mathrm{t}=120 \mathrm{~h}$. In total less than $4 \%$ of the total amount of geosmin in water and fish together was found in the gas washing bottles. No geosmin was detected in the methanol used to rinse the exposure tanks and auxiliary equipment upon termination of the geosmin exposure. Geosmin losses due to evaporation and adsorption to rinse the exposure tanks and auxiliary equipment were therefore almost negligible. 


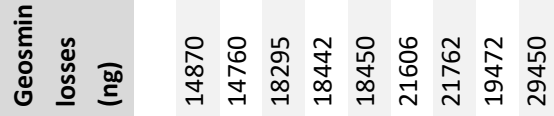

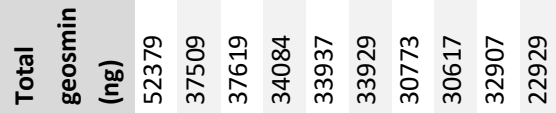
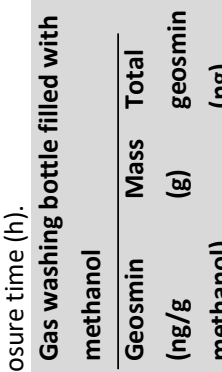

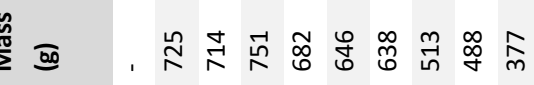

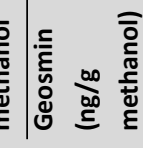

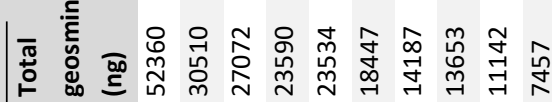

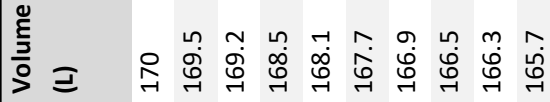

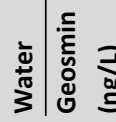

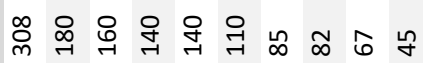

त

ฌ

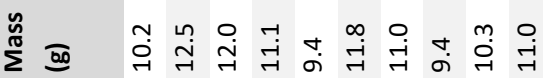

㐫

ๆ

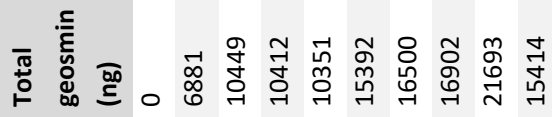

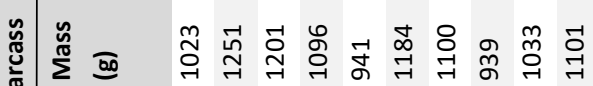

竎

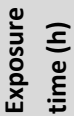

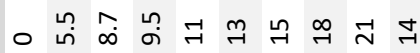

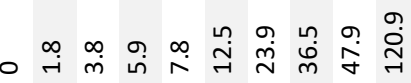

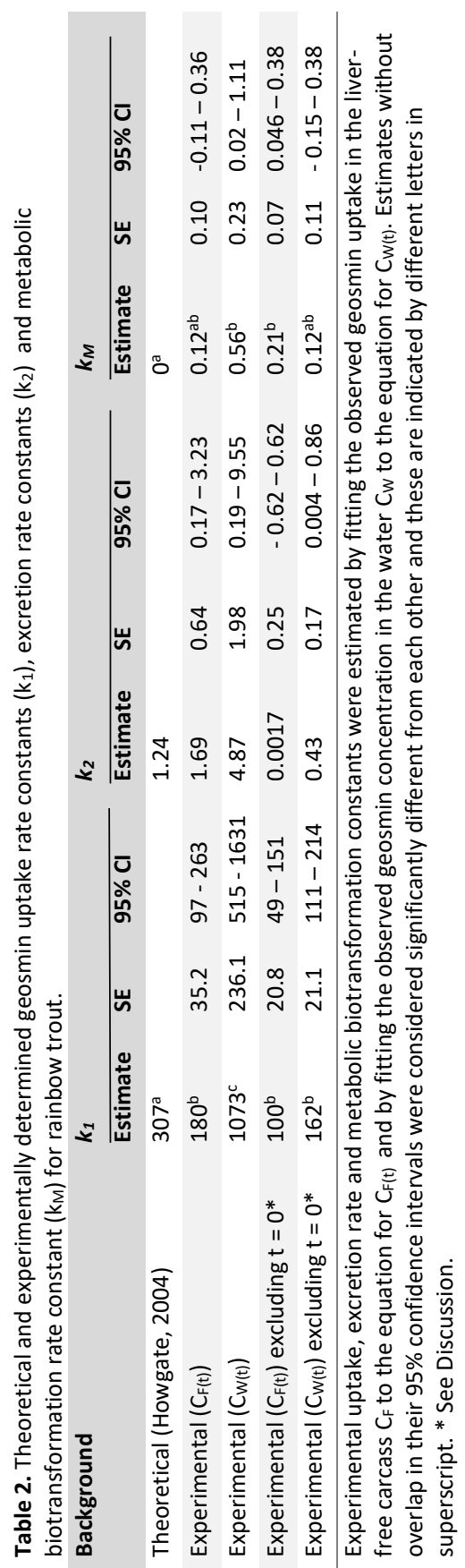



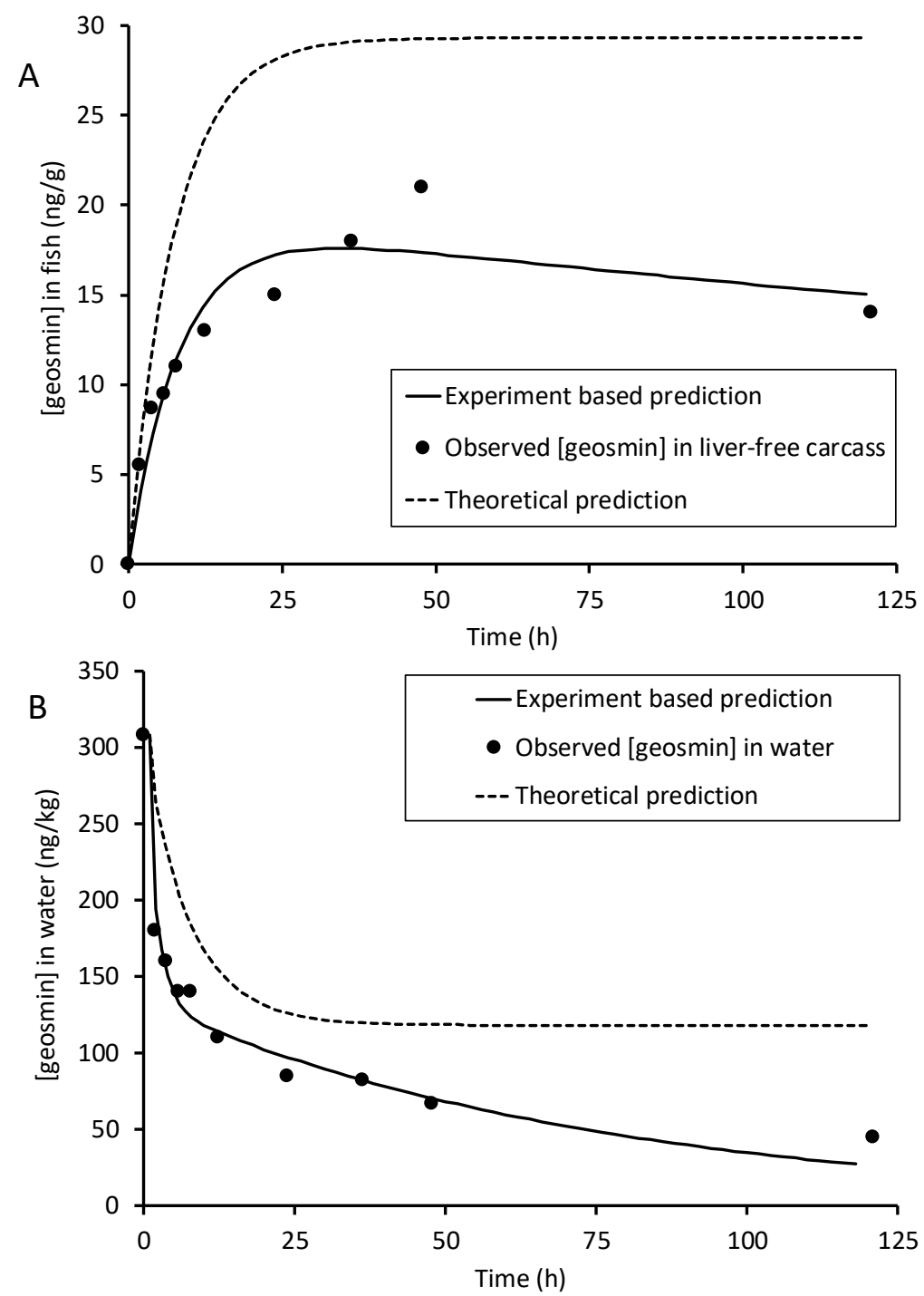

Fig. 1. Observed and predicted geosmin bioconcentration in rainbow trout $(A)$ and the concurrent decline of the geosmin concentration in the water $(B)$. The predictions are based on the equations for $\mathrm{C}_{\mathrm{F}(\mathrm{t})}(\mathrm{A})$ and $\mathrm{C}_{\mathrm{w}(\mathrm{t})}(\mathrm{B})$. The theoretical predictions are based on theoretical uptake $\left(k_{1}\right)$ and excretion $\left(k_{2}\right)$ rate constants according to Howgate (2004), adapted to the mean fish body weight, fish lipid content and water temperature in the experiment. The experiment-based predictions are based on the experimental uptake, excretion and biotransformation rate constants estimated by fitting the equation for $\mathrm{C}_{\mathrm{F}(\mathrm{t})}$ to the observed geosmin concentrations in the liver free carcass $(A)$ and the equation for $\mathrm{C}_{w(t)}$ to the observed geosmin concentrations in the water $(B)$. Both are significant fits to respectively the observed geosmin concentrations in the liver-free carcass and water (non-linear regression analysis, $\mathrm{p}<0.0001$ ). 


\section{Theoretical versus experimental geosmin bioconcentration}

Exposure of rainbow trout to waterborne geosmin resulted in an increase of the geosmin concentration in the fish (Fig. 1A) and a steady decline of the geosmin concentration in the water (Fig. 1B). The equations for $C_{F}(t)$ and $C_{W}(t)$ provided significant fits to respectively the observed geosmin concentrations in the liver-free carcass and to the observed geosmin concentrations in the water. The estimates for the uptake, elimination and biotransformation rate constants all show large $95 \%$ confidence intervals (Table 2 ). The theoretical rate constant for geosmin excretion by rainbow trout does not differ from the two experiment based estimates. The theoretical uptake rate constant for geosmin by rainbow trout is higher than the uptake rate constant estimated from the observed geosmin uptake by the liver-free carcass but lower than the uptake rate constant estimated from the observed geosmin decline in the water (Table 2). The theoretical predictions consequently show a faster geosmin uptake in the fish (Fig. 1A) and a slower decline of the geosmin concentration in the water (Fig. 1B). In the theoretical prediction the biotransformation rate constant $\left(\mathrm{k}_{\mathrm{M}}\right)$ was set at zero and geosmin levels in fish and water reach steady-states. For both experiment based predictions $\mathrm{k}_{\mathrm{M}}$ was estimated to be larger than zero. Consequently the model predicts constant geosmin removal from the system and the concentrations in fish and water do not reach a steady-state. Instead the geosmin concentration in the fish first peak and then start to decline (Fig. 1A). The geosmin concentration in the water continues to decline at the point where the geosmin concentration in the theoretical prediction stabilizes (Fig. 1B).

\section{Geosmin uptake: liver-free carcass versus liver}

Geosmin exposure of rainbow trout resulted in a significant increase over time of the geosmin concentration in the lipid fraction of the liver-free carcass, while the highest geosmin concentration in the lipid fraction of the liver was reached already at the first sampling point ( $2 \mathrm{~h}$ ) and declined thereafter (Fig 2A). The ratio between the lipid-normalized geosmin concentration in the liver and the liver-free carcass initially declined and then stabilized after ca. $20 \mathrm{~h}$ at approximately 0.5 (Fig. 2B), showing that the geosmin concentration was consistently lower in the liver than in the liver-free carcass.

\subsection{Discussion}

Based on the generally accepted model for geosmin bioconcentration in fish (Howgate, 2004), the predicted uptake of geosmin by rainbow trout exposed to waterborne geosmin will result in a decline of the geosmin concentration in the water and an increase of the geosmin concentration in the fish. We indeed observed an increase of the geosmin concentration in the liver-free carcass of rainbow trout, which coincided with a decline ofthe geosmin concentration in the water. These findings are in accordance with the general consensus on the uptake by fish of waterborne lipophilic chemicals in general (Nichols et al., 2007) and 
geosmin in particular (Howgate, 2004) and were previously reported by Robertson et al. (2006).
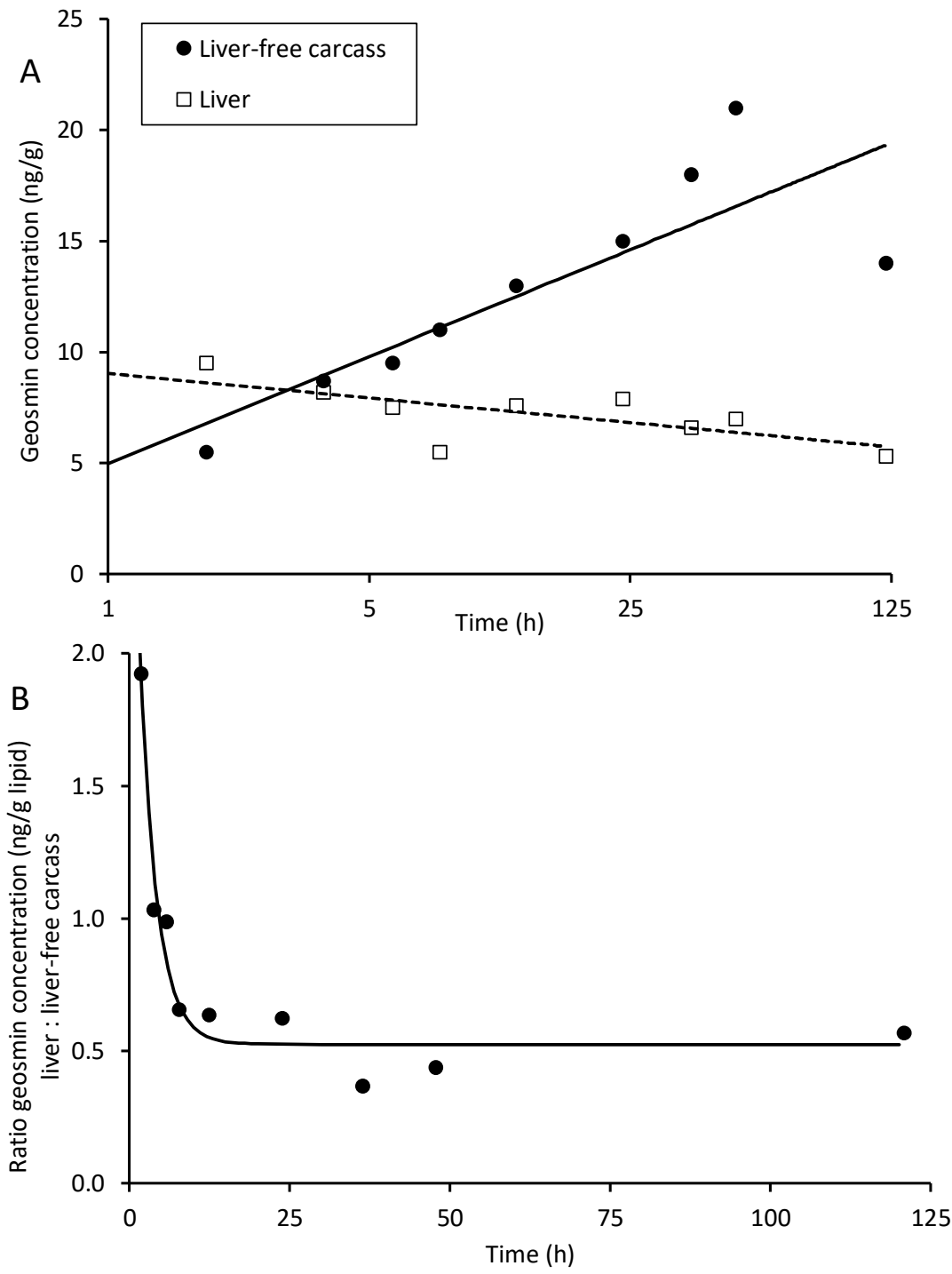

Fig. 2 (A)Lipid-normalized geosmin concentration (ng/g lipid) over time in the liver-free carcass and the liver of rainbow trout during geosmin exposure. (B) The ratio between lipidnormalized geosmin concentrations ( $\mathrm{ng} / \mathrm{g}$ lipid) in liver and whole body over time during geosmin exposure. Ratio $=2.70 \times \mathrm{e}^{(-0.37 \times \text { Time })}+0.52$. Model $p$-value $=0.0002$.

We exposed rainbow trout to geosmin in closed systems with static water of limited volume (high biomass:water ratio). During exposure in static water, the uptake of the chemical by the fish is expected to cause a decline in the water exposure concentration, especially when both the biomass:water volume ratio and the affinity of the chemical for the fish are high. 
Advantage of exposure in static water is that it requires far less of the target chemical than exposure in flow through systems (e.g. according to the OECD 305 test guideline). The uptake and depuration rate constants, however, are intrinsic properties of the organism and therefore independent from the exposure system. A static system thus provides a costeffective alternative for flow through exposure systems when the studied chemical is expensive, as is the case for geosmin. Monitoring the decline of the chemical concentration in the water over time $\left(C_{W(t)}\right)$ next to the increase of the concentration in the fish over time $\left(C_{F(t)}\right)$, provides and additional data set that describes the time-kinetics of the bioconcentration of the chemical. In theory, both data sets yield the same estimates for the rate constants of the bioconcentration process, provided that the chemical partitions to no other compartments than the fish and water compartment and that biotransformation, growth dilution and faecal egestion are absent or taken into account. In the current bioconcentration experiment the observed increase of the geosmin concentration in the fish $\left(C_{F(t)}\right)$ and the decline of the geosmin concentration in the water $\left(\mathrm{C}_{\mathrm{w}(\mathrm{t})}\right)$ lead to conflicting modelling results. The observed geosmin uptake in the fish was lower than the theoretical rate constants predict, which implies a lower concurrent decline of the geosmin concentration in the water than the theoretical rate constants predict. However, the opposite was observed: the geosmin concentration in the water declined faster than predicted by the theoretical rate constants. The observed decline of the geosmin concentration in the water implies a faster geosmin uptake in the fish than predicted by the theoretical rate constants and observed in the fish. These conflicting modelling results are reflected by the significant differences among the estimates and theoretical values for the uptake rate constant $k_{1}$. The observation that the decline of the geosmin concentration in the water is not reflected by a corresponding geosmin increase in this fish suggests that the rate constants estimated from the observed geosmin concentration in the water are overestimations or that some process is overlooked. The rate constants estimated from the observed geosmin concentrations in the fish seem a better representation of the actual values. Oxygen saturation in the experiment was rather low at 60-65\% saturation. Oxygen concentration in the water is an important determinant of the gill ventilation rate (Neely, 1979) and higher gill ventilation rates result in higher uptake $\left(k_{1}\right)$ and depuration $\left(k_{2}\right)$ rate constants (equations in Howgate, 2004). The experimental oxygen conditions thus probably led to relatively fast geosmin uptake in the fish and high values for the uptake $\left(k_{1}\right)$ and depuration $\left(k_{2}\right)$ rate constants compared to uptake at $100 \%$ oxygen saturation. However, the final geosmin concentration reached in the fish was probably not affected by the low oxygen saturation as the bioconcentration factor $\left(k_{1} / k_{2}\right)$ does not depend on the gill ventilation rate. Jointly taken, it appears that net geosmin uptake in vivo is less than theoretical rate constants predict for rainbow trout. It should be noted that although oxygen concentration and temperature do not appear directly in the model we used, these factors 
are accounted for since the estimated rate constant are specific for the experimental conditions.

Clearly the decline of the geosmin water concentration cannot be fully explained by the uptake of geosmin in the fish. Therefore, biotransformation in the fish and other geosmin sinks have to be considered. Given the stable concentration of waterborne geosmin in the preliminary stability study without fish and the negligible amounts of geosmin in the methanol samples collected from the gas washing bottles and the methanol used to rinse of the exposure tanks and their auxiliary equipment upon termination of geosmin exposure, system losses of geosmin due to volatilization, adsorption to the tanks or geosmin removal by microbial degradation (Ho et al., 2007) seem unlikely. Growth dilution and faecal egestion may contribute to the loss of chemicals from fish (OECD, 2012), but not from the system. Growth dilution and faecal egestion are unlikely as the exposure period was short, the fish were not fed the day before and during geosmin exposure and no faeces were observed in the exposure tanks. Any faeces present inside the fish would be included in the liver free carcass sample.

Most geosmin was lost from the system between $\mathrm{t}=0$ and $\mathrm{t}=1.8 \mathrm{~h}$. In this period the geosmin concentration in the water showed a strong decline which did not result in a corresponding increase of the geosmin concentration in the fish. The strong initial decline of the geosmin concentration in the water therefore cannot be entirely attributed to uptake in the fish; other, unknown geosmin sinks also seem to play a role. We therefore excluded the observed geosmin concentrations in fish and water at $\mathrm{t}=0$ and used the observed levels at $\mathrm{t}=1.8 \mathrm{~h}(5.5 \mathrm{ng} / \mathrm{g}$ and $180 \mathrm{ng} / \mathrm{l}$ ) as the initial geosmin concentrations in fish and water to estimate the rate constants by fitting the equations for $C_{F}(t)$ and $C_{W}(t)$ to respectively the observed geosmin concentrations in the fish and the water. The results are included in Table 2. The so obtained estimate for uptake rate constant based on the observed geosmin levels in the fish does not differ from the estimate including the data observed at $t=0$. The uptake rate constant based on the geosmin decline in the water is strongly affected by excluding the $t=0$ data: the estimated rate constant for uptake from the water no longer differs from the estimate based on the observed geosmin uptake in the fish. Excluding the observations at $\mathrm{t}=0$ does not change the notion that net geosmin uptake in vivo is less than theoretical rate constants predict for rainbow trout.

Although assumed to be absent in fish (Howgate, 2004) biotransformation of geosmin has in fact never been investigated. Biotransformation of lipophilic compounds such as geosmin is very likely as biotransformation pathways have very low substrate specificity and almost any non-polar (lipophilic) compound can be metabolized (Jakoby and Ziegler, 1990), and several biotransformation pathways have been established in fish (Kleinow et al., 1987). We therefore did not rule out geosmin biotransformation and maintained the metabolic biotransformation 
rate constant in the bioconcentration model. The model-based equations we used to describe the kinetic profiles of geosmin in water and fish provided both significant as well as visually satisfactory fits to the observed data. Biotransformation will result in a lower bioconcentration of compounds than predicted based on their lipophilicity (Lech and Bend, 1980; Kleinow et al., 1987), which is exactly what we observed. Rather than reaching the equilibrium states as would be the case in absence of biotransformation, the measured levels in water and fish suggest removal of geosmin from the system, which is in accordance with the notion of induced biotransformation. Our kinetic profile for geosmin bioconcentration shows large resemblance with the kinetic profile for trifluralin bioconcentration in rainbow trout, for which biotransformation has been established (Schultz and Hayton, 1999). Biotransformation affects the distribution and accumulation of chemicals in fish (Kleinow et al., 1987). Presence of significant geosmin biotransformation in fish would thus open new opportunities for offflavour mitigation and management next to geosmin depuration. Large variations in biotransformation pathways have been demonstrated among fish species but also among individuals of the same species (Kleinow et al., 1987). Variation in biotransformation capacity can both be inherent, have a genetic basis, and be the result of induction or inhibition by environmental factors and ubiquitous chemicals (Kleinow et al., 1987). Variation with a genetic basis opens opportunities to increase biotransformation capacity by selective breeding. Induction of biotransformation during off-flavour depuration may enhance geosmin elimination and thereby reduce the required depuration time as well as improve depuration results. All this clearly requires further investigations, with establishing the actual presence of geosmin biotransformation and its relative contribution to geosmin elimination being first priorities.

The geosmin concentration in the lipid fraction of the liver at the end of the experiment was approximately two-fold lower than the geosmin concentration in the lipid fraction of the rest of the body. Following absorption from the water by the gills, lipophilic compounds are distributed throughout the fish' body via the circulatory system and exchanged with all vascularized tissues and organs (Streit, 1998). Circulating lipophilic compounds accumulate rapidly in highly perfused organs such as the liver. Accumulation is slower in organs with lower blood flow, such as muscle and adipose tissue (Barron, 1990, 1995; Bickel, 1984; Gunkel and Streit, 1980; all in in Streit, 1998). The relatively high levels of geosmin we observed in the rainbow trout liver shortly after the start of the exposure to geosmin may thus be explained by the high perfusion of this organ. The following decline of the geosmin content of the liver relative to the rest of the fish body can be explained by induced biotransformation in the liver, known for its high biotransformation capacity. This quite plausible mechanism could explain the development over time towards a decreasing geosmin concentration in the liver lipids 
compared to the liver-free carcass lipids (ratio from $\sim 1.5$ at $\mathrm{t}=2 \mathrm{~h}$ to $\sim 0.5$ at $\mathrm{t}=120 \mathrm{~h}$ ). Clearly, geosmin distribution within the fish is not exclusively governed by the lipid content of tissues.

\subsection{Conclusions}

The current study reveals that rainbow trout bioconcentrates waterborne geosmin, but in vivo bioconcentration is less than the generally accepted model predicts based on theoretical rate constants assuming passive distribution based on lipophilicity only. Clearly, geosmin distribution within rainbow trout is not exclusively governed by the lipid content of tissues, given the different lipid-normalized geosmin concentrations in liver compared to the liver-free carcass. Geosmin removal from the water exceeded the concurrent geosmin bioconcentration in the fish. The observed geosmin concentrations in the water and liver free carcass can be described by model-based equations that include biotransformation. The liver usually is the main site of biotransformation, which can explain the relatively low lipid-normalised geosmin levels in the liver, after initial fast uptake, compared to those in the rest of the fish. Because biotransformation affects the distribution and accumulation of chemicals in fish, we advise to perform dedicated biotransformation studies aimed aimed at detecting geosmin and 2methylisoborneol metabolites to confirm the suggested biotransformation of both off-flavour causing compounds.

\section{Acknowledgements}

Financial support for these studies came from the European Commission; European Regional Development Fund (ERDF) - Interreg IV A Flanders - The Netherlands: AquaVlan. 


\section{Effects of exercise and temperature on geosmin excretion by European eel (Anguilla anguilla)}

Schram, E., Schrama, J., Kusters, K., Kwadijk, C., Palstra, A., 2016. Effects of exercise and temperature on geosmin excretion by European eel (Anguilla anguilla). Aquaculture 451, 390395. 


\begin{abstract}
The presence of geosmin in fish products causes an earthy or musty off-flavour. To avoid economic damage resulting from market entrance of off-flavoured fish products, fish farmers utilize the reversibility of geosmin uptake to depurate the off-flavours from their fish crops by holding them in clean water just before harvest. To improve this process, effects of exercise and temperature on the excretion of geosmin by European eel (Anguilla anguilla) were assessed. Fish loaded with geosmin were depurated for $23 \mathrm{~h}$ during which they were subjected to combinations of exercise (spontaneous swimming activity at $0.05 \mathrm{~m} / \mathrm{s}$ or forced swimming at optimal swimming speed of $0.55 \mathrm{~m} / \mathrm{s})$ and temperature $\left(15^{\circ} \mathrm{C}\right.$ or $\left.25^{\circ} \mathrm{C}\right)$ treatments. Oxygen consumption was measured during depuration. Whole body geosmin concentrations were measured in samples collected at $t=0$ and $t=23 \mathrm{~h}$ to assess geosmin excretion. Geosmin excretion by European eel was clearly enhanced by exercise, but temperature had no statistically significant effect. Exercise increased oxygen consumption, which in turn showed a positive linear relation with geosmin excretion. These findings support the idea that the physiological responses aimed at increasing oxygen uptake also affect the branchial exchange of lipophilic xenobiotic chemicals between the fish and its surroundings. Exercise can be used to reduce the time required to depurate off-flavours from fish. These findings are relevant for aquaculture industries confronted with off-flavoured fish crops.
\end{abstract}




\subsection{Introduction}

Fish raised in land-based aquaculture systems will bioconcentrate geosmin $(4 S, 4 a S, 8 a R)-4,8 a-$ dimethyl-1,2,3,4,5,6,7,8-octahydronaphthalen-4a-ol) and 2-methylisoborneol (1,2,7,7tetramethylbicyclo[2.2.1] heptan-2-ol, MIB), lipophilic organic compounds produced by microbiota as a secondary metabolites. Actinomycetes and cyanobacteria are considered the most important geosmin and MIB producers in aquaculture systems (reviewed by Krishnani et al., 2008). The presence of geosmin and MIB in fish products causes an earthy or musty offflavour which human consumers do not appreciate and this can result in economic losses for land-based aquaculture. To avoid economic damage resulting from market entrance of offflavoured fish, fish farmers utilize the reversibility of geosmin and MIB bioconcentration to depurate the off-flavours from their fish crops by placing them in water free of geosmin just before harvest. This procedure, however, is not always sufficiently effective and it is costly as it requires time, effort and use of specific facilities. Moreover, as fish are not fed during the depuration period, they may lose weight (Schram et al., 2010) and exhibit muscle atrophy which has important consequences for the fillet quality (Love, 1997). Therefore better understanding of factors enhancing the geosmin (and MIB) excretion is needed to be able to improve the off-flavour depuration process.

It has been well established that fish accumulate waterborne lipophilic chemicals in their tissues and that the exchange of the chemicals between the fish and water predominantly occurs through the fish gills (reviewed by Streit, 1998). The fish gill's characteristics that allow for the efficient uptake of oxygen also favour the uptake of xenobiotic lipophilic chemicals (McKim and Erickson, 1991). Consequently it has been postulated that the various physiological changes that enable fish to increase oxygen transfer across the gills to handle increased oxygen demands, have similar effects on the exchange of lipophilic chemicals across the gills (McKim and Erickson, 1991; Brauner et al., 1994; Yang et al., 2000; Blewett et al., 2013). Indeed, uptake (e.g. Brinkmann et al., 2014; Blewett et al., 2013; Yang et al., 2000) and excretion (Yang et al., 2000) of lipophilic chemicals by fish have been positively related to their oxygen consumption.

Both exercise and temperature increase lead to a higher oxygen demand in fish. Increasing the water temperature has consequently been predicted to promote geosmin and MIB uptake and excretion by fish (Howgate, 2004), mainly through the increase in gill ventilation rate to compensate for the decrease in oxygen solubility in water concurring with temperature increase (Neely, 1979). Experimental work by Johnsen et al. (1996) indeed suggested a positive effect of temperature on MIB excretion by channel catfish. For geosmin, experimental evidence for this effect of temperature is absent. Various authors have used forced exercise as experimental treatments to increase oxygen consumption and these studies demonstrated 
that the uptake of oxygen and lipophilic chemicals are correlated in fish (e.g. Blewett et al., 2013, Brinkmann et al., 2014; Yang et al., 2000). For geosmin and MIB excretion from fish, the effects of increased oxygen demand by exercise have not been studied to date.

The objective of the current study was to establish the effects of temperature and exercise on geosmin excretion by European eel (Anguilla anguilla). We hypothesized that both exercise and temperature increase lead to faster geosmin excretion from fish in low geosmin water. The underlying mechanism for the effects of exercise and temperature increase may be related to the increase in oxygen demand they both cause, and their effects may therefore be cumulative. The effects of temperature and exercise on geosmin excretion by European eel were assessed experimentally in a split-plot design with two different levels for each treatment.

\subsection{Materials and methods}

\section{Experimental fish}

European eel (A. anguilla) ( $N=120)$, with a mean (SD) weight of $152(14)$ g and a mean (SD) whole body lipid content of 33.1 (2.1)\%, raised at commercial fish farms in the Netherlands were obtained from eel whole sale Joh. Kuijten BV (Spaardam, the Netherlands). The fish were housed in a polyethylene tank containing 390 I tap water under a light regime of 10L:14D. Tank water was kept at $18{ }^{\circ} \mathrm{C}$ and continuously renewed at a rate of ca. 12 tank volumes per day. The treatment of the fish was in accordance with Dutch law concerning animal welfare, as approved by the ethical committee for animal experimentation of Wageningen UR Livestock Research (no. 2012079b).

\section{Treatments and experimental design}

The interactive effects of temperature $(T)$ and exercise $(E)$ on geosmin excretion were investigated at two different levels for each treatment in a split-plot design. Temperature treatments were $15{ }^{\circ} \mathrm{C}$ ('low') and $25{ }^{\circ} \mathrm{C}$ ('high'). Exercise treatments concerned either spontaneous swimming activity at a low flow of $0.05 \mathrm{~m} / \mathrm{s}$ ('low') and forced swimming at the optimal swimming speed $\left(U_{\text {opt }}\right)$ of $0.55 \mathrm{~m} / \mathrm{s}$ ('high'; $U_{\text {opt }}$ based on Burgerhout et al., 2013). The two levels for each of the two treatments yielded four unique combinations of $T^{*} \mathrm{E}$. Two identical experimental units (swim tunnels, $Z$ ) were available to test two combinations of $T^{*} E$ in parallel in one test day (D), yielding eight unique combinations of $T^{*} E^{*} Z$. Each combination of $T^{*} E^{*} Z$ was duplicated, yielding 16 tests to be performed in eight test days (D). Temperature treatments $(T)$ were randomly assigned to the test days (D, main plots). Within test days the exercise treatments $(E)$ were randomly assigned to the experimental units ( $Z$, sub-plots) (Table 1). 
Table 1. Experimental design. Temperature treatments $(T)$ were randomly assigned to the test days (D, main plots). Within test days the exercise treatments $(E)$ were randomly assigned to the experimental units ( $Z$, sub-plots). Measured water temperature, total biomass ( $N=5$ individual fish), whole body lipid content, whole body geosmin concentration and oxygen consumption are presented per test group.

\begin{tabular}{|c|c|c|c|c|c|c|c|c|c|}
\hline $\begin{array}{l}\text { Test } \\
\text { day } \\
\text { (D) }\end{array}$ & $\begin{array}{l}\text { Swim } \\
\text { tunnel } \\
(\mathrm{Z})\end{array}$ & $\begin{array}{c}\text { Temperature } \\
\text { (T) }\end{array}$ & $\begin{array}{c}\text { Exercise } \\
\text { (E) }\end{array}$ & $\begin{array}{l}\text { Sampling } \\
\text { time }\end{array}$ & $\begin{array}{c}\text { Actual } \\
\text { temperature } \\
\left({ }^{\circ} \mathrm{C}\right)\end{array}$ & $\begin{array}{c}\text { Total } \\
\text { biomass } \\
\text { (g) }\end{array}$ & $\begin{array}{c}\text { Lipid } \\
\text { content } \\
\text { (\%) }\end{array}$ & $\begin{array}{c}\text { Geosmin } \\
\text { concentration } \\
(\mathrm{ng} / \mathrm{g})\end{array}$ & $\begin{array}{c}\mathrm{MO}_{2} \\
(\mathrm{mg} \mathrm{O} / \mathrm{kg} / \mathrm{h})\end{array}$ \\
\hline 1 & . & . & . & $t=0$ & . & 800 & 34.0 & 19 & - \\
\hline 1 & 2 & Low & High & $t=23$ & 17.5 & 851 & 30.6 & 13 & 159 \\
\hline 1 & 1 & Low & Low & $t=23$ & 17.4 & 698 & 35.7 & 14 & 43 \\
\hline 2 & . & . & . & $\mathrm{t}=0$ & . & 780 & 33.4 & 17 & - \\
\hline 2 & 2 & Low & High & $t=23$ & 15.3 & 757 & 28.1 & 14 & 69 \\
\hline 2 & 1 & Low & Low & $t=23$ & 15.6 & 820 & 33.1 & 16 & 28 \\
\hline 3 & . & . & . & $t=0$ & . & 724 & 33.7 & 17 & - \\
\hline 3 & 1 & High & High & $t=23$ & 25.7 & 747 & 34.4 & 13 & 105 \\
\hline 3 & 2 & High & Low & $t=23$ & 25.7 & 754 & 34.7 & 15 & 34 \\
\hline 4 & . & . & . & $t=0$ & . & 751 & 32.2 & 14 & - \\
\hline 4 & 1 & Low & High & $t=23$ & 15.1 & 791 & 32.2 & 11 & 89 \\
\hline 4 & 2 & Low & Low & $t=23$ & 15.3 & 807 & 32.9 & 14 & 21 \\
\hline 5 & . & . & . & $t=0$ & . & 500 & 36.1 & 18 & - \\
\hline 5 & 1 & High & High & $t=23$ & 25.3 & 837 & 34.6 & 14 & 212 \\
\hline 5 & 2 & High & Low & $t=23$ & 25.6 & 850 & 32.5 & 13 & 64 \\
\hline 6 & . & . & . & $\mathrm{t}=0$ & . & 726 & 32.5 & 13 & - \\
\hline 6 & 2 & High & High & $t=23$ & 25.0 & 717 & 31.8 & 11 & 110 \\
\hline 6 & 1 & High & Low & $t=23$ & 24.6 & 748 & 33.8 & 12 & 79 \\
\hline 7 & . & . & . & $t=0$ & . & 754 & 32.9 & 17 & - \\
\hline 7 & 2 & High & High & $t=23$ & 24.8 & 792 & 36.6 & 10 & 130 \\
\hline 7 & 1 & High & Low & $t=23$ & 25.0 & 772 & 32.4 & 12 & 75 \\
\hline 8 & . & . & . & $t=0$ & . & 762 & 29.1 & 13 & - \\
\hline 8 & 1 & Low & High & $t=23$ & 15.4 & 779 & 30.8 & 9.5 & 180 \\
\hline 8 & 2 & Low & Low & $t=23$ & 15.3 & 774 & 35.5 & 12 & 25 \\
\hline
\end{tabular}

\section{Experimental procedures and facilities}

Prior to each single test day, 15 fish were randomly taken from the experimental fish stock (initial $N=120$ ) and loaded with geosmin. To this end a group of 15 fish was placed in a polyester tank filled with 160 I local tap water that was spiked with $1000 \mathrm{ng} / \mathrm{l}$ geosmin (Sigma Aldrich). Tank water was not renewed but aerated by an air stone to supply oxygen to the fish. After $72 \mathrm{~h}$ of geosmin exposure at $18{ }^{\circ} \mathrm{C}$, fish were randomly split into three groups of equal size $(n=5)$. One group served to determine the initial geosmin content of the fish. The remaining two groups were assigned to two 127 I Blazka-type swim tunnels as described in Van de Thillart et al. (2004). After introduction, the fish were allowed to acclimate to the swim tunnels for one hour. Swim tunnels were set up in a temperature controlled room to install the temperature treatments. The exercise treatments were installed by allowing the fish to swim in a water flow that was created by gradual increment of a frequency controller (Siemens Micro Master) driving a propeller at the rear end of the tunnels. The water in each swim tunnel 
water was recycled over a pumping tank $(170 \mathrm{l})$ at a flow rate of $40 \mathrm{l} / \mathrm{min}$. The whole procedure was repeated eight times to conduct the 16 tests. All water in the swim tunnels and pumping tanks was renewed after each test. Fish were not fed from one day before the start of the preexperimental geosmin loading onwards.

Fish were sampled for geosmin concentration measurement upon termination of the tests after $23 \mathrm{~h}$. Fish were removed from the swim tunnels and euthanized in a $3 \mathrm{ml} / \mathrm{l}$ phenoxyethanol solution in tap water. For each swim tunnel and test, the whole bodies of the five fish were pooled, homogenized (DRC C10, PSV Group, Genainville, France) and stored at $-20{ }^{\circ} \mathrm{C}$ until analysis.

\section{Oxygen consumption}

Oxygen consumption was measured at $\mathrm{t}=5 \mathrm{~h}$ and $\mathrm{t}=22 \mathrm{~h}$ in both swim tunnels by measuring the decline of the dissolved oxygen concentration every second for a maximum of one hour or until oxygen saturation had declined to 70\% (Loligo Systems DAQ-PAC-G4: a 4-channel respirometry system with galvanic electrodes). During dissolved oxygen concentration measurements the oxygen supply to the swim tunnels was interrupted by manual closure of the water inflow of the swim tunnels. Water temperature was recorded during the swim test.

\section{Geosmin and lipid analysis}

Whole fish samples were thawed overnight at $4{ }^{\circ} \mathrm{C}$. From each pooled whole fish sample a subsample of approximately $1 \mathrm{~g}$ was taken. To each (sub) sample, $100 \mu \mathrm{l}$ of internal standard solution (D5-geosmine in water, $1 \mu \mathrm{g} / \mathrm{ml}$, Sigma Aldrich) was added. Samples were extracted by accelerated solvent extraction (ASE, Dionex, Amsterdam, the Netherlands) at $40{ }^{\circ} \mathrm{C}$ using a 15:85 (v/v) penthane-dichlorine methane mixture. After extraction, $1 \mathrm{ml}$ of hexane was added to the extract. Extracts were concentrated to $1 \mathrm{ml}$ by gently evaporating the penthanedichlorine methane mixture (Rothavap, Heidolph) and stored in $2 \mathrm{ml}$ amber coloured glass vials at $-20^{\circ} \mathrm{C}$ until geosmin measurement.

To each water sample $(250 \mathrm{ml}), 100 \mu \mathrm{l}$ of internal standard solution (D5-geosmine in water, 1 $\mu \mathrm{g} / \mathrm{ml}$ ) was added. Each water sample was led over an extraction cartridge (Sep-Pak ${ }^{\circledR}$ Vac $6 \mathrm{cc}$ $(1 \mathrm{~g})$ Certified tC18) and then eluted with $5 \mathrm{ml}$ diethyl ether. Water was removed from the collected diethyl ether by addition of sodium sulphate. Diethyl ether samples were concentrated to $1 \mathrm{ml}$ under a gently nitrogen gas flow and stored in a amber coloured glass vial at $-20^{\circ} \mathrm{C}$ until geosmin measurement.

For geosmin concentration measurement $1 \mu \mathrm{l}$ of sample was injected on a Shimadzu GCMS2010 (GC) coupled to a GCMS-QP2010 Ultra (MS) detector (Shimadzu, 's Hertogenbosch, the Netherlands). Analysis was performed in GCxGC mode using a Zoex ZX2 modulator 
(Shimadzu, 's Hertogenbosch, the Netherlands) with a modulation of $6 \mathrm{~s} .1^{\text {st }}$ dimension column was a $30 \mathrm{~m} \times 0.25 \mathrm{~mm}$ i.d. HT8 with a film thickness of $0.25 \mu \mathrm{m}$. The second dimension was a $2.3 \mathrm{~m} \times 0.25 \mathrm{~mm}$ i.d. BPX-50 column with a film thickness of $0.15 \mu \mathrm{m}$. Pressure was set at 124.7 $\mathrm{kPa}$. Injection port, interface and source temperatures were set at 225,290 and $200{ }^{\circ} \mathrm{C}$ respectively. The oven temperature was programmed as follows: $60^{\circ} \mathrm{C}$ holding for 2 minutes, then at $15.71{ }^{\circ} \mathrm{C} / \mathrm{min}$ to $170{ }^{\circ} \mathrm{C}$, then at $5^{\circ} \mathrm{C} / \mathrm{min}$ to $200{ }^{\circ} \mathrm{C}$. Detection was carried out using electron impact (EI) mode in single ion monitoring (SIM) mode. Quantification was performed using GCMSSolutions software (Shimadzu, 's Hertogenbosch, the Netherlands) with m/z 112.1 and 114.1 as quantification ion for geosmin and D5-geosmin respectively. Quantification was performed against a calibration curve fitted using 8 points between 1 and $500 \mathrm{ng} / \mathrm{g}$. Geosmin concentration measurements were validated.

Lipid content of fish samples was determined using a version of the method from Bligh and Dyer (1959) modified by De Boer (1988).

\section{Calculations}

The decline of the geosmin concentration in the fish, $\Delta$ geosmin, was calculated as the relative difference between the observed geosmin concentration at the start and at the end of each swim tests.

The excretion rate constant $k_{2}(1 / d)$ was calculated for each swim test according to Howgate (2004):

$\left.C_{F(t)}=C_{F(t=0)} e^{\left(-k_{2} t\right)}\right)$

Where $C_{F(t=0)}$ and $C_{F(t)}$ are the observed initial and final geosmin concentration in the fish and t time (d).

Oxygen consumption $\left(\mathrm{MO}_{2}\right.$ in $\mathrm{mg} \mathrm{O} / \mathrm{kg} / \mathrm{h}$ ) was calculated from the observed decline of the dissolved oxygen concentration in the swim tunnels according to the formula:

$M O_{2}=\frac{\Delta s a t(t) \cdot m g_{O_{2}}}{m \cdot \Delta t}$

where: $\Delta s a t_{(t)}$ is the decline in oxygen saturation (\%) during the measurement interval, $\mathrm{mg}_{\mathrm{O}_{2}}$ is the absolute amount of dissolved oxygen $(\mathrm{mg})$ in the $127 \mathrm{I} \mathrm{swim} \mathrm{tunnel} \mathrm{at} \mathrm{the} \mathrm{measured}$ oxygen saturation level at the experimental temperature $\left({ }^{\circ} \mathrm{C}\right)$ and divided by $100 \%, m$ is the body mass of the fish $(\mathrm{kg})$ and $\Delta t$ is the length of the time interval (h).

\section{Statistics}

Calculated values for $\Delta$ geosmin, $\mathrm{k}_{2}$ and $\mathrm{MO}_{2}$ per test $(\mathrm{n}=16)$ were expressed as mean (SD) per temperature $(T)$ treatment $(n=4)$, mean (SD) per exercise $(E)$ treatment $(n=4)$ and mean (SD) 
per $T * E$ treatment $(n=2)$. Mean values were tested for significant differences among treatments in a split-plot ANOVA design with temperature (T), exercise (E), main plot (D) and sub-plot (Z) as class variables. As the sub-plot factor swim tunnel (Z) had no significant effect on mean values, it was removed from the model. $\Delta$ geosmin was correlated to oxygen consumption $\mathrm{MO}_{2}$ by linear regression analysis. All statistical procedures were performed in SAS 9.1.

Table 2. The effect of temperature, exercise and their interaction on mean (SD) values for the absolute and relative geosmin excretion, the excretion rate constant $\mathrm{k}_{2}$ and oxygen consumption.

\begin{tabular}{|c|c|c|c|c|c|}
\hline Treatment & $\mathbf{n}$ & $\begin{array}{c}\text { [ } \Delta \text { geosmin] } \\
(\mathrm{ng} / \mathrm{g})\end{array}$ & $\begin{array}{c}\text { [Ageosmin] } \\
(\%)\end{array}$ & $\begin{array}{c}k_{2} \\
(1 / d)\end{array}$ & $\begin{array}{c}\mathrm{MO}_{2} \\
(\mathrm{mg} \mathrm{O} / 2 / \mathrm{kg} / \mathrm{h})\end{array}$ \\
\hline \multicolumn{6}{|l|}{ Temperature $(T)$} \\
\hline High temperature $-25^{\circ} \mathrm{C}$ & 8 & $3.8(2.0)$ & $22.4(10.8)$ & $0.26(0.14)$ & $101(54)$ \\
\hline Low temperature $-15^{\circ} \mathrm{C}$ & 8 & $2.8(2.1)$ & $17.2(11.4)$ & $0.20(0.14)$ & $77(62)$ \\
\hline P-value (T) & & 0.51 & 0.46 & 0.47 & 0.27 \\
\hline \multicolumn{6}{|l|}{ Exercise (E) } \\
\hline High exercise & 8 & $4.1(1.7)$ & $25.0(8.3)$ & $0.29(0.12)$ & 132 (49) \\
\hline Low exercise & 8 & $2.5(2.1)$ & $14.6(11.5)$ & $0.17(0.14)$ & $46(23)$ \\
\hline P-value (E) & & 0.009 & 0.009 & 0.010 & 0.003 \\
\hline \multicolumn{6}{|l|}{ Temperature * Exercise $\left(T^{*} E\right)$} \\
\hline High temperature - High exercise & 4 & $4.3(2.1)$ & $25.6(11.0)$ & $0.30(0.16)$ & $139(50)$ \\
\hline High temperature - Low exercise & 4 & $3.3(2.1)$ & $19.2(11.0)$ & $0.22(0.14)$ & $63(20)$ \\
\hline Low temperature - High exercise & 4 & $3.9(1.4)$ & $24.4(6.1)$ & $0.28(0.08)$ & $124(54)$ \\
\hline Low temperature - Low exercise & 4 & $1.8(2.2)$ & $10.0(11.4)$ & $0.11(0.13)$ & $29(10)$ \\
\hline P-value (T*E) & & 0.22 & 0.20 & 0.26 & 0.62 \\
\hline
\end{tabular}

\subsection{Results}

Main and interactive effects of temperature and exercise on geosmin excretion The mean (SD) relative decline of the geosmin concentration in the fish over $23 \mathrm{~h}$ was $22.4 \%$ (10.8\%) at $25^{\circ} \mathrm{C}$ and $17.2 \%(11.4 \%)$ at $15{ }^{\circ} \mathrm{C}$ (Table 2). However, no statistically significant effect of temperature on the absolute and relative decline of the geosmin concentration, nor the excretion rate constant could be detected. Exercise significantly increased the absolute and relative decline of the geosmin concentration in the fish, as well as the excretion rate constant $\mathrm{k}_{2}$ (Table 2). No statistically significant interactive effects of temperature and exercise $\left(T^{*} E\right)$ on the absolute and relative decline of the geosmin concentration in the fish, nor the excretion rate constant $k_{2}$ could be detected. The combination of high temperature and high exercise led to the highest absolute and relative decline of the geosmin concentration, whereas the lowest values were observed for the combination of low temperature and low exercise (Table 2). 
Main and interactive effects of temperature and exercise on oxygen consumption $\left(\mathrm{MO}_{2}\right)$

The mean (SD) $\mathrm{MO}_{2}$ was $101(54)$ at $25{ }^{\circ} \mathrm{C}$ and $77(62) \mathrm{mg} \mathrm{O} / \mathrm{kg} / \mathrm{h}$ at $15{ }^{\circ} \mathrm{C}$. However no statistically significant effect of temperature on oxygen consumption could be detected (Table 2). Exercise led to a statistically significant increase in oxygen consumption: exercised fish (swimming speed $0.55 \mathrm{~m} / \mathrm{s}$ ) consumed on average 132 (49) $\mathrm{mg} \mathrm{O} / \mathrm{kg} / \mathrm{h}$, while the fish that were not forced to swim (swimming speed $\mathrm{m} / \mathrm{s}$ ) consumed on average $46(23) \mathrm{mg} \mathrm{O} / \mathrm{kg} / \mathrm{h}$ (Table 2). No statistically significant interactive effects of temperature and exercise $\left(T^{*} E\right)$ on oxygen consumption could be detected. The combination of high temperature and high exercise led to the highest oxygen consumption, whereas the lowest values were observed for the combination of low temperature and low exercise (Table 2).

\section{Geosmin excretion in relation to oxygen consumption}

Geosmin excretion by European eel, expressed as the relative decline in geosmin concentration in the fish over $23 \mathrm{~h}$, increased linearly with oxygen consumption ( $p=0.02$, Fig. 1).

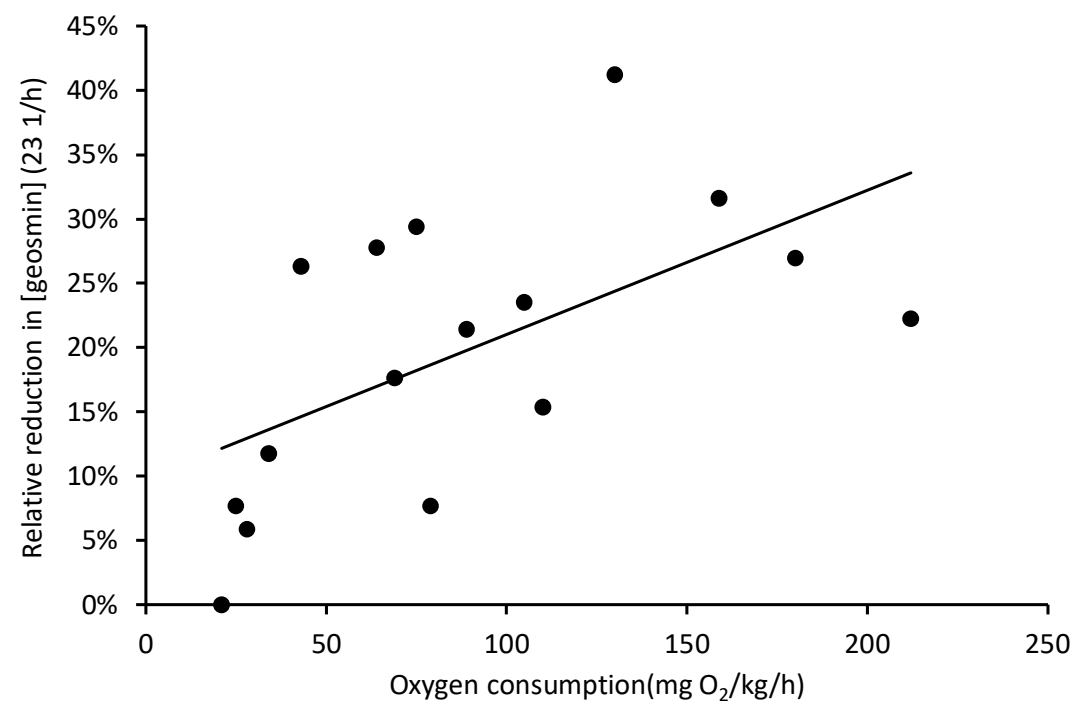

Fig. 1. Geosmin excretion by European eel (expressed as the relative decline of the whole body geosmin concentration over $23 \mathrm{~h}, \Delta$ geosmin (\%)) in relation to its oxygen consumption $\left(\mathrm{MO}_{2}\right) . \Delta$ geosmin $(\%)=9.8(4.4)+0.112(0.04) * \mathrm{MO}_{2}$ (linear regression analysis, $\mathrm{p}=0.02, \mathrm{r}^{2}=$ 0.29 , SE for parameter estimates in parentheses).

\section{Effect of temperature and exercise on off-flavour depuration time}

To illustrate the effects of exercise and temperature on geosmin excretion by European eel, the depuration times required to reach a $75 \%$ reduction of the initial geosmin concentration 
were predicted. The required depuration times for the four combinations of temperature and exercise treatments were predicted using the excretion rate constants $\mathrm{k}_{2}$ calculated from the decline of the geosmin concentrations during the $23 \mathrm{~h}$ tests, equation 1 and an initial geosmin concentration of $20 \mathrm{ng} / \mathrm{g}$. The time to reduce the initial geosmin concentration by $75 \%$ was 4.6 days at high temperature combined with high exercise, 5 days at low temperature combined with high exercise, 6.3 days at high temperature with low exercise and 12.6 days at low temperature with low exercise (Fig. 2).

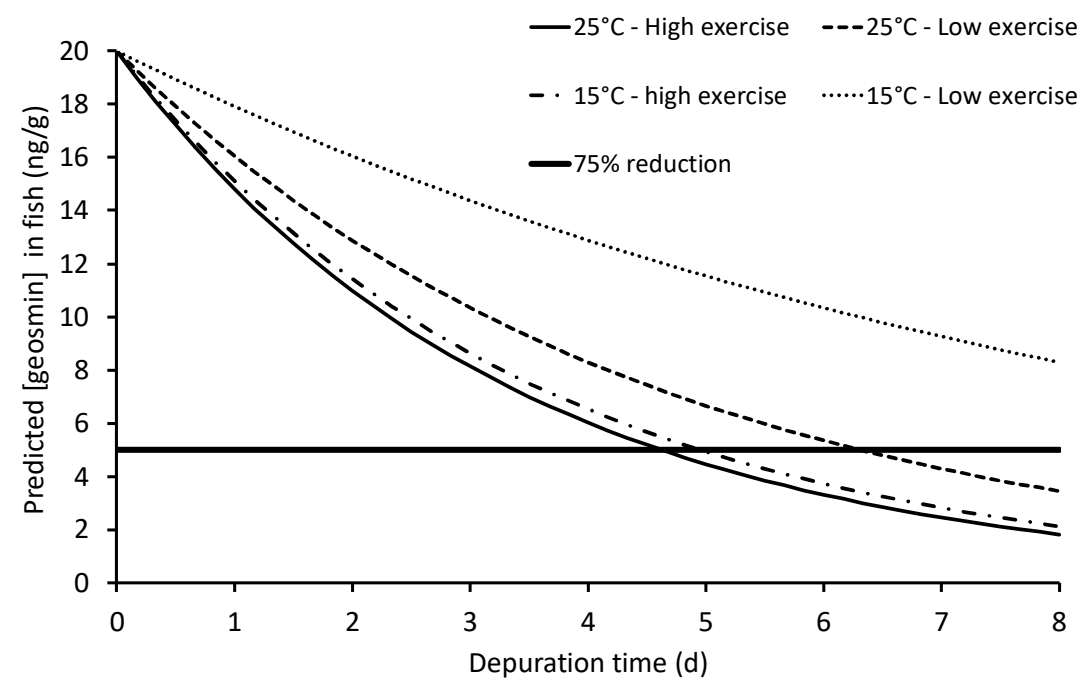

Fig. 2. Model predicted effects of temperature and exercise on geosmin excretion by European eel. Geosmin concentration in the whole body over time $\left(\mathrm{C}_{\mathrm{F}(\mathrm{t})}\right)$ was modelled as exponential decay: $C_{F(t)}=C_{F(0)} e^{-k_{2} t}$. The initial geosmin concentration $\left(C_{F(0)}\right)$ was set at 20 $\mathrm{ng} / \mathrm{g}$. Excretion rate constants $k_{2}$ as experimentally determined for the four different combinations of temperature and exercise treatments were used. Times to reach $75 \%$ reduction of the initial geosmin concentration ( $5 \mathrm{ng} / \mathrm{g}$ ) were $4.6,5,6.3$ and 12.6 days.

\subsection{Discussion}

Geosmin excretion by European eel was clearly enhanced by exercise, while the effect of temperature was not significant. Exercise increased oxygen consumption, which in turn showed a positive linear relation with geosmin excretion. These findings support the idea that the physiological responses aimed at increasing oxygen uptake also affect the branchial exchange of lipophilic chemicals between the fish and its surroundings. Exercise can be used to reduce the time required to depurate off-flavours from fish.

A forced increase of the swimming activity by increasing the flow from 0.05 to $0.55 \mathrm{~m} / \mathrm{s}$ led to a significant increase in the rate at which European eel eliminate geosmin from their bodies. 
An increase in temperature from $15{ }^{\circ} \mathrm{C}$ to $25{ }^{\circ} \mathrm{C}$ did not result in a statistically significant increase of geosmin excretion. Metabolic rate and thus oxygen demand increase in fish as temperature increases, while oxygen concentrations in water decline with increasing temperature. Fish therefore increase their ventilation rate in order to maintain sufficient oxygen uptake when temperature increases (Neely, 1979). Temperature increase induces only a limited increase in oxygen uptake (Brett and Glass, 1973; Puckett and Dill, 1984; Brett, 1964), while exercise can induce a much larger increase in oxygen demand and uptake (Hughes et al., 1983; Wieser and Forstner, 1986). Consequently, effects of exercise on oxygen demand and uptake will be easier to detect in experimental settings than effects of temperature. This may explain why we observed significant effects of exercise on geosmin excretion and oxygen consumption, while the effects of temperature were not significant. We therefore do not entirely exclude any temperature effect on geosmin excretion by eel; the (relative) decline in the geosmin concentrations during our trails was consistently higher at $25^{\circ} \mathrm{C}$ as compared to $15^{\circ} \mathrm{C}$. It seems more likely that, in agreement with Johnson et al. (1996), the temperature effect is rather small and that our short-term experiment had insufficient statistical power to detect relatively small effects of temperature while being sufficient to detect the larger effects of exercise.

The excretion rate constants of the off-flavour causing chemicals geosmin and MIB have been postulated to depend on four factors: 1 ) the gill uptake efficiency for the chemicals, 2) the gill ventilation rate, 3 ) the volume of lipid in the fish and 4) the lipophilic nature of the chemicals, expressed as their octanol-water partition coefficients (Kow) (Howgate, 2004, based on Gobas and Mackay, 1997). Effects of exercise on geosmin excretion are most likely caused by its impact on the first two points. Exercise requires energy and thus increases the fish' demand for oxygen to fuel aerobic energy metabolism. An increased oxygen demand leads to various physiological changes in fish aimed at increasing branchial oxygen uptake and internal oxygen distribution. Branchial oxygen uptake is increased by an increased water flow over the gills (Jones and Randall, 1978 in Randall, 1982). Cardiac output also increases under exercise (Randall, 1982; Palstra et al., 2015) and the resulting rise in blood pressure leads to a significantly higher perfusion of secondary gill lamellae, a more even lamellar blood flow and more rigid lamellae and ultimately a higher branchial diffusion and oxygen uptake capacity (Randall and Daxboeck, 1982; Randall et al., 1967).

As branchial uptake is the main route of entry of lipophilic chemicals in fish (reviewed by Streit, 1998), it is considered highly likely that factors that enhance branchial oxygen uptake efficiency in fish have similar effects on the efficiency of the branchial exchange of lipophilic chemicals (McKim and Erickson, 1991; Brauner et al., 1994; Yang et al., 2000; Blewett et al., 2013). In several studies, increased uptake of lipophilic chemicals in fish could be related to 
an, exercise induced, increased oxygen consumption (Brauner et al., 1994; Yang et al., 2000; Blewett et al., 2013). Excretion rates of lipophilic chemicals are likely to be similarly affected, provided that the chemical is mainly excreted via the fish gill (Yang et al., 2000). These authors established for a range of lipophilic chemicals, fish species and fish sizes that excretion indeed increases with increasing oxygen consumption.

No significant interaction between the temperature and exercise treatments could be detected. As the underlying mechanisms for the effects of temperature and exercise on geosmin excretion are most likely similarly related to treatment effects on branchial oxygen uptake, it seems that the effects of temperature and exercise are additive rather than interactive. Indeed when oxygen consumption was used as single explanatory variable for all treatment combinations, a significant linear relation between oxygen consumption and geosmin elimination was found, which is in agreement with previous work on the excretion of lipophilic chemicals by fish in relation to oxygen consumption (Yang et al., 2000). Increased chemical elimination from the fish with increasing branchial oxygen uptake efficiency also supports the notion that transfer across the fish gills is the main and rate-limiting excretion route for lipophilic chemicals like geosmin (Yang et al., 2000). The relation between oxygen uptake and chemical excretion as established by Yang et al. (2000) is probably applicable to a wide range of lipophilic chemicals. Therefore it is highly likely that the here observed treatment effects on geosmin excretion are also applicable to 2-methylisoborneol, the other chemical that causes off-flavour in fish.

We estimated the geosmin excretion rate constants $\left(k_{2}\right)$ for each of the four experimental combinations of temperature and exercise in order to quantify treatment effects on geosmin excretion. This is appropriate for the current objective of 'proof of principle', but it should be noted that these estimates for $k_{2}$ are based on only two observations in time ( $t=0$ and $t=23 \mathrm{~h}$ ) and represent only a relatively short depuration period during which the fish excreted between ca. 10 and $26 \%$ of the geosmin in their bodies. It thus remains to be confirmed by longer depuration trials to what extent the here presented geosmin excretion rate constants are representative for European eel under the different temperature and exercise regimes.

Despite these limitations, we used the excretion rate constants to explore the practical implications of our current findings for off-flavour depuration. The depuration times required to reach a $75 \%$ reduction of the initial geosmin concentration were calculated under the assumption that geosmin elimination from eel follows a pattern of exponential decay (Howgate, 2004). The absolute values of the required depuration times presented here are specific for the chosen initial $(20 \mathrm{ng} / \mathrm{g})$ and final $(5 \mathrm{ng} / \mathrm{g})$ geosmin concentrations. However, the relative differences in required depuration time among treatments only depend on the excretion rate constants. It then appears that depurating off-flavours from European eel in 
warm water and under forced exercise may reduce the required depuration time by up to $60 \%$ as compared to commonly practiced depuration in cold water without forced exercise.

\subsection{Conclusions and perspectives}

Exercise significantly increases the rate at which European eels eliminate the off-flavour causing chemical geosmin from their bodies. This effect of exercise is probably related to increased gill exchange efficiency for the chemical as the increased elimination was related to an increased oxygen consumption. Forcing fish to swim during off-flavour depuration shortens the required depuration time. These findings are relevant for the aquaculture industries confronted with off-flavoured fish crops.

Although the economic damage caused by off-flavour to the aquaculture industry has never been quantified in detail, it seems clear that shorter depuration times save considerable time, efforts and space in commercial farms. This study showed that forced exercise may reduce depuration time considerably supporting its implementation in depuration protocols.

\section{Acknowledgements}

The authors wish to thank N. Ros, Y. van Es and A. Hofman (IMARES) for assistance with animal care, Dr. G. van den Thillart (Molecular Cell Biology Group, Institute of Biology Leiden, Leiden University and ZFscreens, The Netherlands) for use of the swim-tunnels and Dr. W.J. Koops for assisting the experimental design. This study was funded by the Dutch Ministry of Economic Affairs. 


\section{Geosmin depuration from European eel (Anguilla anguilla) is not affected by the water renewal rate of depuration tanks}

Published as

Schram, E., van Kooten, T., van de Heul, J. W., Schrama, J. W., Verreth, J. A. J., Murk, A. J., 2017, Geosmin depuration from European eel (Anguilla anguilla) is not affected by the water renewal rate of depuration tanks. Aquaculture Research 48, 4646-4655. 


\section{Abstract}

This study established that geosmin depuration from European eel is not affected by the water renewal rate of depuration tanks. A general fish bioaccumulation model extended with terms that account for effects of tank water renewal rate and systems losses of chemicals, predicted strong effects of the water renewal rate of depuration tanks on geosmin depuration from European eel. Model predictions were validated in a depuration experiment with geosmin loaded European eel $(n=95)$ with a mean (SD) individual weight $134.4(5.0)$ g and a mean (SD) lipid content 33.7 (2.8)\% (w/w). Fish were depurated for 24,48 or $72 \mathrm{~h}$ at three different tank water renewal rates $(0.3,3.3$ and $331 / \mathrm{d})$. Treatments were installed by three different mean (SD) water flow rates (13.8 (1.3), 143.5 (9.2) and 1511 (80) l/kg fish/d) over 30 I tanks. Eels eliminated geosmin from their bodies but unlike the model predicted, this was independent of the water renewal rate of the depuration tanks. Although being eliminated from the fish, geosmin hardly appeared and certainly did not accumulate in the water of the depuration tanks as the model predicted. This observation may be explained by geosmin being eliminated from eel as metabolite rather than the parent compound. Geosmin elimination from eel seems not to occur according to the generally accepted passive diffusion mechanism for excretion of lipophilic chemicals and geosmin biotransformation by the eel seems indicated. Clearly geosmin depuration from European eel cannot be enhanced by increasing water renewal rates of depuration tanks. 


\subsection{Introduction}

Off-flavour is an important quality issue in farmed fish as it results in low appreciation by human consumers. Most common is an earthy/musty off-flavour caused by the presence of geosmin and/or 2-methylisoborneol (MIB) in fish tissues. Geosmin and MIB are secondary metabolites produced by a wide range of microbiota common to land-based aquaculture systems. Actinomycetes and cyanobacteria are considered the most important geosmin and MIB producers in aquaculture systems (reviewed by Krishnani et al., 2008). Fish concentrate these chemicals in body lipids. This bio concentration of geosmin and MIB is assumed to be passive, concentration driven and reversible. The chemicals can freely diffuse in and out of the fish via the gills depending on the fugacity gradient between water and fish. As a result, an equilibrium re-establishes when the chemical concentrations in the water or fish change (Howgate, 2004). Fish farmers utilize this mechanism to depurate off-flavours from their fish stocks by placing them in water free of geosmin and MIB just before harvesting. Fish are depurated until excretion has resulted in a reduction of the geosmin and MIB concentrations in the fish to levels below human sensory detection limits. This procedure, however, is costly as fish are not fed in this period so they may lose weight while they take time and space. Therefore better understanding of factors enhancing the geosmin excretion is needed to be able to enhance this process.

Uptake and excretion of geosmin and MIB by fish have been described by a first order kinetics one-compartment model (Howgate, 2004) based on the general fish aquatic bioaccumulation model (OECD 305, 2012). According to this model and under the condition that excreted geosmin and MIB do not accumulate in the water, the chemical concentrations in offflavoured fish show exponential decay during depuration in clean water. Total geosmin excretion then only depends on the initial concentrations in the fish and an excretion rate constant (Howgate, 2004). In aquatic environments with nearly infinite water volumes compared to fish volumes, such as most natural aquatic environments, it is unlikely that the excretion of chemicals by fish significantly affects the chemical's concentrations in the water. However, in artificial aquatic environments with high fish densities, compounds excreted by fish can accumulate to significant levels in the water, depending on the amounts excreted and the water flow-rate over the tank (Eding and van Weerd, 1999; Schram et al., 2009). In industrial off-flavour depuration systems excreted geosmin and MIB may thus accumulate in the water. Excreted chemicals may then be re-absorbed by the fish, effectively reducing the net excretion and increasing the depuration time required to bring the concentrations in the fish below human sensory detection limits. The decline of the chemical concentration in the fish during excretion then not only depends on the initial concentration in the fish and the excretion rate constant but also on the uptake rate constant, the fish density (biomass per water volume) and the water renewal rate of the depuration tank. To enable application to 
industrial depuration systems we extended the general fish aquatic bioaccumulation model (OECD 305, 2012) to a model that accounts for reuptake of excreted chemicals. This extended model revealed that for a given fish density the chemical accumulation in the water and consequently the net chemical excretion, depends on the water renewal rate of the depuration tank. In theory, water renewal rate of the depuration tank, here expressed as the water flow rate over the depuration tank relative to the tank volume (flow/tank volume), thus appears to be an important factor controlling the performance of off-flavour depuration systems. In commercial practise however, the water flow rate over off-flavour depuration systems is often minimized to reduce operational costs related to water use or low due to limited water availability. This implies that the performance of industrial off-flavour depuration facilities is possibly far from optimal. The goal of this study was therefore to investigate the effect of water renewal rate of depuration tanks on geosmin excretion by offflavoured fish. To this end European eel (Anguilla Anguilla) were loaded with geosmin and subsequently depurated at different tank renewal rates to monitor geosmin concentrations in water and fish over time. The experimental design was based on model predicted effects of tank water renewal rate on geosmin excretion using the above mentioned extended model. Based on the model output our study hypothesis was that increasing the water renewal rate of a depuration tank leads to faster decline of the geosmin concentration in the fish and reduced geosmin accumulation in the depuration tank water.

\subsection{Materials and methods}

\section{Model predictions}

\section{Extended model derivation}

Bio concentration of chemicals in aquatic organisms can be described mathematically by an organism-water two compartment model:

$\frac{d C_{F}}{d t}=k_{1} C_{W}-\left(k_{2}+k_{E}+k_{M}+k_{G}\right) C_{F}$

where $\mathrm{dC}_{\mathrm{F}} / \mathrm{dt}$ is the change of the chemical concentration in the fish $C_{F}(\mathrm{~g} / \mathrm{kg})$ over time, $C_{W}$ the constant chemical concentration in the water $(\mathrm{g} / \mathrm{I}), k_{1}, k_{2}, k_{E}, k_{M}$, and $k_{G}$ the rate constants $(1 / d)$ for the uptake from the water $\left(k_{1}\right)$, elimination to the water $\left(k_{2}\right)$, fecal egestion $\left(k_{E}\right)$, metabolic biotransformation $\left(k_{M}\right)$ and growth dilution $\left(k_{G}\right)$. The sum of $k_{2}, k_{E}, k_{M}$, and $k_{G}$ represents the total elimination or depuration rate constant $k_{T}$ (Arnot and Gobas, 2006). As biotransformation, faecal egestion and growth dilution of geosmin and MIB are assumed to be insignificant, Howgate (2004) excluded these rate constants from the mathematical model. Equation 1 then simplifies to:

$\frac{d C_{F}}{d t}=k_{1} C_{W}-k_{2} C_{F}$ 
Solving equation 2 for contaminated fish in clean water $\left(C_{w}=0\right)$ and under the assumption that the chemical does not accumulate in the water, yields an equation that describe the depuration of the chemical from the fish as exponential decay (Howgate, 2004):

$$
C_{F(t)}=C_{F(t=0)} e^{\left(-k_{2} t\right)}
$$

where $C_{F(t=0)}$ is the initial chemical concentration in the fish.

The bio concentration model by Arnot and Gobas (2006) assumes a constant chemical concentration $\left(C_{W}\right)$ in the water. However, as for the high fish densities we predicted accumulation of excreted geosmin in the water. We therefore extended the model by allowing $C_{W}$ to vary over time as a function of chemical uptake and excretion by the fish and chemical outflow via the tank effluent. In addition we included a term to account for the geosmin system losses established in a preliminary stability study. The change of $C_{W}$ over time is then described by:

$\frac{d C_{W}}{d t}=z k_{2} C_{F}-z k_{1} C_{W}-k_{Q} C_{W}-k_{S} C_{W}$

The first term describes the increase in concentration as a result of chemical elimination from fish. The second term is the change rate of the chemical concentration in the water as a result of uptake by fish. The tank volume is constant and hence there is also an implicit outflow of water with concentration $C_{W}$. This chemical loss as a function of the tank water renewal rate $k_{Q}$ is described by the third term. The fourth term describes the system losses of the chemical at rate $k_{s}$. The parameter $z$ is the ratio of fish to water volume (BM/V in Table 1$)$, which is used to account for the different volumes of water and masses of fish. We assume that the fish and water have the identical density one. Other assumptions to equation 4 are that the water inflow does not contain any chemical. We solved the system formed by equations 2 and 4 analytically using Mathematica 9.0 (Wolfram Research, Champaign, Illinois, USA) to yield equations for $C_{F}(t)$ and $C_{W}(t)$.

$$
\begin{aligned}
& C_{F(t)}=\frac{1}{1000}\left(e^{-\frac{1}{2} t\left(k_{2}+k_{Q}+k_{S}+k_{1} z+\sqrt{-4 k_{2}\left(k_{Q}+k_{S}\right)+\left(k_{2}+k_{Q}+k_{S}+k_{1} z\right)^{2}}\right)}\left(-k_{2} C_{F 0}\left(-1+e^{t D}\right)\right)\right. \\
& \left.+k_{1}\left(-1+e^{t D}\right)\left(2 C_{W 0}+C_{F 0} z\right)+\frac{C_{F 0}\left(\left(-1+e^{t D}\right)\left(k_{Q}+k_{S}\right)+\left(1+e^{t D}\right) D\right)}{\sqrt{-4 k_{2}\left(k_{Q}+k_{S}\right)+\left(k_{2}+k_{Q}+k_{S}+k_{1} z\right)^{2}}}\right) \\
& C_{W(t)}=e^{-\frac{1}{2} t\left(k_{2}+k_{q}+k_{s}+k_{1} z+D\right)} \\
& \left(\frac{\left(k_{2}\left(-1+e^{t D}\right)\left(C_{W 0}+2 C_{F 0} z\right)+C_{W 0}\left(\left(k_{Q}+k_{S}\right)-e^{t D}\left(k_{Q}+k_{S}\right)-k_{1}\left(-1+e^{t D}\right) z+\left(1+e^{t D}\right) D\right)\right.}{2 \sqrt{-4 k_{2}\left(k_{Q}+k_{S}\right)+\left(k_{2}+k_{Q}+k_{S}+k_{1} z\right)^{2}}}\right)
\end{aligned}
$$


Where $D=\sqrt{\left(k_{2}\right)^{2}-2 k_{2}\left(k_{Q}+k_{S}-k_{1} z\right)+\left(k_{Q}+k_{S}+k_{1} z\right)^{2}}, C_{F O}$ is the chemical concentration in the fish $(\mathrm{g} / \mathrm{kg})$ at $\mathrm{t}=0, C_{\text {wo }}$ the chemical concentration in the water $(\mathrm{g} / \mathrm{l})$ at $\mathrm{t}=0$ and $\mathrm{t}$ is time (days).

We used these equations to predict the geosmin concentrations in fish and water for different tank water renewal rates, at various points in time.

\section{Geosmin uptake and excretion rate constants}

Geosmin uptake and excretion rate constants have not been previously determined for European eel. To obtain estimates for the geosmin uptake and excretion rate constants for eel, we interpolated the body weight and temperature ranges for the rate constants as derived by Howgate (2004) for rainbow trout with a lipid content of $10 \%(w / w)$. We assumed that the gill uptake efficiency for chemicals and the gill ventilation rate are similar for rainbow trout and European eel. Geosmin uptake and excretion rate constants were derived for the mean body weights and water temperatures in the depuration experiment. As the excretion rate constant depends on lipid volume (Gobas and Mackay, 1987), the $k_{2}$ values obtained by interpolation were recalculated for the mean lipid volumes of the eels per treatment based on the linear dependence of $k_{2}$ on lipid content in the Gobas and Mackay (1987) model (Howgate, 2004). Lipid mass was converted to volume assuming a lipid density of $0.86 \mathrm{~g} / \mathrm{ml}$. The calculated rate constants per treatment are presented in Table 1.

\section{Geosmin system loss rate}

The geosmin system loss rate was established in a stability study. Three depuration tanks with stagnant water and identical to the depuration tanks used in the depuration experiment were spiked with geosmin. Water samples for geosmin concentration measurements were collected at $\mathrm{t}=0$ and $\mathrm{t}=72 \mathrm{~h}$. The observed decline of the geosmin concentration over time was modelled as exponential decay and yielded a system loss rate constant $k_{s}$ of $0.131 / \mathrm{d}$.

\section{Prediction of experimental results}

Pre-experimental model predictions were used to decide on the levels of the tank water renewal rate treatments in the depuration experiment. Actual experimental conditions were used as model input to predict treatment effects on the decline of geosmin levels in the fish and the accumulation of geosmin in the tank water (Table 1). The decline over time of the geosmin concentration in the fish under the assumption that excreted geosmin does not accumulate in the water was predicted using Eq. 3 and included to represent depuration in an infinite water volume (referred to as Depuration at $\mathrm{CW}=0$ ). 
Table 1. Model input and conditions for the depuration experiments. Parameters marked with (*) were used as model input. Parameters marked with (\#) are experimental conditions.

\begin{tabular}{|c|c|c|c|c|c|}
\hline \multirow[b]{2}{*}{ Parameter } & \multicolumn{5}{|c|}{ Values per water flow rate } \\
\hline & Symbol & Low & Medium & High & Unit \\
\hline $\begin{array}{l}\text { Mean (SD) dissolved oxygen } \\
\text { concentration }\end{array}$ & & $8.3(3.7)$ & $8.3(1.7)$ & $9.0(0.4)$ & $(\mathrm{mg} / \mathrm{L})$ \\
\hline Fish biomass ${ }^{*}$ & BM & 0.668 & 0.668 & 0.668 & $(\mathrm{~kg})$ \\
\hline Fish biomass ${ }^{\#}$ & & 0.661 & 0.657 & 0.686 & $(\mathrm{~kg})$ \\
\hline Tank volume ${ }^{*}, \#$ & v & 30 & 30 & 30 & (L) \\
\hline Fish to water ratio (BM/V) & z & 0.022 & 0.022 & 0.022 & \\
\hline Fish lipid content ${ }^{\#}$ & & 33.0 & 34.2 & 33.8 & $(\% \mathrm{w} / \mathrm{w})$ \\
\hline Mean (SD) water temperature & & $19.8(0.6)$ & $19.2(0.7)$ & $18.3(0.2)$ & $\left({ }^{\circ} \mathrm{C}\right)$ \\
\hline Uptake rate constant ${ }^{*}$ & $\mathrm{k}_{1}$ & 365 & 351 & 331 & $(1 / d)$ \\
\hline Excretion rate constant ${ }^{*}$ & $\mathrm{k}_{2}$ & 0.25 & 0.23 & 0.22 & $(1 / d)$ \\
\hline $\begin{array}{l}\text { Initial geosmin concentration in } \\
\text { the fish }{ }^{*}, \#\end{array}$ & $\mathrm{C}_{\mathrm{F} 0}$ & 22 & 22 & 22 & (ng/g) \\
\hline $\begin{array}{l}\text { Initial geosmin concentration in } \\
\text { water*\# }\end{array}$ & $\mathrm{C}_{\text {wo }}$ & 0 & 0 & 0 & (ng/g) \\
\hline Water flow rate ${ }^{\#}$ & $\mathrm{Q}$ & $13.8(1.3)$ & $143.5(9.2)$ & $1511(80)$ & (L/kg fish/d) \\
\hline Tank water renewal rate ${ }^{\#, *}$ & $k_{Q}$ & 0.3 & 3.3 & 33.1 & $(1 / d)$ \\
\hline System loss rate ${ }^{*}$ & $\mathrm{ks}_{\mathrm{s}}$ & 0.131 & 0.131 & 0.131 & $(1 / d)$ \\
\hline
\end{tabular}

\section{Depuration experiment}

\section{Ethics statement and origin of the experimental animals}

The treatment of the fish was in accordance with Dutch law concerning animal welfare, as approved by the ethical committee for animal experimentation of Wageningen UR Livestock Research (protocol 2012113). European eel (Anguilla anguilla) raised at a commercial fish farm in the Netherlands were obtained from eel whole sale Joh. Kuijten BV, Spaardam, the Netherlands.

\section{Pre-experimental loading with geosmin}

Before the start of the depuration experiment European eel $(n=95)$ with a mean (SD) individual weight of 134.4 (5.0)g and a mean (SD) lipid content of 33.7 (2.8)\% (w/w) were exposed to waterborne geosmin for $96 \mathrm{~h}$. To this end the fish were stocked in a polyester tank filled with 300 I local tap water spiked with geosmin $(3.8 \mathrm{ml}$ of $100 \mu \mathrm{g} / \mathrm{ml}$ geosmin stock solution in acetone, Sigma Aldrich). Tank water was aerated by an air stone to supply oxygen to the fish. Fish were not fed the day before the start and during geosmin exposure. 


\section{Experimental design and procedures}

The experiment was set up as a $3 \times 3$ factorial design with tank water renewal rate $\left(\mathrm{k}_{\mathrm{Q}}\right)$ and depuration time (T) as independent factors. Fish loaded with geosmin were depurated for 24 , 48 or $72 \mathrm{~h}$ at three different tank water renewal rates (low, medium and high, Table 2) with duplicate aquaria for each of the nine different combinations of depuration time $(T)$ and tank water renewal rate $\left(k_{Q}\right)$. At the end of the pre-experimental geosmin exposure $(T=0)$ fish (n = 95) were randomly split into 19 groups of five fish and weighed per group. One group was used to determine the initial geosmin content of the fish. Each of the 18 remaining groups was randomly assigned to one of 18, 30 I glass aquaria. Tank water renewal rate treatments and depuration times were randomly assigned to the aquaria. Oxygen was supplied to each aquarium via a minimal flow of pure oxygen to prevent volatizing of excreted, waterborne geosmin (geosmin removal from aquaria via other routes than the outflowing water would potentially override the effect of water flow rate treatments). Water flow rate over the depuration tanks, temperature and dissolved oxygen concentration (Hach Lange Multimeter) in the aquaria were monitored at $\mathrm{T}=18,24,48$ and $72 \mathrm{~h}$. Oxygen supply and water flow rate were adjusted when necessary.

Table 2. Experimental conditions during the geosmin from fish depuration experiments. Mean (SD) values for water flow rate, tank water renewal rate, water temperature and dissolved oxygen concentration.

\begin{tabular}{lllllll} 
& \multicolumn{2}{l}{ Water flow rate } & $\begin{array}{l}\text { Tank water } \\
\text { renewal rate* }\end{array}$ & $\begin{array}{l}\text { Water } \\
\text { temperature }\end{array}$ & {$\left[\mathrm{O}_{2}\right]$} \\
Treatment & $(\mathrm{ml} / \mathrm{min})$ & $(\mathbf{I} / \mathbf{k g}$ fish/d) & $(\mathbf{1} / \mathrm{d})$ & $\left({ }^{\circ} \mathrm{C}\right)$ & $(\mathrm{mg} / \mathrm{I})$ \\
Low flow & $6.3(0.5)$ & $13.8(1.3)$ & 0.3 & $19.8(0.6)$ & $8.3(3.7)$ \\
Medium flow & $68.3(5.2)$ & $143.5(9.2)$ & 3.3 & $19.2(0.7)$ & $8.3(1.7)$ \\
High flow & $689(33)$ & $1511(80)$ & 33.1 & $18.3(0.2)$ & $9.0(0.4)$
\end{tabular}

\section{Water and fish sampling}

Water and fish samples were collected at $\mathrm{t}=24,48$ and $72 \mathrm{~h}$ from two aquaria for each tank water renewal rate treatment (low, medium, high, Table 2) per sampling time. Water samples $(250 \mathrm{ml})$ were collected in glass bottles from the outflow of the aquaria and stored at $4{ }^{\circ} \mathrm{C}$ until analysis. Fish ( $n=5$ per aquarium) were quickly netted from the aquaria and euthanized a $3 \mathrm{ml} / \mathrm{l}$ phenoxy-ethanol solution in tap water. Whole fish were pooled per aquarium, homogenized using a refrigerated mincer (DRC C10, PSV Group, Genainville, France) and stored at $-20{ }^{\circ} \mathrm{C}$ until further analysis.

\section{Geosmin and lipid analysis}

Whole fish samples were thawed overnight at $4{ }^{\circ} \mathrm{C}$. From each pooled whole fish sample a subsample of approximately $1 \mathrm{~g}$ was taken. To each (sub) sample, $100 \mu \mathrm{l}$ of internal standard 
solution (D5-geosmine in water, $1 \mu \mathrm{g} / \mathrm{ml}$, Sigma Aldrich) was added. Samples were extracted by accelerated solvent extraction (ASE, Dionex, Amsterdam, the Netherlands) at $40^{\circ} \mathrm{C}$ using a 15:85 (v/v) penthane-dichlorine methane mixture. After extraction, $1 \mathrm{ml}$ of hexane was added to the extract. Extracts were concentrated to $1 \mathrm{ml}$ by gently evaporating the penthanedichlorine methane mixture (Rothavap, Heidolph) and stored in $2 \mathrm{ml}$ amber coloured glass vials at $-20^{\circ} \mathrm{C}$ until geosmin measurement. To each water sample $(250 \mathrm{ml}), 100 \mu \mathrm{l}$ of internal standard solution (D5-geosmine in water, $1 \mu \mathrm{g} / \mathrm{ml}$ ) was added. Each water sample was led over an extraction cartridge (Sep-Pak ${ }^{\circledR}$ Vac $6 \mathrm{cc}(1 \mathrm{~g})$ Certified tC18) and then eluted with $5 \mathrm{ml}$ diethyl ether. Water was removed from the collected diethyl ether by addition of sodium sulphate. Diethyl ether samples were concentrated to $1 \mathrm{ml}$ under a gently nitrogen gas flow and stored in a amber coloured glass vial at $-20^{\circ} \mathrm{C}$ until geosmin measurement. For geosmin concentration measurement $1 \mu \mathrm{l}$ of sample was injected on a Shimadzu GCMS2010 (GC) coupled to a GCMS-QP2010 Ultra (MS) detector (Shimadzu, 's Hertogenbosch, the Netherlands). Analysis was performed in GCxGC mode using a Zoex ZX2 modulator (Shimadzu, 's Hertogenbosch, the Netherlands) with a modulation of $6 \mathrm{s.} 1^{\text {st }}$ dimension column was a 30 $\mathrm{m} \times 0.25 \mathrm{~mm}$ i.d. HT8 with a film thickness of $0.25 \mu \mathrm{m}$. The second dimension was a $2.3 \mathrm{~m} \times$ $0.25 \mathrm{~mm}$ i.d. BPX-50 column with a film thickness of $0.15 \mu \mathrm{m}$. Pressure was set at $124.7 \mathrm{kPa}$. Injection port, interface and source temperatures were set at 225,290 and $200{ }^{\circ} \mathrm{C}$ respectively. The oven temperature was programmed as follows: $60^{\circ} \mathrm{C}$ holding for 2 minutes, then at $15.71{ }^{\circ} \mathrm{C} / \mathrm{min}$ to $170{ }^{\circ} \mathrm{C}$, then at $5{ }^{\circ} \mathrm{C} / \mathrm{min}$ to $200{ }^{\circ} \mathrm{C}$. Detection was carried out using electron impact (EI) mode in single ion monitoring (SIM) mode. Quantification was performed using GCMSSolutions software (Shimadzu, 's Hertogenbosch, the Netherlands) with m/z 112.1 and 114.1 as quantification ion for geosmin and D5-geosmin respectively. Quantification was performed against a calibration curve fitted using 8 points between 1 and $500 \mathrm{ng} / \mathrm{g}$. Geosmin concentration measurements were validated. Lipid content of fish samples was determined using a version of the method from Bligh and Dyer (1959) modified by De Boer (1988).

\section{Calculations and statistics}

As geosmin is lipophilic, concentrations in fish were normalized for lipid content (\%, w/w). Lipid normalized geosmin concentrations in fish ( $\mathrm{ng} / \mathrm{g}$ lipid) were expressed as mean $(\mathrm{n}=2)$ per tank water renewal rate treatment and sampling time. Two-way ANOVA was used to detect significant differences among mean lipid normalized geosmin concentration in fish. Data were log-transformed to obtain residuals that were normally distributed (Shapiro-Wilk's test, $p=$ 0.37 ) and to obtain homogeneity of variance of residuals across treatment levels (Levene's test, $p=0.52$ ). As the two-way ANOVA did not indicate any effect of tank water renewal rate treatment on geosmin concentration in the fish, the observed geosmin concentrations in the fish at different tank water renewal rates were also pooled per sampling time. The excretion rate constant $k_{2}$ and the geosmin concentration at $\mathrm{t}=0\left(\mathrm{C}_{\mathrm{Ft}=0}\right)$ were estimated by fitting the 
observed lipid normalized geosmin concentration data to Eq. 2 by log-linear regression analysis (OECD 305, 2012). Data were natural log-transformed and the geosmin concentration in the fish at $\mathrm{t}=0$ was excluded.
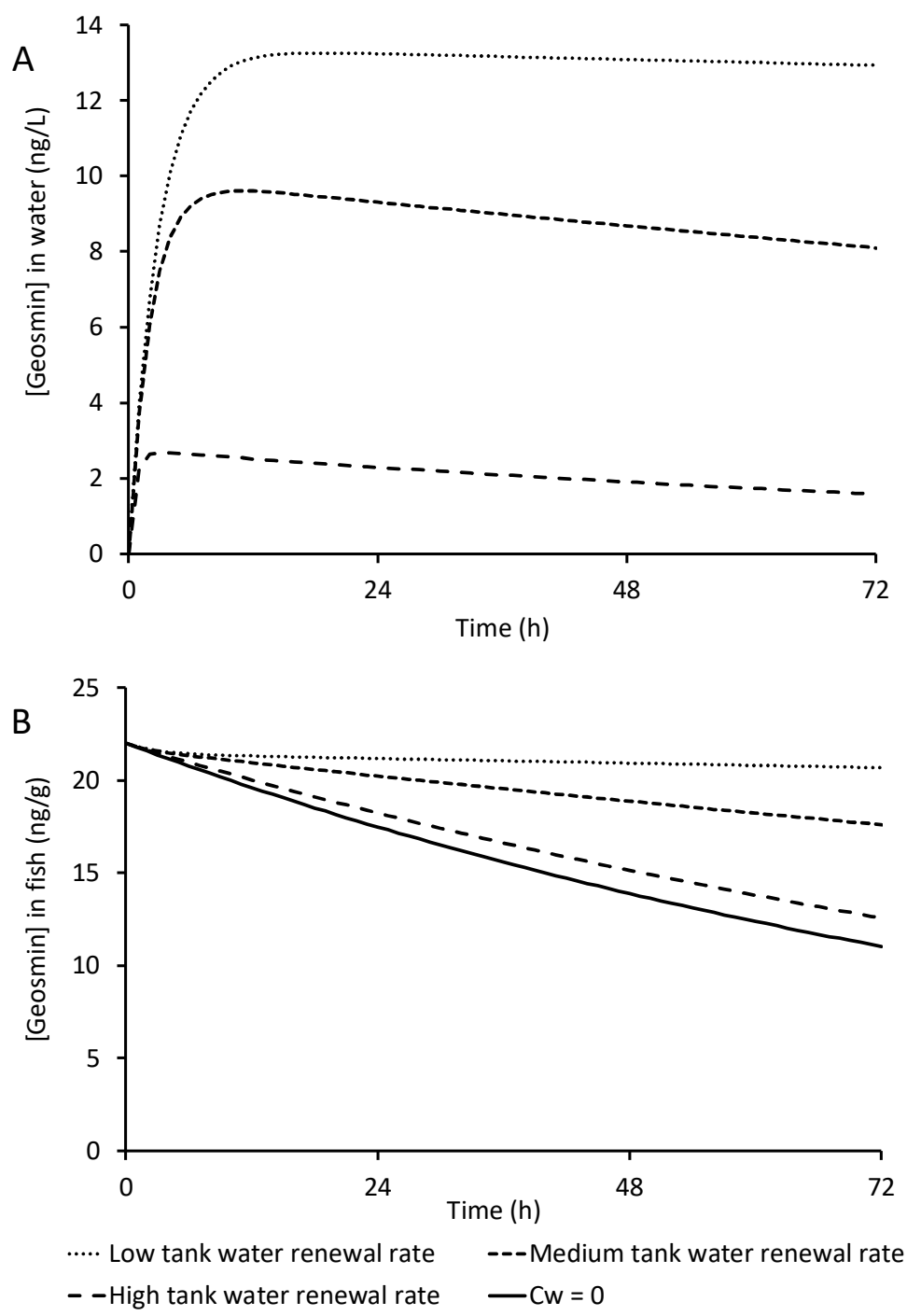

Fig 1. Model predictions of the effect of different tank water renewal rates on the accumulation of geosmin in the water $(A)$ and on the decline of the lipid-normalized geosmin concentration in fish (B) during geosmin depuration from European eel with an initial geosmin content of $22 \mathrm{ng} / \mathrm{g}$ lipid. In (B) the solid line represents the results for an infinite water volume with a constant geosmin concentration in the water of $0(\mathrm{CW}=0)$. 


\subsection{Results}

\section{Prediction of experimental results}

Our extended model predicted marked effects of tank water renewal rate on geosmin accumulation in depuration tanks (Fig. 1A) and on the geosmin excretion by the fish (Fig. 1B). Specific for the experimental conditions (Table 2), the model predicted that the geosmin concentration in the experimental fish after $72 \mathrm{~h}$ of depuration had declined by $6 \%$ at the low tank water renewal rate, by $20 \%$ at the medium tank water renewal rate and by $42 \%$ at the high tank water renewal rate. Geosmin depuration from the fish at the high tank water renewal rate approached the geosmin depuration in an infinite water volume; $\mathrm{C}_{W}=0$ (Fig. $1 \mathrm{~B}$ ). Clearly system losses of geosmin do not overrule tank water renewal rate treatments as $k_{Q} \gg$ ks.

\section{Depuration experiment}

Mean ( $n=2$ ) lipid normalized geosmin concentrations in the pooled fish ( $\mathrm{ng} / \mathrm{g}$ lipid) over time are presented for the tank water renewal rate treatments (Fig. 2). Significant differences were detected among the mean $(n=6)$ geosmin concentrations in the fish lipid per depuration time ( $\mathrm{T}$ ) (Two-way ANOVA, $\mathrm{P}_{\mathrm{T}}=0.0002$ ). No significant differences were detected among the mean $(n=6)$ geosmin concentrations in the fish lipid per tank water renewal rate treatment $\left(k_{Q}\right)$ (Two-way ANOVA $P_{k Q}=0.99$ ). In addition, no significant interaction between depuration time and water flow rate was detected (Two-way ANOVA $P_{k Q} \times T=0.54$ ); the significant change of the geosmin concentration in the fish lipid over time did not differ among the tank water renewal rate treatments. Interestingly, geosmin was not present and did not accumulate in the water of the depuration tanks except for a small peak in the depuration tanks with low tank water renewal rate at $\mathrm{t}=24 \mathrm{~h}(8 \pm 2.6 \mathrm{ng} / \mathrm{l})$.

\subsection{Discussion}

According to general consensus, the exchange of the off-flavour causing chemical geosmin between water and fish is passive and reversible as the chemical is supposed to freely diffuse in and out of the fish driven by the concentration gradient between water and fish. Based on this, it can be deduced that there are two basic principle options to enhance off- flavour depuration from fish. The first option is increasing the rate at which fish excrete the chemical to the water. This has e.g. been achieved by exercising the fish during off-flavour depuration (Schram et al., 2016). The second option is increasing the rate at which excreted chemicals are removed from the depuration tank. Constant removal of excreted geosmin from the water surrounding the fish will maintain a maximum concentration gradient between water and fish, resulting in maximal geosmin excretion. According to these assumptions, in an aquaculture system with limited water volume increasing the water flow 


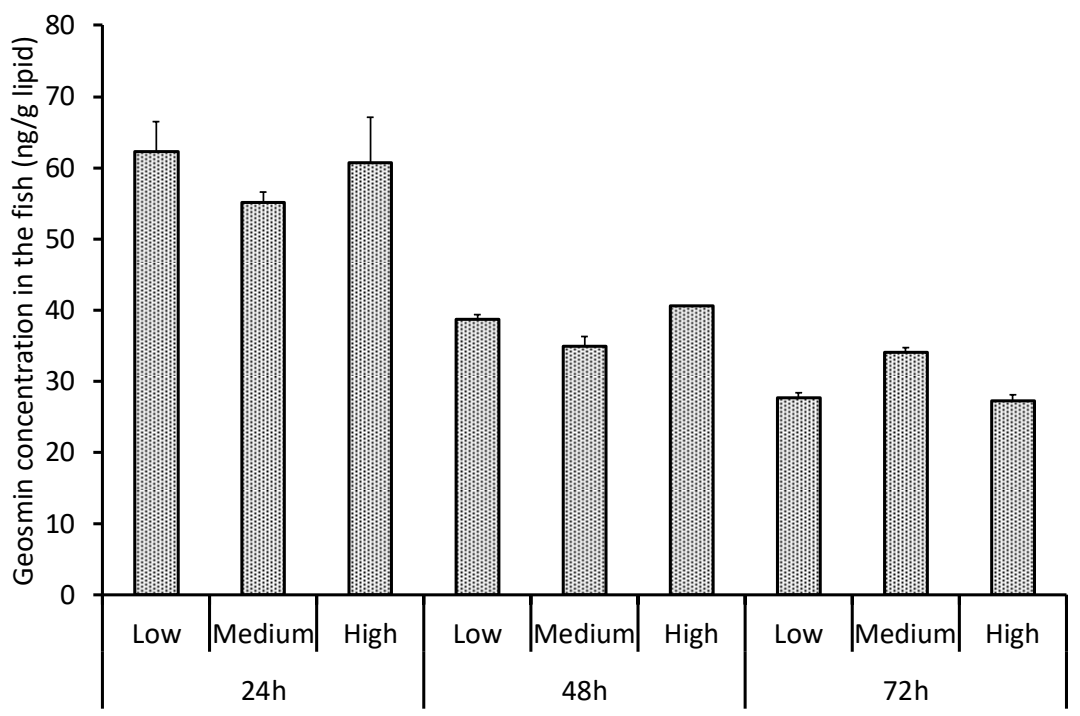

Fig. 2. Measured mean $(n=2)$ lipid normalized geosmin concentrations in pooled European eel ( 5 per group) depurated for 24,48 or $72 \mathrm{~h}$ at low, medium or high tank water renewal rates.

rate over a depuration tank and subsequently the rate at which the water in the depuration tank is renewed, will stimulate geosmin depuration by reducing the accumulation of excreted geosmin in the water. We extended the existing geosmin depuration model to a model that accounts for this effect of the tank water renewal rate of depuration tanks. This model indeed predicted a marked effect of tank water renewal rate on geosmin elimination from eel rate as well as on the accumulation of the chemical in the water phase. Surprisingly, we did not detect any effect of tank water renewal rate over the depuration tank on geosmin elimination from the fish nor on geosmin accumulation in the water in a depuration experiment that was set up to validate the model outcomes. We did, however, observe a clear elimination of geosmin from the fish while the chemical hardly appeared in the water phase. Only at the lowest tank water renewal rate and after the first day only, geosmin was found in the water phase $(8 \mathrm{ng} / \mathrm{l})$. The model predicted effects of tank water renewal rate on geosmin depuration from fish are based on re-uptake of excreted geosmin, which requires the accumulation of excreted geosmin in the water. Our observation that geosmin did not appear in the water phase is therefore consistent with the absence of treatment effects.

Although the geosmin did not appear in the water, it clearly was eliminated from the fish in a time-dependent manner. A possible explanation for this seemingly contradicting effect is excretion of geosmin metabolites rather than the parent compound due to biotransformation of geosmin by the eel. Although generally assumed to be absent (Howgate, 2004), no studies are available examining geosmin biotransformation in different fish species. For other 
lipophilic compounds, however, both phase I and phase II biotransformation pathways have directly or indirectly been established in fish and especially in eel (Kleinow et al., 1987; De Boer et al., 1994). Elaborate toxicological literature exists showing the relevance of biotransformation for elimination of lipophilic compounds from fish and other organisms (e.g. Sijm and Opperhuizen, 1989). Phase I biotransformation makes non-polar (lipophilic) compounds more polar by adding a hydroxyl $(-\mathrm{OH})$ group to the molecule. Phase II metabolism further acts on the $-\mathrm{OH}$ group making these compounds even more polar and easier to excrete. Geosmin already contains an $-\mathrm{OH}$ group, so phase II metabolism is quite likely to occur. The thus excreted conjugated geosmin metabolite will not be detected when measuring geosmin, so the geosmin would seemingly disappear. We also found earlier indirect indications for geosmin biotransformation in our geosmin bioconcentration studies in rainbow trout (Schram et al., 2018).

We extended the general fish aquatic bioaccumulation model (OECD 305, 2012) to account for accumulation of geosmin in the water phase in situations with limited water volumes. As fish take up geosmin from the water phase (as during the pre-experimental loading of the fish), subsequent re-absorption of excreted geosmin in depurating fish is to be expected and should be included in situations where the requirement for the OECD model that the chemical concentration in the water phase is stable and unaffected by either chemical uptake or excretion by the fish is violated. This may typically occur under conditions where the water volume to fish biomass ratio is relatively small, like in aquaculture and experimental settings. The extended model can then be used to predict the development over time of chemical concentrations in fish and water, the net effect of both uptake and excretion. Like the OECD model, the extended model assumes dynamic and reversible exchange of chemicals between water and fish and the absence of biotransformation. In case this latter assumption is violated, as the current experiment suggests, our extended model is fundamentally not suitable to describe geosmin elimination from eel. We consequently did not attempt to fit the experimental data to the extended model.

Alternatively, the decline of the geosmin concentration in the eel over time could be modelled as exponential decay using Eq. 3. This requires the absence of geosmin in the water (OECD, 2012; Howgate, 2004) and this condition was largely met in the current experiment. As a significant effect of the tank water renewal rate treatment was absent, we pooled the geosmin concentrations measured in the fish lipid per depuration time. Linear regression analysis then reveals a significant relation between $C_{F t}$ and depuration time $(P<0.0001, F i g .3)$ and yields an elimination rate constant $k_{2}$ of $0.0141 / \mathrm{h}$ from the fish, which corresponds to $0.341 / \mathrm{d}$. It seems that only in the initial phase of geosmin elimination excretion of the parent geosmin molecule is relevant, as only after the first $24 \mathrm{~h}$ some geosmin could be detected. After that biotransformation and excretion of geosmin metabolites seems to become more relevant. 
Geosmin elimination from eel that is based on two processes rather than excretion alone can also explain why the experimentally obtained geosmin elimination rate constant of $0.34 \mathrm{1} / \mathrm{d}$ is larger than the excretion rate constant that we derived for the experimental eels based on the excretion rate constants for rainbow trout (Table 2, Howgate, 2004).

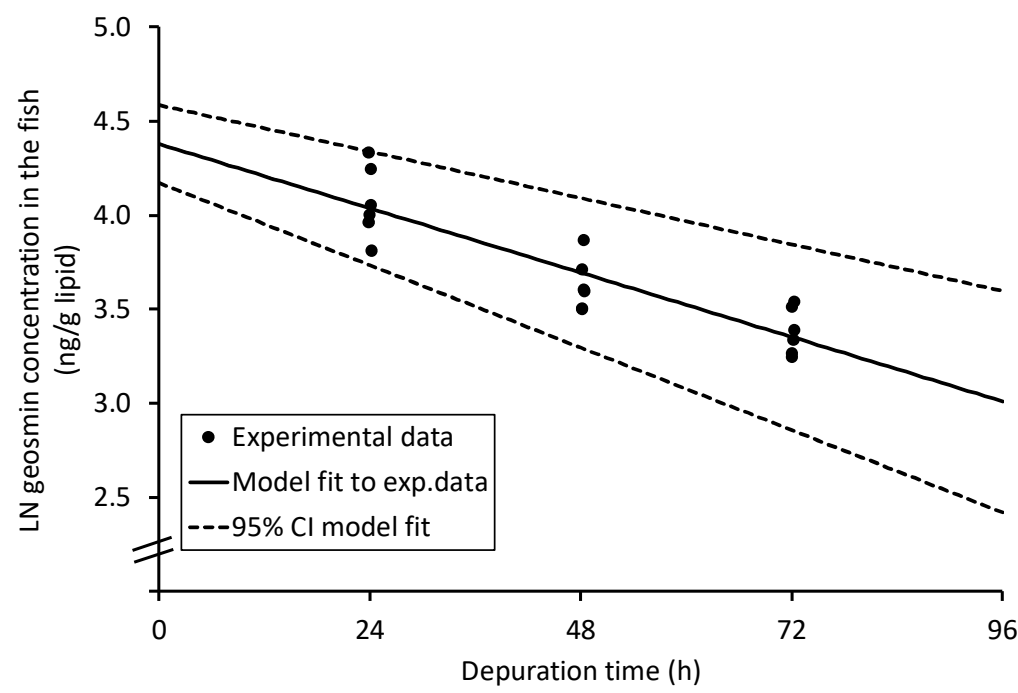

Fig. 3. $L N$ transformed geosmin concentration in the fish $\left(C_{F}, n g / g\right.$ lipid $)$ as function of depuration time $(T, h)$. ( $\left.L N C_{F t}=4.379-0.0142 . T, p<0.0001, r^{2}=0.78\right)$. Dotted lines represent the $95 \%$ confidence intervals of the model prediction.

We demonstrated that European eel loaded with geosmin eliminates the chemical from its body. The elimination mechanism however appears to differ from the general consensus that the lipophilic chemicals such as geosmin and MIB are excreted by passive diffusion depending on the concentration gradient between water and fish. Based on our observations that the tank water renewal rate over depuration tanks does not affect the elimination of geosmin from eel and that geosmin seems to 'disappear' from the system, we consider biotransformation of geosmin by eel the most probable explanation for this observation. In toxicological studies phase I and II biotransformation are the generally accepted mechanisms for elimination of lipophilic compounds from fish and other organisms. Further studies are required to fully establish the mechanism and magnitude of geosmin biotransformation in European eel.

When fish excrete geosmin and MIB as metabolites rather than the parent compounds, measures that aim to optimize the off-flavour depuration process by increasing the rate at which excreted chemicals are removed from the depuration tank will be largely ineffective, as shown in the current study. Instead, measures that enhance biotransformation capacity would 
appear better options to make off-flavour depuration more effective. Whether this notion is generic across fish species and off-flavour causing chemicals or is specific for geosmin elimination by European eel and how to stimulate the biotransformation demands further characterization of the responsible enzymes in eel and other species. 


\section{Interactive effects of temperature and water exchange of depuration tanks on geosmin excretion by Atlantic salmon (Salmo salar)}

Schram, E., Kwadijk, C.J.A.F., Blom, E., Verreth, J.A.J., Murk, A.J., Schrama, J.W., Interactive effects of temperature and water exchange of depuration tanks on geosmin excretion by Atlantic salmon (Salmo salar) 


\section{Abstract}

Fish farmers utilize the reversibility of the bioconcentration process to depurate geosmin and other off- flavour causing chemicals from their fish by placing them in clean water just before harvest. To better understand and improve this process, we investigated effects of temperature and water exchange of depuration tanks on geosmin elimination from Atlantic salmon (Salmo salar). Fish loaded with geosmin were depurated for $144 \mathrm{~h}$ during which they were subjected to combinations of water exchange (stagnant water or a water exchange rate of $\sim 1200 \mathrm{l} / \mathrm{kg}$ fish/d) and temperature $\left(\sim 11.5\right.$ or $\left.\sim 14.5^{\circ} \mathrm{C}\right)$ treatments. Model predictions indicated enhanced depuration by water exchange, elevated temperature and interactive effects of these two factors, plus geosmin accumulation in the depuration tank water. The latter was predicted but not observed in the experiment and furthermore the elevated temperature did not enhance geosmin elimination from Atlantic salmon. The water exchange significantly increased geosmin elimination from Atlantic salmon, indicating that removal of excreted geosmin from the direct environment of this fish is needed to obtain maximal geosmin elimination from the fish. 


\subsection{Introduction}

According to the general fish aquatic bioaccumulation model (Arnot \& Gobas, 2006; OECD, 2012) the uptake and excretion of moderately lipophilic chemicals by fish is a process of passive diffusion driven by differences in concentrations and affinities of chemicals for water and lipids. Exchange predominantly takes place over the water/blood barrier in the fish gill where the chemical diffuses in and out of the fish depending on the fugacity gradient. This bioconcentration process is dynamic and reversible. Placing contaminated fish in water free of the chemical results in a net outflow of the chemical to the water and an exponential decline of its concentration in the fish (reviewed in Arnot \& Gobas, 2006).

On the basis of its moderately lipophilic nature (logKow $=3.57$ ), bioconcentration of geosmin in fish is assumed to occur according to the general fish aquatic bioaccumulation model (Howgate, 2004). Geosmin is one of the chemicals responsible for earthy/musty off-flavours in fish, which is considered a quality defect by human consumers. In land-based aquaculture systems off-flavour chemicals are often produced by microbiota in biofilters (reviewed by Azaria \& Van Rijn, 2018). Following release to the water, these chemicals are quickly bioconcentrated in fish, rendering it off-flavoured (reviewed by Howgate, 2004). Fish farmers use the reversibility of the bioconcentration process to remove off-flavour causing chemicals from their fish. Before harvest, fish are placed in clean water until off-flavour chemical levels have declined below their human sensory detection thresholds. This depuration process however is not always effective and predictable. Also, it adds significantly to the production costs due to biomass losses (Schram et al., 2008; Burr et al., 2012) and additional operational and investments costs associated to depuration systems. Further optimization of the depuration process is needed to prevent market entrance of off-flavoured fish.

According to the general fish aquatic bioaccumulation model, the geosmin concentration in the fish declines exponentially when the fish is depurated in geosmin free water. The decline of the concentration in the fish over time then only depends on the geosmin concentration in the fish at the start of the depuration process and the excretion rate constant (Howgate, 2004). For a given initial geosmin concentration in the fish the time required to depurate geosmin from fish can then be reduced by increasing the excretion rate by e.g. increasing the water temperature (Howgate, 2004) or by exercising the fish during off-flavour depuration (Schram et al., 2016).

In industrial off-flavour depuration systems with high fish densities, excreted geosmin likely accumulates in the water (Schram et al., 2009) where it is available for re-uptake in the fish. Geosmin accumulation in the depuration tank water also violates the assumption to exponential decay of zero geosmin in the water. Excretion then does not depend on the initial 
geosmin concentration in the fish and the excretion rate constant alone but also on the uptake rate constant, the fish density and the geosmin removal rate from the depuration tank. The time required to depurate geosmin from the fish can then be reduced not only by increasing the rate of excretion but also by increasing the removal rate from the direct environment of the fish by e.g. increasing the water exchange rate of the depuration tank. We hypothesize that these two basic mechanisms for reduction of the depuration time, i.e., increasing the excretion rate and increasing the removal of excreted geosmin, interact. The net effect of the increased geosmin excretion then depends on the removal of excreted geosmin from the direct environment of the fish. In other words, for a maximum reduction of depuration time by increased excretion, re-uptake of excreted geosmin must be prevented by removing it away from the fish.

The effect of increased water exchange rate of depuration tanks on geosmin excretion was previously studied for European eel (Schram et al., 2017) and Atlantic salmon (Davidson et al., 2020). Surprisingly the geosmin depuration from eel did not increase with water exchange, which was explained by possible biotransformation of geosmin by the eel. In the recent study by Davidson et al. (2020) with Atlantic salmon, water exchange rate of depuration tanks did enhance net geosmin excretion. They observed the lowest off-flavour levels in Atlantic salmon depurated at the highest water exchange rates. The above mentioned interaction between geosmin excretion by the fish and removal from the depuration tank by water exchange has however not yet been studied.

Therefore, this study aims to unveil main and interactive effects of increased geosmin excretion and geosmin removal on the net elimination of geosmin by fish. Elevated water temperature was used to enhance geosmin excretion rates (Howgate, 2004). Depuration tanks with and without water exchange were used to create different geosmin removal rates from the tanks. Experiments were conducted with Atlantic salmon (Salmo salar) and the results compared to those predicted by applying a previously published mathematical depuration model that accounts for effects re-uptake, fish density and water flow rate over the depuration tank (Schram et al., 2017). This model was used to predict effects of temperature, water exchange rate of depuration tanks and to explore the interaction effect.

\subsection{Materials and methods}

\section{Depuration model and prediction of experimental results}

The derivation of the equations for the geosmin concentrations in the water $\left(C_{W(t)}\right)$ and the fish $\left(C_{F(t)}\right)$ over time as a function of uptake, excretion, fish density and water flow rate over the depuration tank were described in detail in Schram et al. (2017). In brief: Howgate (2004) obtained a simplified model for geosmin bioconcentration in fish by excluding 
biotransformation, faecal egestion and growth dilution from the general fish bioconcentration model for moderately lipophilic chemicals (reviewed Arnot and Gobas (2006):

$\frac{d C_{F}}{d t}=k_{1} C_{W}-k_{2} C_{F}$

where $\mathrm{dC}_{\mathrm{F}} / \mathrm{dt}$ is the change of the chemical concentration in the fish $C_{F}(\mathrm{~g} / \mathrm{kg})$ over time, $C_{W}$ the constant chemical concentration in the water $(g / l), k_{1}$ the rate constant $(1 / d)$ for the uptake from the water and $k_{2}$ the rate constant $(1 / d)$ for excretion to the water.

Table 1. Model input

\begin{tabular}{|c|c|c|c|}
\hline Parameter & Symbol & $\begin{array}{l}\text { Value or } \\
\text { range }\end{array}$ & Unit \\
\hline Geosmin concentration inflowing water & $C_{W(0)}$ & 0 & (ng/kg) \\
\hline $\begin{array}{l}\text { Uptake rate constant geosmin at high } \\
\text { temperature }\end{array}$ & $k_{1}$ & 229 & $(1 / d)$ \\
\hline $\begin{array}{l}\text { Excretion rate constant geosmin at high } \\
\text { temperature }\end{array}$ & $k_{2}$ & 0.57 & $(1 / d)$ \\
\hline $\begin{array}{l}\text { Uptake rate constant geosmin at low } \\
\text { temperature }\end{array}$ & $k_{1}$ & 172 & $(1 / d)$ \\
\hline $\begin{array}{l}\text { Excretion rate constant geosmin at low } \\
\text { temperature }\end{array}$ & $k_{2}$ & 0.42 & $(1 / d)$ \\
\hline Initial geosmin concentration in the fish & $C_{F(0)}$ & 10000 & (ng/kg) \\
\hline Water flow rate - tanks with water exchange & Q & 1200 & (I/kg fish/d) \\
\hline Water flow rate - tanks with stagnant water & Q & 0 & (I/kg fish/d) \\
\hline Tank volume & V & 170 & (l) \\
\hline Individual fish weight & W & 200 & (g) \\
\hline Total fish biomass per tank & $\mathrm{BM}$ & 1.0 & (kg) \\
\hline
\end{tabular}

This model assumes a constant chemical concentration $\left(C_{w}\right)$ in the water. However, at high fish densities we predict accumulation of excreted geosmin in the water. The model was therefore extended by allowing $C_{W}$ to vary over time as a function of chemical uptake and excretion by the fish and chemical outflow via the tank effluent, which is described by:

$\frac{d C_{W}}{d t}=z k_{2} C_{F}-z k_{1} C_{W}-Q C_{W}$

Where the first term describes the increase in concentration as a result of elimination from fish, the second term is the change rate of the concentration in the water as a result of uptake by fish, and the third term is the loss rate from the inflow of clean water (at rate $Q$ ). The tank volume is assumed constant and hence there is also an implicit outflow of water with concentration $C_{W}$ The parameter $z$ is the ratio of fish to water volume ( $B M / V$, Table 1$)$, which is used to account for the different volumes of water and masses of fish present. Fish and 
water were assumed to have an identical density (one). Other assumptions to equation (2) are that the water inflow does not contain any chemical.

The system formed by equations (1) and (2) was solved mathematically using Mathematica 9.0 (Wolfram Research, Champaign, Illinois, USA) to yield equations for $C_{F}(t)$ and $C_{W}(t)$ (Schram et al., 2017). We used these equations for $C_{F}(t)$ and $C_{W}(t)$ to predict the results of the depuration experiment with Atlantic salmon. Therefore model input (Table 1) closely resembled the actual experimental conditions for Atlantic salmon (Table 2). As geosmin uptake $\left(k_{1}\right)$ and excretion $\left(k_{2}\right)$ rate constants are unknown for Atlantic salmon, we used the rate constants derived by Howgate (2004) for rainbow trout with a lipid content of $10 \%(w / w)$. We obtained rate constants specific for the fish weight and temperatures in the current experiment by interpolation of Howgate's (2004) rate constants for different body weights and temperatures. As the excretion rate constant depends on lipid volume (Gobas \& Mackay, 1987), the $k_{2}$ values were recalculated to the lipid content of $3.5 \%(w / w)$ of the Atlantic salmon in the current experiment. We assumed equal gill uptake efficiency for chemicals and the gill ventilation rate for rainbow trout and Atlantic salmon.

\section{Depuration experiment}

Ethics statement and origin of the experimental animals

The treatment of the fish was in accordance with Dutch law concerning animal welfare, as approved by the ethical committee for animal experimentation of Wageningen UR Livestock Research (protocol 2013146.a). Atlantic salmon fry obtained from Meridian salmon Ltd, UK was raised to smolts of ca. $200 \mathrm{~g}$ and transferred to seawater in the research facilities of Wageningen Marine Research, The Netherlands.

\section{Pre-experimental loading of fish with geosmin}

Before the start of the depuration experiment two batches of Atlantic salmon ( $n=80$ per batch) with mean (SD) individual weights of 199.1(42.0) and 202. (35.8)g and a mean (SD) lipid content of $3.5(0.6) \%(w / w)$ were exposed to waterborne geosmin for 5 days. To this end fish were stocked in a polyethylene tank filled with $830 \mathrm{I}$ seawater with a salinity of $33 \mathrm{~g} / \mathrm{l}$. On day 1 of the geosmin loading of the fish, tank water was spiked with geosmin $(1$ I of a $0.5 \mu \mathrm{g} / \mathrm{ml}$ geosmin stock solution in water, Sigma Aldrich). On day 2 to $4,80 \%$ of the tank water was replaced daily with new seawater and then spiked again with geosmin. Water temperature was kept at $14.0^{\circ} \mathrm{C}$. Tank water was aerated by an air stone to supply oxygen to the fish. Fish were not fed the day before the start and during the 5 days of geosmin exposure.

\section{Experimental design and procedures}

The experiment was set up as a $2 \times 2 \times 3$ factorial block design with water exchange (Q), water temperature $(\mathrm{T})$ and depuration time $(\mathrm{Ti})$ as factors and two sessions in time as blocks to 
obtain replication of the experimental treatments. Sessions were identical and during each session fish were depurated at two different water exchange rates $Q$ (water flow rates were $\sim 1200$ and $0 \mathrm{l} / \mathrm{kg}$ fish/d, Table 2) and two different water temperatures T ( 11.5 and 14.5 ${ }^{\circ} \mathrm{C}$, Table 2) for three different depuration times Ti (24, 72 and $\left.144 \mathrm{~h}\right)$, with one tank for each of the twelve different combinations of $Q, T$ and Ti. At the start of each session ( $t=0)$, fish ( $n$ $=80$ ) were randomly split into 16 groups of five fish and weighed per group. Four randomly assigned groups served to determine the initial geosmin content of the salmon. Each of the 12 remaining groups was randomly assigned to one of 12,180 I polyester tanks.

Water exchange was installed by pumping water to the fish tanks by peristaltic pumps (Watson Marlow 505, Rotterdam, The Netherlands). The water pumped to the fish tanks was extracted from one of two temperature controlled water reservoirs of $400 \mathrm{I}$. The temperature controlled water reservoirs were continuously supplied with new, geosmin free seawater. The effluent of the experimental tanks was discharged. No water was supplied to the tanks assigned to the stagnant water treatments for the entire duration the experiment. The tanks with stagnant water were placed au bain marie in a larger tank which was flown through with water originating from one of the two temperature controlled water reservoirs to install the temperature treatments.

Table 2. Experimental conditions. Mean (SD) values for water flow rate, water temperature and dissolved oxygen concentration.

\begin{tabular}{llllll}
$\begin{array}{l}\text { Session } \\
1\end{array}$ & $\begin{array}{l}\text { Water } \\
\text { exchange } \\
\text { treatment (Q) }\end{array}$ & $\begin{array}{l}\text { Temperature } \\
\text { treatment }(\mathbf{T})\end{array}$ & $\begin{array}{l}\text { Water flow } \\
\text { rate } \\
(\mathbf{L} / \mathbf{k g} \text { fish/d) }\end{array}$ & $\begin{array}{l}\text { Temperature } \\
\left({ }^{\circ} \mathbf{C}\right)\end{array}$ & $\begin{array}{l}{\left[\mathbf{O}_{2}\right]} \\
(\mathbf{m g} / \mathrm{L})\end{array}$ \\
\hline & Water exchange & High & $1203(52)$ & $14.6(0.2)$ & $10.3(3.0)$ \\
& Water exchange & Low & $1267(162)$ & $11.6(0.2)$ & $11.4(2.8)$ \\
& Stagnant & High & 0 & $14.5(0.1)$ & $10.8(4.2)$ \\
& Stagnant & Low & 0 & $11.4(0.4)$ & $14.5(4.6)$ \\
& Water exchange & High & $1150(149)$ & $14.7(0.1)$ & $8.3(0.9)$ \\
& Water exchange & Low & $1271(117)$ & $11.8(0.2)$ & $9.8(2.2)$ \\
& Stagnant & High & 0 & $14.6(0.1)$ & $11.7(4.0)$ \\
& Stagnant & Low & 0 & $11.6(0.2)$ & $12.9(5.4)$
\end{tabular}

Oxygen was supplied to each tank via a minimal flow of pure oxygen to prevent volatizing of excreted, waterborne geosmin. Each tank was covered by a $6 \mathrm{~mm}$ glass sheet. The glass cover sheets were equipped with a circular hatch (diameter $150 \mathrm{~mm}$ ) to allow introduction of fish and collection of water samples. The hatches were covered by glass sheets ( $200 \times 200 \mathrm{~mm}$ ) during the experiment, leaving a minimal opening for passage of aeration tubing. Water flow rate, temperature and dissolved oxygen concentration (Hach Lange Multimeter) were monitored in each individual tank up to the moment the fish were sampled and the tank 
removed from the experiment. Water quality was measured at $\mathrm{Ti}=0,24,48,72,96,120$ and $144 \mathrm{~h}$. Oxygen supply, temperature and water flow rate were adjusted when necessary.

A preliminary stability study in seawater at $14.0^{\circ} \mathrm{C}$ assessed geosmin loss from the tanks via other routes than the outflowing water. The stability study was limited to the higher temperature used in the experiment as chemical losses due to volatilization would be the highest at the highest temperature. Three tanks identical to those used in the experiment but with stagnant water and without fish were spiked with $300 \mathrm{ng} / \mathrm{l}$ geosmin. Monitoring geosmin concentrations over time established that $95 \%$ to $100 \%$ of the initial geosmin concentration remained in the exposure tanks after $144 \mathrm{~h}$ in seawater at $14{ }^{\circ} \mathrm{C}$.

\section{Sampling}

Four samples of five fish were collected at the start of each the two sessions. During each session fish were sampled at $\mathrm{Ti}=24,72$ and $144 \mathrm{~h}$, one tank with five fish for each QxT treatment per session. For sampling, fish were rapidly netted and anaesthetised in $0.1 \%(\mathrm{v} / \mathrm{v})$ 2-phenoxyethanol (Sigma, St. Louis, USA). Fish were then filleted. Fillets were de-skinned, pooled per tank $(n=5)$, homogenized and stored at $-20^{\circ} \mathrm{C}$ until analysis. Individual fish weight was measured at stocking and upon fish sampling (Mettler PM40). Water samples of $250 \mathrm{ml}$ were collected from each tank just before fish stocking and upon fish sampling at the various sampling times. Water samples were stored in entirely filled glass bottles, closed with lids with a Teflon inlay and stored at $4{ }^{\circ} \mathrm{C}$ until further analysis.

\section{Geosmin and lipid analysis}

Fish fillet samples were thawed overnight at $4{ }^{\circ} \mathrm{C}$. From each fish fillet a subsample of approximately $1 \mathrm{~g}$ was taken and $100 \mu \mathrm{l}$ of internal standard solution (D5-geosmine in water, $1 \mu \mathrm{g} / \mathrm{ml}$, Sigma Aldrich) was added. Samples were extracted by accelerated solvent extraction (ASE, Dionex, Amsterdam, the Netherlands) at $40{ }^{\circ} \mathrm{C}$ using a 15:85 (v/v) penthanedichlorinemethane mixture. After extraction, $1 \mathrm{ml}$ of hexane was added to the extract. Extracts were concentrated to $1 \mathrm{ml}$ by gently evaporating the penthane-dichlorinemethane mixture (Rotavap, Heidolph) and stored in $2 \mathrm{ml}$ amber coloured glass vials at $-20{ }^{\circ} \mathrm{C}$ until geosmin measurement.

To each water sample $(250 \mathrm{ml}) 100 \mu \mathrm{l}$ of internal standard solution (D5-geosmine in water, 1 $\mu \mathrm{g} / \mathrm{ml}$ ) was added. Water samples were led over extraction cartridges (Sep-Pak ${ }^{\circledR} \operatorname{Vac} 6 \mathrm{cc}(1 \mathrm{~g})$ Certified tC18) that were subsequently eluted with $5 \mathrm{ml}$ diethylether. Water was removed from the collected diethylether by addition of sodium sulphate. Diethylether samples were concentrated to about $1 \mathrm{ml}$ under a gently nitrogen gas flow and stored in an amber coloured glass vial at $-20^{\circ} \mathrm{C}$ until geosmin measurement. 
For geosmin measurement $1 \mu$ l of sample was injected on a Shimadzu GCMS2010 (GC) coupled to a GCMS-QP2010 Ultra (MS) detector (Shimadzu, 's Hertogenbosch, the Netherlands). Analysis was performed in GCXGC mode using a Zoex ZX2 modulator (Shimadzu, 's Hertogenbosch, the Netherlands) with a modulation of $6 \mathrm{~s} .1^{\text {st }}$ dimension column was a $30 \mathrm{~m}$ $x 0.25 \mathrm{~mm}$ i.d. HT8 with a film thickness of $0.25 \mu \mathrm{m}$. The second dimension was a $2.3 \mathrm{~m} \times 0.25$ $\mathrm{mm}$ i.d. BPX-50 column with a film thickness of $0.15 \mu \mathrm{m}$. Pressure was set at $124.7 \mathrm{kPa}$. Injection port, interface and source temperatures were set at 225,290 and $200{ }^{\circ} \mathrm{C}$ respectively. The oven temperature was programmed as follows: $60^{\circ} \mathrm{C}$ holding for 2 minutes, then at $15.71^{\circ} \mathrm{C} / \mathrm{min}$ to $170^{\circ} \mathrm{C}$, then at $5^{\circ} \mathrm{C} / \mathrm{min}$ to $200^{\circ} \mathrm{C}$. Detection was carried out using electron impact (EI) mode in single ion monitoring (SIM) mode. Quantification was performed using GCMSSolutions software (Shimadzu, 's Hertogenbosch, the Netherlands) with m/z 112.1 and 114.1 as quantification ion for Geosmin and D5-Geosmin respectively. Quantification was performed against a calibration curve fitted using 8 points between 1 and $500 \mathrm{ng} / \mathrm{g}$. We validated the method for geosmin extraction, concentration and measurement in low fat $6 \%$ w/w) fish samples according to NEN 7777 (anonymous, 2011) and established a limit of detection of $6.1 \mathrm{ng} / \mathrm{g}$, a recovery of 93.5 to $99.2 \%$ and an extended uncertainty of $27.8 \%$. Lipid content of fish samples was determined using the gravimetric method according to Bligh \& Dyer (1959) modified by De Boer (1988).

\section{Calculations and statistics}

Geosmin concentrations in fish fillets (ng/g) were normalized for lipid content (\%, w/w). The decline of the geosmin concentration in the fish over time was predicted by fitting a log linear straight line regression model with a common constant and eight separate straight lines and slopes for the four duplicated treatment combinations of $Q$ and $T$ to the measured geosmin concentrations in the fish:

$\ln (\mu)=B_{0}+B_{1 j}^{*}$ time

with different slopes $\beta_{1 j}, j=1,2,3,4$ for the four different $Q \times T$ treatments. Here $\mu$ denotes the mean geosmin concentration as predicted by the model. Possible lack-of-fit of the straight lines model was assessed from residual plots and by adding quadratic and cubic time effects to the straight lines model. Quadratic nor cubic terms were needed in the model as they were not significant (F-tests, $P>0.10$ ). The same constant could be used for the two sessions (F-tests, $\mathrm{P}>0.10$ ). The measured geosmin concentrations $(\mathrm{Y})$ were considered as pseudo Poisson data with variance proportional to Poisson variance, i.e.,

$\operatorname{variance}(Y)=\varphi \mu$

Here $\varphi$ denotes the dispersion parameter. Estimates for the model parameters and F-tests for the terms in the model were obtained using the general linear model procedure in GenStat. An estimate for $\varphi$ was calculated from Pearson's chi-square. 
Pairwise differences of slopes between the four $Q \times T$ treatments were tested by t-tests. Main and interactive effects of $Q$ and $T$ were assessed by accumulated analysis of deviance by fitting the measured geosmin concentrations in the fish to:

$\ln (\mu)=B_{0}+\left(b_{1}+b_{1 Q} * X_{Q}+b_{1 T} X_{T}+b_{1 Q T} * X_{Q} X_{T}\right) *$ time

Here $\mathrm{X}_{\mathrm{Q}}, \mathrm{X}_{\mathrm{T}}$ are dummy variables with the values -1 for the low levels and +1 for the high levels of $Q$ and $T$. The importance of main effects and interaction were assessed by F-tests using the general linear model procedure in GenStat.

\subsection{Results}

\section{Prediction of experimental results}

Model predictions revealed a marked effect of water exchange on geosmin accumulation in the water of depuration tanks (Fig. 1A) and geosmin depuration from the fish (Fig. 1B). In stagnant water predicted geosmin levels in water and fish reach an equilibrium after approximately $48 \mathrm{~h}$ (Fig. $1 \mathrm{~A}$ and $1 \mathrm{~B}$ ). When water is exchanged, the geosmin level in water initially increases, peaks (in this specific case after approximately $8 \mathrm{~h}$ of depuration) at a much lower level than in stagnant water and then declines over time (Fig. 1A). The predicted effect of water temperature on geosmin accumulation in depuration tanks and geosmin depuration from fish is less pronounced than the predicted effect of water exchange. The model predictions reveal an interaction between the effects of water temperature and water exchange on geosmin depuration from fish: in stagnant water there is hardly an effect of increased water temperature, while when water is exchanged, the higher temperature is predicted to result in a faster decline of the geosmin level of the fish (Fig. 1B).

Table 3. Estimated slopes for the decline of the geosmin concentration in Atlantic salmon.

$\begin{array}{llll}\text { Treatment } & \text { Slope B } & \text { SE(b) } & \text { P-value slope ß } \\ \text { Water exchange - High T } & -0.0189 & 0.0041 & <0.001 \\ \text { Water exchange - Low T } & -0.0257 & 0.0056 & <0.001 \\ \text { Stagnant - High T } & -0.0158 & 0.0036 & <0.001 \\ \text { Stagnant - Low T } & -0.0092 & 0.0025 & <0.001\end{array}$

\section{Depuration experiment}

Averaged over all treatments, a strong reduction of the geosmin concentration in fillets of Atlantic salmon over time $\left(P_{\text {Time }}=<0.001\right)$ was observed. In addition to this main effect of depuration time, each of the four QxT treatment combinations also showed a significant reduction of the geosmin concentration over time (Fig. 2, Table 3). The main effect of exchanging the water of a depuration tank (Q) affected the decline of the geosmin 
concentration in salmon with time $\left(\mathrm{P}_{\mathrm{TimeQ}}=0.009\right)$, while the main effect of temperature had no impact on the time-related decline $\left(\mathrm{P}_{\mathrm{TimeT}}=0.39\right)$. There was a tendency for an interactive effect of water exchange and temperature on the decline of the geosmin concentration with time $\left(P_{\text {TimeQxT }}=0.09\right)$. In the water exchange treatments no geosmin was detected in the water, both at high and low temperature, except for a very small amount at $\mathrm{Ti}=24 \mathrm{~h}$ in one
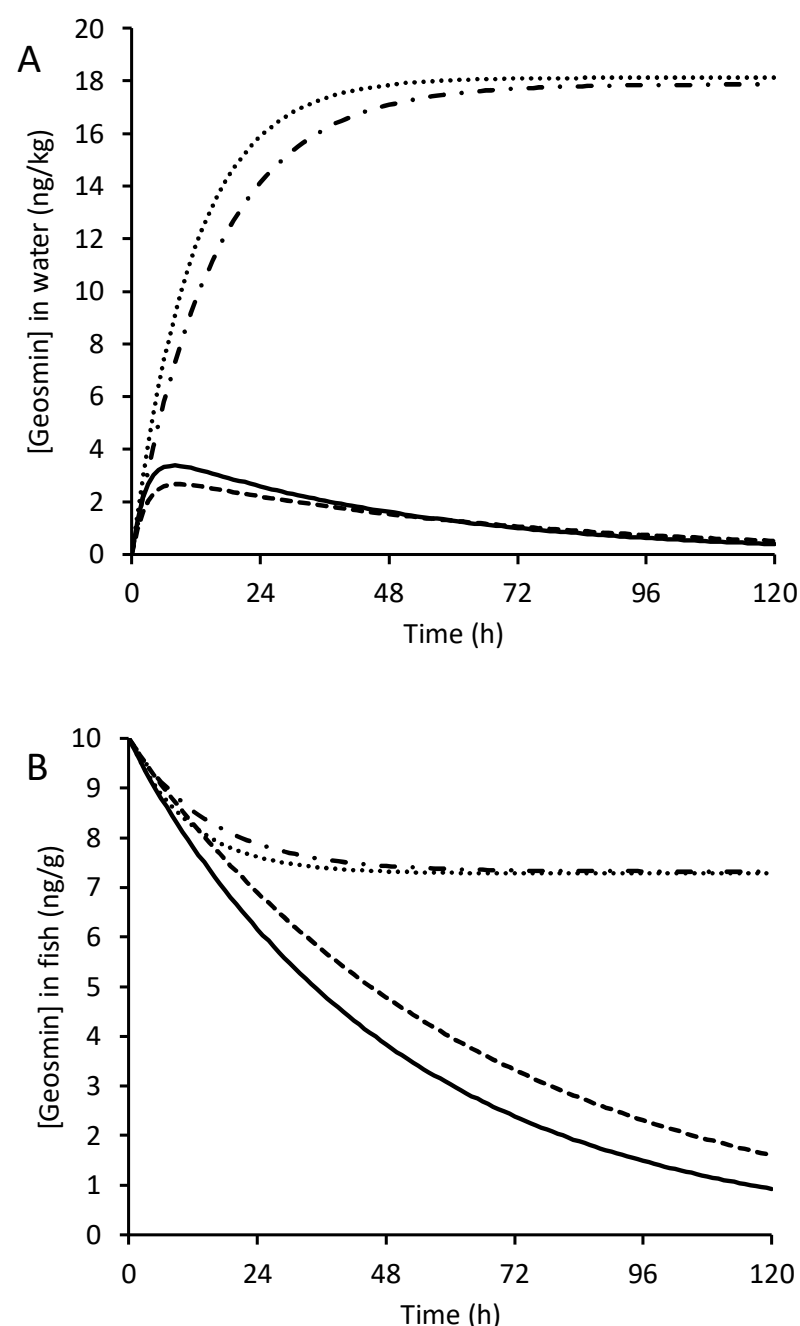

- - Stagnant water - Low T …. Stagnant water - High T

---Water exchange - Low T -Water exchange - High T

Fig 1. Model predictions of the effect of water exchange $(Q)$ and temperature treatments (T) on the accumulation of geosmin in the water (A) and on the decline of the geosmin concentration in fish (B) during geosmin depuration from Atlantic salmon with an initial geosmin content of $10 \mathrm{ng} / \mathrm{g}$. 


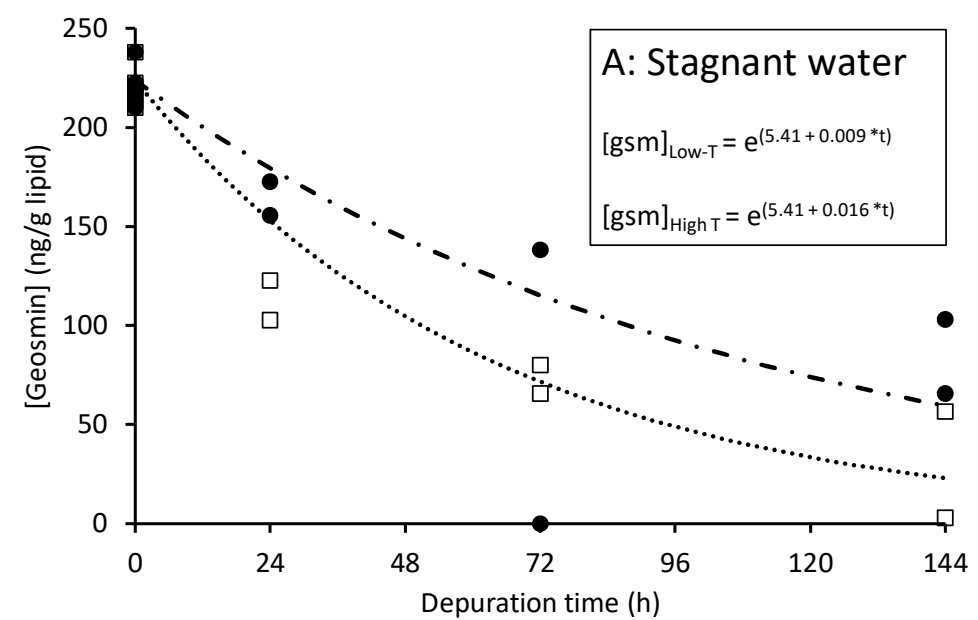

$\square$ Data Stagnant - High T ….Stagnant - High T

- Data Stagnant - Low T ․ - Stagnant - Low T

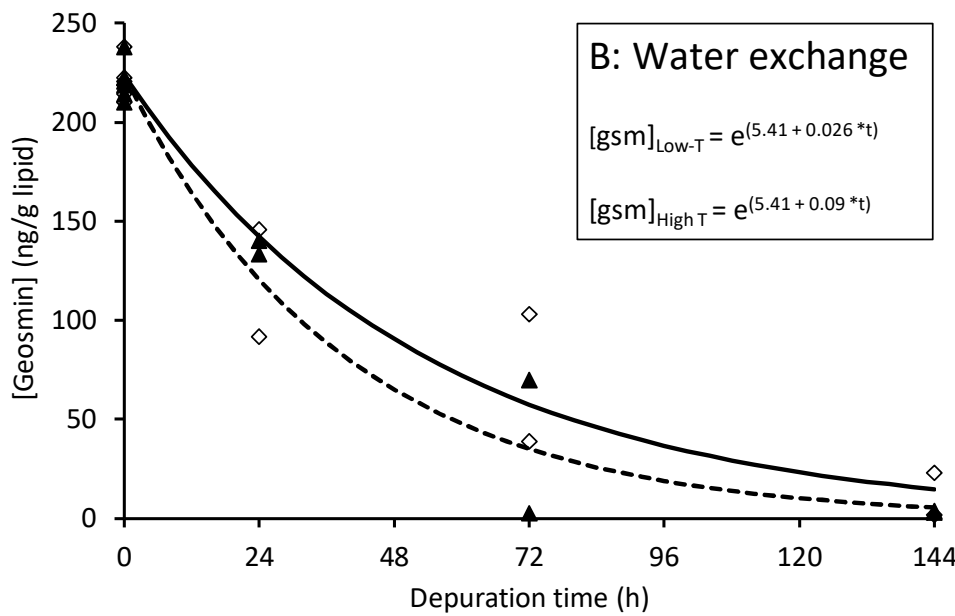

$\diamond$ Data Water exchange - High T -Water exchange - High T

$\Delta$ Data Water exchange - Low T - --Whater exchange - Low T

Fig. 2. Observed decline of the geosmin concentration in fillets of Atlantic salmon over time in depuration tanks with stagnant water $(A)$ and water exchange $(B)$ at low $\left(11.6^{\circ} \mathrm{C}\right)$ and high $\left(14.6^{\circ} \mathrm{C}\right)$ water temperature.

replicate of the water exchange - high temperature treatment. In the stagnant water treatments geosmin was detected in the water of four depuration tanks, two times at $\mathrm{Ti}=24$ and two times at $72 \mathrm{~h}$. Geosmin concentrations ranged from 21 to $3.6 \mathrm{ng} / \mathrm{l}$. Geosmin did not accumulate in the tanks with stagnant water: at the last sampling point at $T i=144 \mathrm{~h}$, no geosmin was detected. 


\subsection{Discussion}

We studied two basic mechanisms which enhance the depuration rate of geosmin from fish: the effect of increased temperature on the excretion rate from the fish body to the water and the effect of water exchange removing geosmin from the direct environment of the fish. A model approach was used to predict the effects of these two mechanisms on the development of geosmin in water and fish over time. A depuration experiment with Atlantic salmon aimed to validate the predicted effects.

The model indeed predicted a strong positive effect of water exchange on the net excretion of geosmin by the fish, a slighter positive effect of increased temperature, and revealed an interaction effect. To illustrate these effects, we calculated the depuration times required to reach an arbitrary target concentration in the fish of $1 \mathrm{ng} / \mathrm{g}$ for each of the four modelled combinations of water exchange rate and temperature. In stagnant water this target concentration is not reached as the geosmin concentration in the fish reaches an equilibrium just below $8 \mathrm{ng} / \mathrm{g}$ (Fig 1B), irrespective of the temperature. With water exchange the required depuration time is $151 \mathrm{~h}$ at the low temperature and $117 \mathrm{~h}$ at the high temperature. These theoretical depuration times are specific for the model input (Table 1). However, they do illustrate the generic observation that increasing the temperature, and thereby the chemical excretion rate, only has a relevant effect on depuration time in case the excreted chemical is removed from the fish's direct environment.

In accordance with model predictions and previous research by Davidson et al. (2020), the depuration experiment showed a significant main effect of water exchange of the depuration tank on geosmin elimination by salmon. This may be explained by prevention of re-uptake of excreted geosmin by salmon as a result of its removal from the depuration tank by the outflowing water. In other words, in agreement with the consensus that lipophilic compounds freely move in and out of fish, this experiment indirectly shows that re-uptake of excreted geosmin indeed may occur. Except for a minute amount at $\mathrm{t}=24 \mathrm{~h}$ in one replicate, no geosmin was detected in any of the depuration tanks with water exchange, which is consistent with the notion that water exchange removes excreted geosmin from the depuration tank. The difference between stagnant water and water exchange treatments was not as pronounced as predicted by the model (Fig. 1 vs. Fig. 2). In stagnant water, the geosmin concentrations in water and salmon are predicted to quickly stabilize after an initial decrease in the fish and increase in the water. Neither were observed in the experiment. Geosmin was detected at $t=$ $24 \mathrm{~h}$ and $\mathrm{t}=72 \mathrm{~h}$ in some of the tanks, but in all cases no geosmin was present in the water at $t=144 \mathrm{~h}$, the end of the depuration experiment. Geosmin initially appeared in the water but the predicted geosmin accumulation in the water over time did certainly not occur. The geosmin concentrations in the Atlantic salmon in the stagnant tanks continuously declined 
during the depuration experiment, suggesting that geosmin removal by water exchange was not essential for geosmin elimination from the fish. Apparently geosmin sinks are present in the stagnant depuration tanks. System losses from the water phase, e.g. evaporation and adsorption to the tank walls or to any of the auxiliary pieces of equipment in the depuration tanks are unlikely geosmin sinks because the preliminary geosmin stability test without fish showed no significant reduction of geosmin from the water phase after $144 \mathrm{~h}$. Whether this also excludes microbial degradation of geosmin (Azaria and Van Rijn, 2018) and binding to particles (Durrer et al., 1999) is not clear. Both geosmin degrading microbiota and particles may have been introduced in the experimental tanks with the fish, but this is unknown. Another possible geosmin sink is biotransformation in the fish, either in the fish liver or in the intestinal microbiome. Although geosmin biotransformation is generally assumed to be absent in fish, the required biotransformation pathways for lipophilic compounds have been established in fish (Kleinow et al., 1987). Our previous work indeed indicated a possible role of biotransformation in geosmin elimination from European eel (Schram et al., 2017) and rainbow trout (Schram et al,. 2018). Clearly, continuous exchange of the water in depuration tanks enhances geosmin elimination from Atlantic salmon. At the same time, without this water exchange elimination also takes place; water exchange seems not essential for continuous elimination. Whether this is because geosmin is removed from the water in other ways or that the fish metabolizes geosmin is not clear. When a fish would excrete a geosmin metabolite instead of the parent compound, this would not be detected with the current chemical analysis. With more understanding about mechanisms behind the observed disappearance of geosmin, this phenomenon could perhaps be manipulated to enhance depuration without increasing water exchange.

No significant main effect of temperature on the decline of the geosmin concentration in fillets of salmon over time was observed. However, there is some evidence for interaction between water exchange and temperature treatments. Judging from Fig. 2, the effect of temperature seems more pronounced within the stagnant tanks than within the tanks with water exchange. It cannot be excluded that a higher temperature may enhance microbial degradation of geosmin, either in the tank or in the fish. The effect of temperature on geosmin excretion rate has been postulated to act through the increase in gill ventilation rate to compensate for the decrease in oxygen solubility in water and increase in physiological oxygen demand concurring with temperature increase (Howgate, 2004; Neely, 1979). In the stagnant depuration tanks the mean dissolved oxygen concentration was indeed higher at the low temperature (14.5 versus $10.8 \mathrm{mg} / \mathrm{l})$. In the depuration tanks with water exchange, the contrast in dissolved oxygen concentration between the low and the high temperature is much smaller (11.4 versus $10.3 \mathrm{mg} / \mathrm{l})$, probably caused by the water exchange. It then seems likely that in the tanks with water exchange, temperature had no effect on geosmin excretion because it caused no 
difference in oxygen levels and thus gill ventilation rates. Although we have no gill ventilation rate data to corroborate this, we attribute the absence of a main temperature effect on geosmin excretion to a lack of contrast in gill ventilation rates between the temperature treatments in the tanks with water exchange.

The predicted interaction effect between temperature and water exchange implies that the temperature effect on the net geosmin excretion depends on the water exchange rate. The model prediction shows a very small temperature effect in tanks with stagnant water and a larger temperature effect on geosmin elimination in depuration tanks with water exchange. The experiment however suggests the opposite, i.e., no temperature effect when water is exchanged and possibly an effect in stagnant water, although there was only some evidence for significance of this interaction $(p=0.09)$. This contrast in predicted and observed interaction may be explained by the experimental conditions. The predicted interaction effect requires that 1 . the temperature effect is present in all treatments and 2 . in the stagnant depuration tanks the net effect of temperature is reduced because geosmin is not removed. Since both criteria were not met in the experiment, it is not surprising that treatments did not interact as predicted. Based on this experiment we cannot draw a clear conclusion regarding our interaction hypothesis, which was confirmed by modelling. The main effect of water exchange indicates that removal of excreted geosmin from the direct environment of this fish is needed to obtain maximal geosmin elimination from the fish. It then remains plausible that an increased geosmin excretion rate needs to be accompanied by an increased removal of the excreted geosmin from the fish's direct environment to obtain an optimal effect on the net elimination and depuration time. We therefore can reject nor accept our interaction hypothesis. It is clear that more data are needed to falsify our hypothesis. Also in the depuration tanks without water exchange geosmin was ultimately removed from the direct environment of this fish. It is very important to unveil the mechanisms underlying this removal, which only occurred in the presence of fish and seems to be enhanced by a higher temperature. These mechanisms offer potential opportunities to enhance geosmin removal without the need for increased water exchange.

Besides removal via the outflowing water other geosmin sinks seem to have played a role in the current experiment. As they were not accounted for in the depuration model, we could not obtain estimates for the uptake and excretion rates constants $k_{1}$ and $k_{2}$ by fitting the experimental data to the depuration model. Since no geosmin could be detected in the water of the depuration tanks with water exchange, the estimated slopes for the exponential decay of the geosmin concentration in salmon represent the total elimination rate constant. This yields total elimination rate constants of 0.46 and $0.621 / d$ (estimates for the slopes $(1 / \mathrm{h})$, Table 2, multiplied by 24) for the high and low temperatures in the experiment. These slopes are not significantly different, i.e., there is no main effect of temperature. The excretion rate 
constants for rainbow trout of the same size and lipid content derived from Howgate (2004) as described above are $0.541 / \mathrm{d}$ and $0.471 / \mathrm{d}$ for the higher and lower temperature, so within the range of the rate constants obtained from the depuration experiment. Possibly the excretion rate constants presented by Howgate (2004) are reasonable estimates for Atlantic salmon.

In conclusion, exchanging the water of depuration tanks significantly affects geosmin elimination by Atlantic salmon but temperature effects on geosmin excretion were not detected. Based on this experiment we cannot draw a clear conclusion regarding our interaction hypothesis.

\section{Acknowledgements}

The authors thank Pieter Vereijken of Biometris, Wageningen University \& Research, The Netherlands for data analysis. This study was funded by the European Commission (contract: 604956 SpaceTaste) 


\section{Effect of feeding during off-flavour depuration on geosmin excretion by Nile tilapia (Oreochromis niloticus)}

Schram, E., Kwadijk, C.J.A., Hofman, A., Blanco, A., Murk, A.J., Verreth, J.A.J., Schrama, J.W., 2021. Effect of feeding during off-flavour depuration on geosmin excretion by Nile tilapia (Oreochromis niloticus). Aquaculture 531. 


\section{Abstract}

The effect of feeding during off-flavour depuration on the elimination of geosmin from muscle tissue (fillet) and ovaries as a model for caviar was assessed in Nile tilapia (Oreochromis niloticus) (mean (SD) weight of 185 (15.0) g). The experiment had a 2x4 factorial design with feeding level (starved or fed) and depuration time (24, 48, 72 and 96 h) as factors with duplicates for each of the 8 treatment combinations. Fish were normally loaded with geosmin prior to the experiment. During off-flavour depuration geosmin levels in fillet and ovary declined over time in both fed and starved tilapia. In fed tilapia geosmin declined faster from the ovaries compared to starved fish $(p=0.018)$. The same trend of a faster decline was observed for the muscle tissue (fillets) of fed tilapia, though only numerically $(p=0.11$ ). Because faster geosmin elimination paralleled with high blood lipids, we do not rule out that blood lipids are involved in geosmin transport via the circulatory system and that low blood lipid levels are limiting geosmin elimination in starved fish. No difference in geosmin elimination rate was detected between ovary and muscle tissue in Nile tilapia. Off-flavour depuration time is strongly reduced when farmers adopt a practice of feeding Nile tilapia during off-flavour depuration. 


\subsection{Introduction}

Geosmin and 2-methylisoborneol (MIB) are secondary metabolites produced by a wide range of microbiota common to land-based aquaculture systems. Upon their release to the water these chemicals are quickly bioconcentrated by fish due to their lipophilicity (geosmin logKow: 3.57 and MIB logKow: 3.31, Howgate, 2004). The presence of these chemicals in fish tissues causes an earthy or musty off-flavour, which is considered a quality defect by human consumers. Bioconcentration of geosmin and MIB is dynamic and reversible; the chemicals can freely diffuse in and out of the fish via the gills depending on the current fugacity gradient between water and fish (Howgate, 2004). Fish farmers utilize this mechanism to depurate offflavours from their fish crops by placing them in water free of geosmin and MIB just before harvest. Fish are depurated until excretion has resulted in a reduction of the geosmin and MIB concentrations in the fish to levels below their sensory detection limits. This process however is not always sufficiently effective to prevent market entrance of off-flavoured fish. The general objective of this study is therefore to improve our understanding of the off-flavour depuration process.

Off-flavour depuration generally lasts a few days up to a week, depending mainly on the initial geosmin or MIB levels in the fish and the rates of excretion. Excretion rates depend among other factors on fish size, lipid content and temperature (Howgate, 2004). During off-flavour depuration fish are generally not fed to allow fish to empty their intestinal tracts prior to slaughter and to reduce the water flow over the depuration system required to maintain good water quality.

Geosmin elimination from the fish's body by excretion to the water via the gills requires its transport from peripheral tissues to the gills via the circulatory system. Fasting fish during offflavour depuration may negatively affect both geosmin transport and excretion through effects on blood lipids and gill ventilation. In blood organic xenobiotic compounds partition between water (plasma) and plasma lipid fractions (Jandacek and Tso, 2001) and hydrophobic xenobiotic compounds with log octanol/water partition coefficients (logKow) larger than three are bound to lipoproteins (Spindler-Vomachka et al., 1984) and specific plasma transporter proteins (Schmieder and Henry, 1988). In rainbow trout, only a minor fraction of moderately lipophilic compounds is dissolved in the plasma (Schmieder and Henry, 1988). For geosmin this has not been studied, but given its lipophilic nature (logKow of 3.57) it is highly likely that the plasma lipid fraction, including lipoproteins is involved in geosmin transport via the circulatory system. Since starvation affects blood lipid content and composition (Sheridan, 1988; Figueiredo-Silva et al., 2013) an effect of starvation on geosmin transport and subsequent elimination seems likely. Feeding increases gill ventilation to compensate for an increased oxygen demand due to feed induced thermogenesis. Since gill ventilation rate is an 
important promotor for the rate at which geosmin is excreted via the gills (Howgate, 2004), feeding fish may also promote geosmin exchange over the gills. Given these potential effects of feeding on blood lipids and gill ventilation, we hypothesized that feeding of fish promotes the elimination of geosmin from fish to water during off-flavour depuration. Except for anecdotal accounts of more successful off-flavour depuration in fed fish, there are to the best of our knowledge no scientific records on the effect of starvation or feeding on geosmin elimination from fish. The first objective of the current study was therefore to establish the effects of feeding versus starvation on geosmin excretion by fish.

Normally off-flavour issues relate to the geosmin and MIB levels in fish fillets, but off-flavour may also occur in sturgeon caviar produced in farms. Off-flavours in high-end seafood products such as caviar are obviously not accepted by consumers. In case of caviar the ovary is the organ of main interest. Uptake and elimination of lipophilic chemicals in biota varies among tissues and organs due to differences in perfusion, lipid content and lipid composition (Streit, 1998). We thus hypothesized that off-flavour chemicals are eliminated from the lean muscle tissues (fillet) faster than from ovaries. The second objective of this study was therefore to establish the difference in geosmin elimination rate from fish fillets and ovaries.

As sturgeons with developed ovaries are too large and valuable for use in an experimental setting, we used female tilapia with ovaries as model species. Female tilapia already develop ovaries at small body sizes of 100-200 g. To assess the elimination rates of geosmin from fillet tissue and ovaries of fed and starved tilapia, off-flavoured female tilapia were sampled over time during depuration.

\subsection{Materials and methods}

\section{Ethics statement and origin of the experimental animals}

The treatment of the fish was in accordance with Dutch law concerning animal welfare, as approved by the ethical committee for animal experimentation of Wageningen UR Livestock Research (protocol 2013163b). Nile tilapia were progenies of the brood stocks kept at Wageningen University and Research, The Netherlands. Nile tilapia fry was transferred to the research facilities of the institute Wageningen Marine Research, Yerseke, the Netherlands at a mean weight of $5 \mathrm{~g}$.

\section{Pre-experimental loading of fish with geosmin}

Nile tilapia were raised from $5 \mathrm{~g}$ to approximately $180 \mathrm{~g}$ in a recirculating aquaculture system (RAS) prior to their use in the current experiment over a period of 120 days. In RAS microbial production of geosmin is common (Azaria and van Rijn, 2018). To create off-flavoured Nile tilapia for the current study, we raised the fish in a RAS of which we knew that it was 
contaminated with microbial geosmin. The fish consequently accumulated geosmin during the time spent in this RAS, rendering them off-flavoured at the start of the experiment. During the geosmin enrichment period, fish were fed at a level of $20 \mathrm{~g} / \mathrm{kg}^{0.8} / \mathrm{d}$. The day before their transfer to the experimental systems fish were not fed.

\section{Experimental design and procedures}

The experiment was set up as a $2 \times 4$ factorial design with two feeding levels (F) and four depuration times $(T)$ as factors. The feeding level treatments $(F)$ were starvation (no feeding) and feeding. Depuration times (T) were $24,48,72$ and $96 \mathrm{~h}$. The treatments were randomly assigned to 16 experimental units (tanks), with two tanks for each of the eight different combinations of $\mathrm{F} \times \mathrm{T}$ to obtain replication.

At the start of the experiment $(T=0)$ the fish $(n=120)$ were randomly split into 20 groups of five fish and weighed per group. Overall mean (SD) body weight was 184.8 (15.0) g. Four randomly assigned groups served to determine the initial geosmin content of fish. Each of the 16 other groups was randomly assigned to one of the 16,180 I polyester tanks. These 16 tanks were randomly assigned to one of the eight treatments.

Experimental tanks were refreshed with local tap water at a measured mean (SD) flow rate of 1263 (75) l/d. Water was pumped from a temperature controlled water reservoir to the fish tanks by peristaltic pumps (Watson Marlow 505, Rotterdam, The Netherlands). The water reservoir was continuously supplied with new local tap water. The effluent of the experimental tanks was discharged. The entire experimental facility was set up at $20^{\circ} \mathrm{C}$ in a temperature controlled room. Oxygen was supplied to each tank via a minimal flow of pure oxygen instead of air to prevent volatizing of excreted, waterborne geosmin (overall mean (SD) oxygen saturation was $86(15) \%)$. Each tank was covered by a $6 \mathrm{~mm}$ glass sheet to prevent fish from jumping out of the tanks. The glass cover sheets were equipped with a circular hatch (diameter $150 \mathrm{~mm}$ ) to allow for introduction of fish. The hatches were covered by glass sheets $(200 \times 200 \mathrm{~mm})$ during the experiment, leaving a minimal opening for passage of aeration tubing. Water quality parameters were monitored daily in each individual tank up to the moment fish were sampled and the tank removed from the experiment. Mean (SD) temperature was $20.2(0.12){ }^{\circ} \mathrm{C}$ and $\mathrm{pH}$ ranged between 7.5 and 7.7. The mean (SD) water oxygen saturation was $86.9(15.3) \%$ in tanks with starved fish and $81.3(6.7) \%$ in tanks with fed fish.

Fish were fed at a rate of 1.1\%/d. Feed (Skretting ME-2 Meerval start, $49 \%$ protein, $11 \%$ crude lipids) was given daily in two equally sized portions ( $5 \mathrm{~g} /$ portion) at 9:00 am and 5:00 pm. To confirm feed intake the presence or absence of uneaten feed pellets was recorded 30 minutes 
after each bidaily feeding event. Out of the total of 40 feeding events, left-over feed was observed in 33 cases, indicating that fish were slightly over-fed.

\section{Sampling}

During the experiment fish samples were collected at $t=0,24,48,72$ and $96 \mathrm{~h}$, with two tanks and five fish per tank for each treatment. Individual fish weight was measured at stocking (Mettler PM40). For sampling fish were rapidly netted and anaesthetised in $0.1 \%(\mathrm{v} / \mathrm{v}) 2$ phenoxyethanol (Sigma, St. Louis, USA). Blood samples were taken from each of the five fish per tank by puncture of the caudal vessel with a syringe fitted with a 25-gauge needle. Heparin was used as anti-coagulant. The five blood samples per tank were pooled and stored in $5 \mathrm{ml}$ cryo tubes (Greiner bio-one, Germany) at $-80{ }^{\circ} \mathrm{C}$ until analysis. After blood sampling fish were killed by a blow to the head. Ovaries were dissected, pooled per tank $(n=5)$ and stored at -80 ${ }^{\circ} \mathrm{C}$ in glass containers until analysis. Fish were then filleted. Fillets were de-skinned, pooled per tank $(n=5)$, homogenized and stored at $-20^{\circ} \mathrm{C}$ until analysis. All fish tissue samples were kept on ice during sample collection.

\section{Geosmin and lipid analysis}

Fish fillet and ovary samples were thawed overnight at $4{ }^{\circ} \mathrm{C}$. From each fish fillet sample a subsample of approximately $1 \mathrm{~g}$ was taken. To each (sub) sample $100 \mu \mathrm{l}$ of internal standard solution (D5-geosmine in water, $1 \mu \mathrm{g} / \mathrm{ml}$, Sigma Aldrich) was added. Samples were extracted by accelerated solvent extraction (ASE, Dionex, Amsterdam, the Netherlands) at $40^{\circ} \mathrm{C}$ using a 15:85 (v/v) penthane-dichlorinemethane mixture at $40{ }^{\circ} \mathrm{C}$. After extraction, $1 \mathrm{ml}$ of hexane was added to the extract. Extracts were concentrated to $1 \mathrm{ml}$ by gently evaporating the penthane-dichlorinemethane mixture (Rotavap, Heidolph) and stored in $2 \mathrm{ml}$ amber coloured glass vials at $-20^{\circ} \mathrm{C}$ until geosmin measurement.

To each water sample of $250 \mathrm{ml} 100 \mu \mathrm{l}$ of internal standard solution (D5-geosmine in water, 1 $\mu \mathrm{g} / \mathrm{ml}$ ) was added. Water samples were led over an extraction cartridge (Sep-Pak ${ }^{\circledR}$ Vac $6 \mathrm{cc}$ (1 g) Certified tC18) and then eluted with $5 \mathrm{ml}$ diethylether. Water was removed from the collected diethylether by addition of sodiumsulfate. Diethylether samples were concentrated to $1 \mathrm{ml}$ under a gentle nitrogen gas flow and stored in a amber coloured glass vial at $-20^{\circ} \mathrm{C}$ until geosmin measurement.

For geosmin concentration measurement $1 \mu \mathrm{l}$ of sample was injected on a Shimadzu GCMS2010 (GC) coupled to a GCMS-QP2010 Ultra (MS) detector (Shimadzu, 's Hertogenbosch, the Netherlands). Analysis was performed in GCxGC mode using a Zoex ZX2 modulator (Shimadzu, 's Hertogenbosch, the Netherlands) with a modulation of $6 \mathrm{~s} .1^{\text {st }}$ dimension column was a $30 \mathrm{~m} \times 0.25 \mathrm{~mm}$ i.d. HT8 with a film thickness of $0.25 \mu \mathrm{m}$. The second dimension was a $2.3 \mathrm{~m} \times 0.25 \mathrm{~mm}$ i.d. BPX-50 column with a film thickness of $0.15 \mu \mathrm{m}$. Pressure was set at 124.7 
$\mathrm{kPa}$. Injection port, interface and source temperatures were set at 225,290 and $200{ }^{\circ} \mathrm{C}$ respectively. The oven temperature was programmed as follows: $60^{\circ} \mathrm{C}$ holding for 2 minutes, then at $15.71{ }^{\circ} \mathrm{C} / \mathrm{min}$ to $170{ }^{\circ} \mathrm{C}$, then at $5{ }^{\circ} \mathrm{C} / \mathrm{min}$ to $200{ }^{\circ} \mathrm{C}$. Detection was carried out using electron impact (EI) mode in single ion monitoring (SIM) mode. Quantification was performed using GCMSSolutions software (Shimadzu, 's Hertogenbosch, the Netherlands) with m/z 112.1 and 114.1 as quantification ion for Geosmin and D5-Geosmin respectively. Quantification was performed against a calibration curve fitted using 8 points between 1 and $500 \mathrm{ng} / \mathrm{g}$. Geosmin concentration measurements were validated. Lipid content of fillet and ovary samples was determined using a modified version (De Boer, 1988) of the method from Bligh and Dyer (1959).

\section{Calculations and statistics}

In fish tissues geosmin is associated to lipids and variation in lipid content may therefore cause variation in geosmin levels. To remove this variation from our data, geosmin concentrations were normalized for lipid content, i.e., expressed as ( $\mathrm{ng} / \mathrm{g}$ lipid). This was done by dividing the measured geosmin concentrations by the lipid contents of the samples. Outlier analysis detected two outliers for the geosmin level in the fillet of fed fish, one at $T_{24}$ and one at $T_{48}$. The measured geosmin fillet concentrations were far above the mean geosmin concentration at $T_{0}$. The deviation from $T_{0}$ was more than three times the standard error of the geosmin concentration at $T_{0}$. These two data points were omitted in the data analysis. All statistical procedures were performed in SAS 9.4.

Under the assumption that geosmin does not accumulate in the water because of the continuous supply of geosmin-free water to the tanks, the decline of the geosmin concentration in the lipid fractions of the fillet and the ovary over time $C_{F(t)}(\mathrm{ng} / \mathrm{g}$ lipid) can be described as exponential decay (Howgate, 2004) (equation 1):

$\left.C_{F(t)}=C_{F(t=0)} e^{\left(-k_{2} t\right)}\right)$

where $C_{F(t=0)}$ is the initial chemical concentration in the fish and $k_{2}$ the rate constant $(1 / \mathrm{h})$ for the elimination to the water. This equation can be rewritten into a straight line linear regression model (equation 2):

$\operatorname{Ln}\left(C_{F(t)}\right)=\operatorname{Ln}\left(C_{F(t=0)}\right)-k_{2} \cdot t$

The decline of the geosmin concentration over time was predicted by fitting equation 2 to the measured geosmin concentrations by non-linear regression analysis. In total four models were fitted, one for each duplicated combination of feeding treatment (fed or starved) and tissue type (fillet or ovary). This yielded four estimates for slopes and two for intercepts (treatments shared their $T_{0}$ samples). The decline of the geosmin concentration over time was tested for treatment effects, i.e., differences in the estimated slopes, using a sum of square reduction 
test, for both the fillet and the ovary. The significance of the decline of the geosmin concentration over time was assessed for each combination of treatment and tissue by considering the $95 \%$ confidence intervals for the estimates of the slopes: the null-hypothesis of no change over time was rejected in case the $95 \%$ confidence intervals did not contain zero.

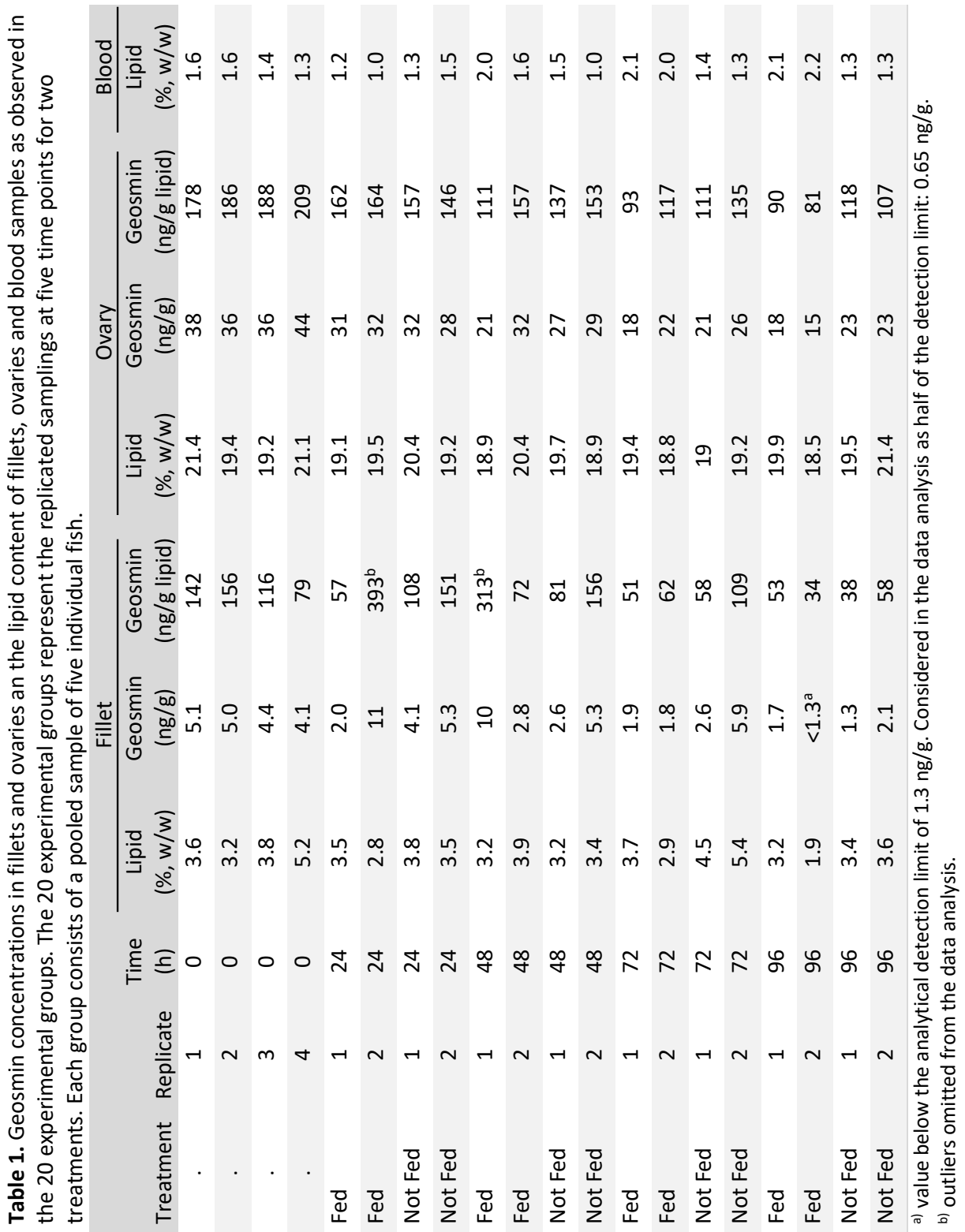

To judge the quality of the regression fit, pseudo $R^{2}$ values were calculated per tissue type combined for the treatments as (equation 3): 
Pseudo $R^{2}=1-\frac{\text { Sum of squares Residual }}{\text { Sum of squares Total }}$

Under the null-hypothesis of equally fast geosmin elimination from both tissues, the lipid normalized geosmin concentration ratio fillet:ovary does not change over time. This ratio was calculated for each combination of feeding treatment (F) and depuration time (T). The change over time in the geosmin fillet:overy ratio was assessed by linear regression analysis separately for each feeding treatment. Any differences in geosmin elimination between fillet and ovary would be detected by a slope that is significantly different from zero. Blood lipid content at $T_{24}, T_{48}, T_{72}$ and $T_{96}$ were analysed for the effect of feeding treatment (starved vs. feeding) and the interaction between treatment and time by two-way ANOVA. Tukey post hoc analysis was done to compare individual means.

\subsection{Results}

\section{Raw data}

An overview of the geosmin concentrations in the fillets and ovaries and the blood lipid content observed in the experiment is presented in Table 1.

\section{Treatment effects on geosmin elimination}

Both fed and starved Nile tilapia eliminated geosmin from their muscle tissues (fillet) and ovaries in a time dependent manner: all estimated slopes are negative and significantly different from zero (Table 2). The fed fish showed faster elimination of geosmin from their ovaries than the starved fish ( $p=0.018$, Fig. 1). No treatment effect on geosmin elimination from the fillet was detected ( $p=0.11$, Fig. 1 ), but numerically also in the fillet feeding increased the elimination rate.

Table 2. Results of the linear regression analysis of the development over time of the natural logarithm transformed geosmin concentrations for the fillets and ovaries of fed and starved Nile tilapia.

\begin{tabular}{llllll} 
Tissue & Model parameter & Estimate & s.e. & 95\% CI LL & 95\% Cl UL \\
Fillet & Intercept & 4.8155 & 0.0985 & 4.6093 & 5.0217 \\
& Slope $k_{2}$-Starved & -0.0074 & 0.00217 & -0.0119 & -0.0028 \\
& Slope $k_{2}$ - Fed & -0.0114 & 0.00217 & -0.0159 & -0.0069 \\
\multirow{2}{*}{ Ovary } & Intercept & 5.2402 & 0.0283 & 5.1814 & 5.299 \\
& Slope $k_{2}$ - Starved & -0.0057 & 0.00063 & -0.007 & -0.0044 \\
& Slope k2 - Fed & -0.0081 & 0.00063 & -0.0094 & -0.0067
\end{tabular}



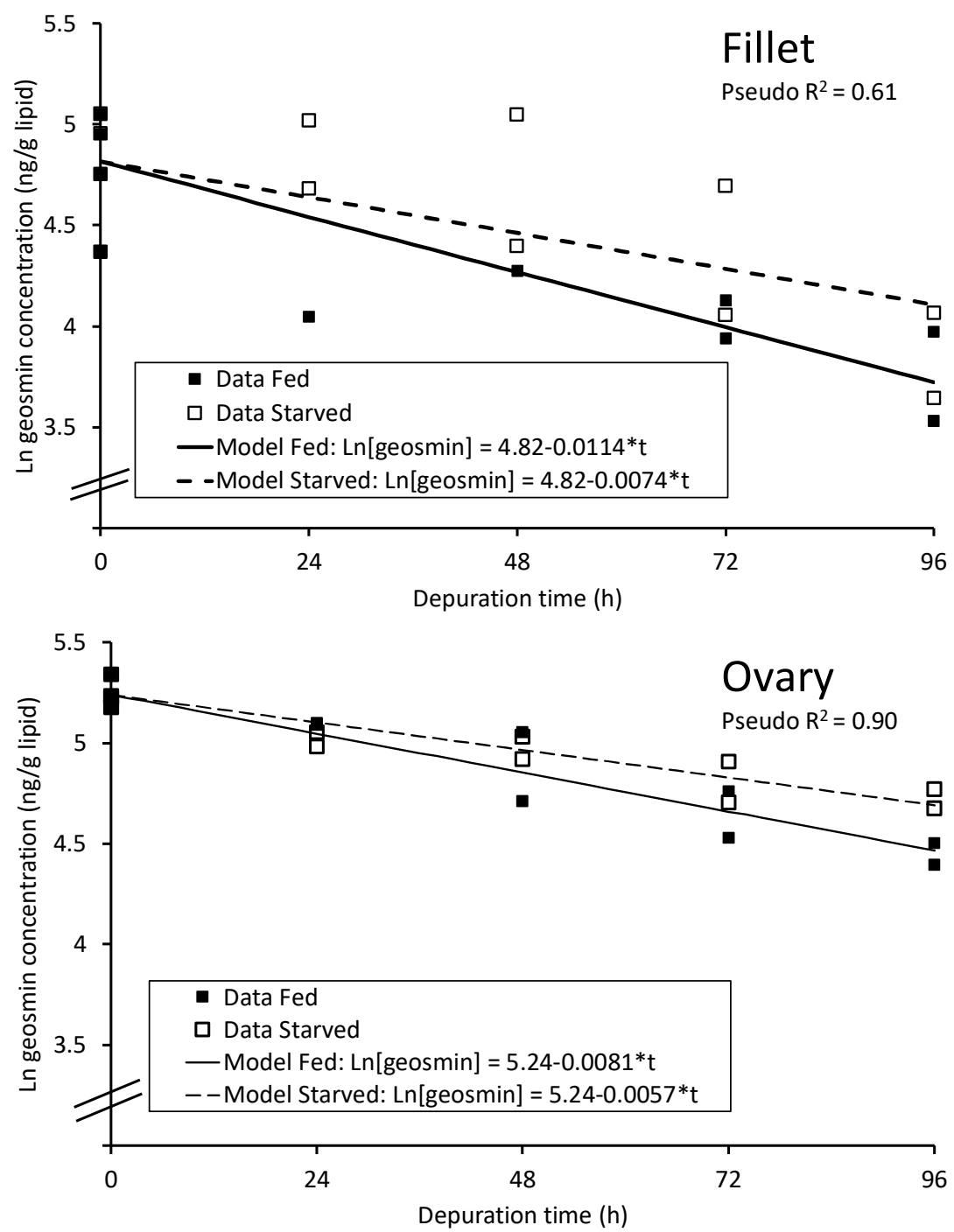

Fig. 1. Decline of natural logarithm transformed geosmin concentrations over time from the fillets (top) and ovaries (bottom) of Nile tilapia that were fed or starved during off-flavour depuration.

\section{Tissue effects on geosmin elimination}

No tissue effects on geosmin elimination were detected as the lipid normalized geosmin concentration ratio fillet:ovary did not change over time for both the fed $(p=0.71)$ and the starved Nile tilapia ( $p=0.33$ ) (Fig. 2). 


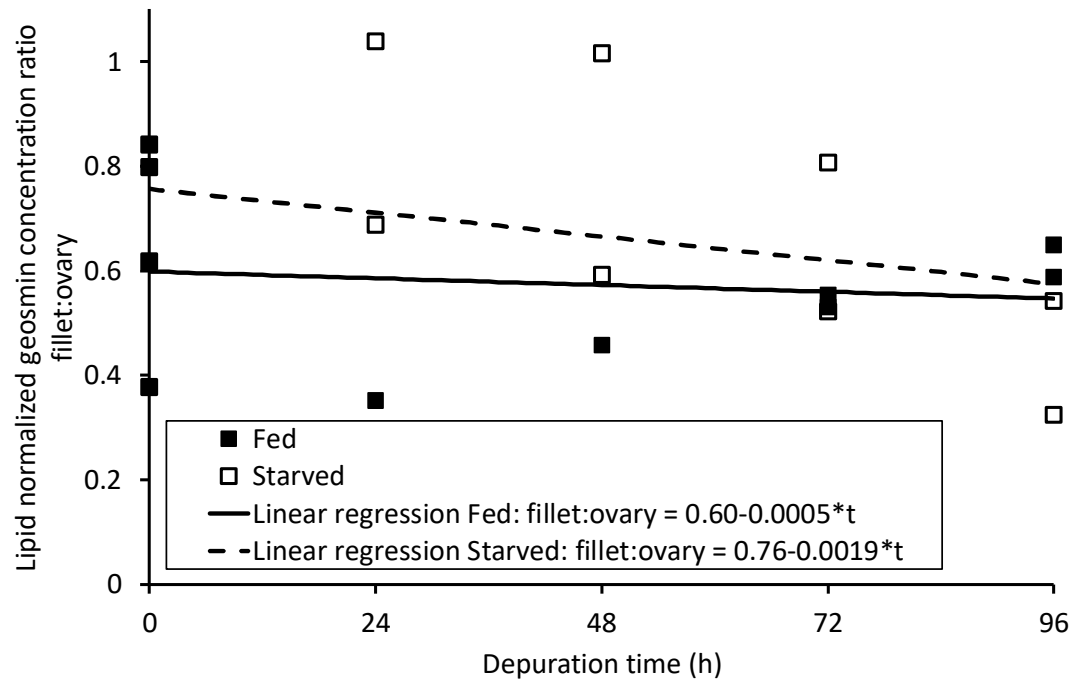

Fig. 2. Lipid normalized geosmin concentration ratio fillet:ovary over time for Nile tilapia that were fed or starved during off-flavour depuration.

\section{Treatment effects on blood lipid content}

Blood lipid content per feeding treatment and per sampling time is given in Table 3. Blood lipid content averaged over time points was higher in fed fish than in starved fish (two-way ANOVA, P Preatment $=0.001$ ). However, the effect of feeding treatment on blood lipid content altered with time, being indicated by the interaction effect between feeding treatment and time $\left(P_{\text {Treatment }}{ }^{*}\right.$ Time $\left.=0.008\right)$. Comparison of means per time point and treatment by post hoc analysis revealed that blood lipid content changed during the course of the depuration experiment in the fed fish but not in the starved fish (Table 3). In the fed fish blood lipid increased with time during depuration and was highest at $\mathrm{T}_{72}$ and $\mathrm{T}_{96}$ (Table 3).

Table 3. Mean (SD) blood lipid content per treatment (Starved or Fed) and sampling time. Mean values marked with different letters in superscript are significantly different $(p<0.05$, Tukey, post hoc analysis.

\section{Blood lipid content (\%)}

\begin{tabular}{ccc} 
Time (h) & Starved fish & Fed fish \\
0 & \multicolumn{2}{c}{$1.48(0.15)$} \\
24 & $1.40(0.14)^{\mathrm{ab}}$ & $1.10(0.14)^{\mathrm{a}}$ \\
48 & $1.25(0.35)^{\mathrm{a}}$ & $1.80(0.28)^{\mathrm{abc}}$ \\
72 & $1.35(0.07)^{\mathrm{ab}}$ & $2.05(0.07)^{\mathrm{bc}}$ \\
96 & $1.30(0.00)^{\mathrm{a}}$ & $2.15(0.07)^{\mathrm{c}}$
\end{tabular}




\subsection{Discussion}

Feeding Nile tilapia during off-flavour depuration resulted in a significant higher elimination rate of geosmin from the ovary. Our data suggest the same effect for the muscle tissue (fillets), but for fillets the feeding treatment gave only a numerical difference. We attribute this to the relatively higher analytical variation in the data caused by the low (initial) geosmin levels in fillets rather than absence of an enhancing effect of feeding during off-flavour depuration on geosmin elimination from the fillets.

Geosmin excretion by fish predominantly takes place via exchange between blood and water in the gills (Howgate, 2004). For depuration of off-flavours this implies the need of geosmin transport from peripheral tissues to the gills via the circulatory system. We hypothesized that geosmin would be eliminated faster from fed fish than starved fish due to higher blood lipid content and gill ventilation in the fed fish. The higher level of blood lipids, assumed to be mainly present as lipoproteins (Sheridan, 1988), could increase the transport capacity of the circulatory system while the higher gill ventilation promotes excretion from blood to water over the gills. As the amount of lipid in the fish' blood depends, among other factors, on the nutritional status of fish (Sheridan, 1988), we could successfully create differences in blood lipid content between the treatments by feeding and not feeding the groups of experimental fish. In the starved groups the blood lipid content remained unchanged during the experiment at levels ranging from 1.25 to $1.40 \%(w / w)$. In the fed groups the blood lipid content was higher at $T_{48}$ and $T_{72}$ compared to $T_{0}$, which is most likely due to the fact that during the last day of geosmin enrichment $\left(<\mathrm{T}_{0}\right)$ fish were not fed.

Our observation that fed fish with higher blood lipid levels eliminate geosmin faster from their ovaries and possibly their fillets suggests that geosmin excretion in starved fish is limited by low blood lipid levels. It should be noted however that our data do not provide direct evidence for binding of geosmin to blood lipids nor causality between blood lipid levels and geosmin transport and excretion. The efficacy of uptake across the gills as well as the transport capacity of blood depend on the capacity of compounds to bind to various plasma proteins (Streit and Sire, 1993; Schmieder and Weber, 1992). Given their high binding capacity to plasma lipoproteins, uptake of lipophilic compounds with logKow $>3$ across the gill is considered not to be limited by transport capacity of blood (Schmieder and Weber, 1992). Whether this also applies to the reverse process, i.e., excretion of lipophilic compounds over the gills remains undocumented. In contrast to uptake, excretion rates of moderately lipophilic compounds depend on the total lipid volume in the fish (Gobas and Mackay, 1987) but the contribution of blood lipids to the total lipid volume is small. Any effect of blood lipids on geosmin excretion is therefore more likely related to a functional role in geosmin transport than to a contribution to the total lipid volume. Considering that transport of geosmin from peripheral tissues to the 
gills requires the exchange of geosmin between tissue and blood lipid compartments, it seems quite plausible that a larger blood lipid compartment leads to faster excretion and that, in contrast to uptake, low blood lipid can limit excretion as our observations suggest. Uptake of lipophilic compounds is limited by its delivery at the gill surface, i.e., the gill ventilation rate (Schmieder and Weber, 1992). Gill ventilation rate is also an important determinant for the rate of excretion across the gills of lipophilic compounds (Gobas and Mackay, 1987) including geosmin according to Howgate (2004). We consequently attributed the positive effect of exercise on geosmin excretion in eel (Schram et al., 2016) to physiological adaptions, including increased gill ventilation, needed to handle the exercise induced increased oxygen demand (Schram et al., 2016). Feeding also increases oxygen demand in fish (Jobling, 1981). Our observations corroborate with this finding, in the tanks with fed fish mean oxygen saturation levels were slightly lower ( $81.3 \%$ compared to $86.9 \%$ ). Liver activity and perfusion may also be increased in fed fish. Given that there is some indirect evidence suggesting geosmin biotransformation in the liver of rainbow trout (Schram et al., 2018) and biotransformation rate may be increased with increased metabolism, geosmin elimination through biotransformation may be increased in fed compared to starved fish. We do not rule out that geosmin is partially excreted via the faeces, and this intestinal excretion may have been enhanced in the fed fish due to a higher content of the intestinal tract compared to the starved fish.

Although our data seem to suggest faster elimination from the fillets (Table 2), no significant tissue effect was detected in this study (Figure 2). This is surprising considering that the fillets were around a fivefold leaner (lipid content $~ 3.6 \% \mathrm{w} / \mathrm{w}$ ) than the ovaries (lipid content $\sim 19.6 \% \mathrm{w} / \mathrm{w}$ ) and the rate at which lipophilic compounds are eliminated from tissues decreases with increasing lipid content (Gobas and Mackay, 1987). Differences in perfusion between muscle tissue and the ovary may also have played a role, where higher perfusion led to faster elimination (Streit, 1998). However, without information on the perfusion of the ovary relative to the fillet it is impossible to evaluate whether or not higher perfusion to some extend counteracted the negative effect of the higher lipid content on the elimination rate of geosmin from the ovary.

The current observation of a faster elimination of geosmin in fed fish has several implications for industrial depuration practises. Fish farmers use the reversibility of geosmin bioconcentration to depurate off-flavours from their fish crops by placing them in water free of geosmin just before harvest. The time required for successful depuration is then largely determined by the initial levels of off-flavour compounds and their elimination rates (Howgate, 2004). Higher initial geosmin levels lead to longer depuration times to reach tissues concentrations below sensory detection limits, more so when elimination rates are lower. In general fish are not fed during depuration. Only in case of long-term depuration of large fish 
such as sturgeons, fish are occasionally fed (Sindilariu, pers. comm.). Because one of the practical reasons for not feeding fish during depuration is to allow the fish to empty their intestinal tract before slaughther, it is probably not possible to feed fish up to the last day of the depuration period. Also changing conditions and fish handling at the start of the depuration period may cause an initial decline in feed acceptance. It thus seems clear that feed intake during the depuration period will be lower than during the preceeding production phase. To what extent this limits the room for enhancing geosmin excretion by feeding the fish remains unclear until the effect of feeding level on geosmin excretion has been clarified.

Another practical reason for not feeding fish during off-flavour depuration is that it would place additional demands on the depuration system to handle the higher waste production of the fish. In case fish are fed, the water in the depuration system has to be renewed more frequently or recycled after internal purification to maintain proper water quality. The first action increases water demand which conflicts with farming fish in recirculating aquaculture systems (RAS) with the objective to reduce water demand. The second action (water recycling) requires biological filters. Since these are potential sources of off-flavour chemicals (e.g. Azaria and van Rijn, 2018), this may lead to geosmin and MIB exposure in the depuration system and a longer off-flavour depuration time. Clearly the practical implications of feeding fish during off-flavour depuration remain to be elucidated.

To illustrate that the practice of starving fish during off-flavour depuration leads to suboptimal performance of the depuration process we used our estimates for the geosmin elimination rates to calculate the time required to reach an arbitrary sensory detection limit of $25 \mathrm{ng} / \mathrm{g}$ lipid for all four combinations of treatment and tissue. This sensory detection limit corresponds to $0.9 \mathrm{ng} / \mathrm{g}$ in the fillet and $4.9 \mathrm{ng} / \mathrm{g}$ in the ovary based on the respective average lipid contents. We thus take into account that higher lipid levels concur with higher sensory detection limits (Howgate, 2004). To reach the sensory detection limit in the fillets the required depuration times are $140 \mathrm{~h}$ for the fed fish and $216 \mathrm{~h}$ for the starved fish. This seemingly large effect of feeding the fish during off-flavour depuration is remarkable considering the absence of significant treatment effects. Although it should be treated with caution because we extrapolated the effects in time far beyond the duration of our experiment, it does illustrate that relatively small differences in elimination rates, which may be difficult to detect experimentally, can have strong impacts on the longer term. For the ovaries the required depuration times to reach a geosmin concentration of $25 \mathrm{ng} / \mathrm{g}$ lipid are $251 \mathrm{~h}$ for the fed fish and $354 \mathrm{~h}$ for the starved fish. Again the starved fish need more time to eliminate geosmin and given the significant feeding treatment effect this is not surprising.

More remarkable are the differences between the fillet and the ovary. Irrespective of the feeding treatment, the fish needed more time to eliminate geosmin from their ovaries 
compared to the fillets. Since the geosmin elimination rates did not significantly differ between fillets and ovaries this difference in required depuration time can be largely attributed to the higher initial geosmin levels in the ovaries. Clearly Nile tilapia bioconcentrates more geosmin in its ovaries than in its fillets under a given geosmin exposure. Normalizing geosmin levels for lipid content reduced the average ratio fillet:ovary for the initial geosmin level from $0.12: 1$ to $0.6: 1$. This indicaties that the higher lipid content largely but not entirely explains the higher geosmin level in the ovary. In line with our previous findings (Schram et al., 2018) it seems that geosmin distribution within the fish is not exclusively governed by the lipid content of tissues.

The finding that fish bioconcentrate geosmin to higher levels in their ovaries and consequently need more time for depuration compared to muscle tissues is relevant for off-flavour depuration in the aquaculture production of sturgeons for caviar and meat. Given the contrast in lipid content of sturgeon ovaries ( $28-37 \%$, Ovissipour et al., 2015) and meat ( $6-10 \%$, Jankowska et al., 2002; Vaccaro et al., 2005) it is likely that sturgeons will accumulate more geosmin in their ovaries than in their muscle tissue. In that case the time required for successful off-flavour depuration is probably determined by the ovary and not the fillet. This is confirmed by practical observations at commercial sturgeon farms (Bonpunt, pers. comm.). It also means that using the sensory quality of fillets as indicator for the sensory quality of the ovary may result in the harvest of still off-flavoured caviar. It should be noted that the use of female tilapia as a model for sturgeon was a pragmatic choice, i.e., readily available small fish with developed ovaries, and not based on similarities in physiology.

In conclusion, Nile tilapia that are fed during off-flavour depuration eliminate geosmin faster from their ovaries when compared to starved fish. We attribute this mainly to increased gill ventilation induced by an increased oxygen demand. At the same time we do not rule out that low blood lipid levels in starved fish limit geosmin elimination.

\section{Acknowledgements}

This study was funded by the European Commission (contract: 604956 SpaceTaste). 
7. General discussion 


\subsection{Introduction}

\section{Objectives of this thesis}

This thesis investigated the bioconcentration and excretion of geosmin, one of the compounds causing off-flavour in fish, with the objective to improve the so called off-flavour depuration process. Starting point of the research was the theoretical framework set up by Howgate (2004) to describe the uptake, distribution and excretion of off-flavour chemicals by fish. It provides very useful mathematical models on uptake and excretion of geosmin by fish and also allows for deducing measures that potentially improve geosmin depuration processes. However, the theoretical framework relies heavily on scientific literature on the bioconcentration of moderately lipophilic chemicals other than geosmin (e.g. Nichols et al., 1990; Arnot and Gobas, 2006; McKim et al., 1985; Neely, 1979). Concepts developed and studied for these other chemicals were applied to geosmin on the basis of its lipophilicity while experimental data on geosmin itself were scarce. To use it for the optimization of geosmin depuration processes Howgate's (2004) theoretical framework needed to be experimentally validated. Six experiments were conducted with various fish species, testing both uptake and excretion. Various measures to promote geosmin elimination were deduced from the theoretical framework and tested in the experiments.

\section{Main findings}

The results of the experiments provided insight in de validity of the theoretical framework, deepened our insight in the physiology underlying geosmin uptake and elimination, and provided insights on which practical recommendations for improved off-flavour depuration can be based. The main findings include:

- Geosmin uptake and excretion by fish differs from Howgate's (2004) theoretical framework. Other processes than passive partitioning between water and fish clearly occur. Biotransformation seems to play a role;

- Geosmin tissue distribution is not exclusively governed by the lipid content of tissues;

- Exercise, increased water exchange of depuration tanks and feeding during depuration may all promote geosmin elimination but clear species differences exist;

- Temperature has limited effect on geosmin excretion.

\section{Outline of the general discussion}

This general discussion first addresses geosmin exposure in aquaculture systems. This leads to three main strategies for off-flavour mitigation in the broader sense, considering the entire chain of events that leads to off-flavoured fish crops. The state of the art of science and technology relevant for each strategy are discussed and future perspectives and 
recommendations are given. The discussion on the experiments focuses on the mechanisms underlying the observed treatment effects. The validity and applicability of the current theoretical framework regarding geosmin bioconcentration is discussed in relation to the results of the experiments conducted in this thesis. In the last part of this general discussion recommendations for future research that were not yet addressed in relation to the three main strategies are presented. Finally, main conclusions are drawn from the experimental work within this thesis.

\subsection{Geosmin exposure in aquaculture systems}

\section{Backgrounds to off-flavour in fish}

The chain of events leading to bioconcentration of geosmin and other off-flavour causing chemicals in fish has been well established. In brief: microbiota produce geosmin, geosmin is released to the water and fish bioconcentrate the waterborne geosmin in their lipid tissues and this causes off-flavour as soon as tissue levels exceed human sensory detection thresholds. The chain of events leading to off-flavour is based on the notion that bioconcentration of geosmin in fish is similar to the established uptake and excretion of other organic chemicals with comparable moderately lipophilic properties. This means that uptake is principally partitioning process of geosmin over water and lipid compartments in the system, driven by differences in concentration and affinities for water and lipid compartments (Gobas and Mackay, 1987; Arnot and Gobas, 2006, reviewed by Howgate, 2004). Geosmin is then freely exchanged between water and fish by diffusion over the blood/water barrier in the gills. Whether this results in a net uptake or excretion depends on the concentrations in water and fish. Equilibrium is reached when there is no net exchange between water and fish. In equilibrium geosmin levels will be much higher in the lipid, i.e., the fish, than in the water as for geosmin's much higher affinity for lipids (logKow $=3.57$ ). Based on this logKow, the equilibrium concentration ratio fish:water is estimated to be fixed at approximately 400:1 for rainbow trout with a lipid content of $10 \%$ (Howgate, 2004), i.e., the bioconcentration factor (BCF). The equilibrium will re-establish when the geosmin concentration in the water changes: geosmin in the fish will further increase when the exposure concentration in the water increases and vice versa. According to this theoretical framework, water and fish could be considered to act as two communicating barrels regarding their geosmin levels, be it that the 'fish barrel' is around 400 times larger than the 'water barrel' in case of rainbow trout with a lipid content of $10 \%$. The BCF and thus equilibrium state concentrations are species specific and determined by, amongst other factors, gill ventilation rate, lipid content, fish size and water temperature (Howgate, 2004). It is important to note that the re-establishment of the equilibrium is not instant but takes time. 


\section{Geosmin dynamics in aquaculture systems}

On the basis of the general consensus on how bioconcentration of moderately lipophilic compounds works, i.e., under the assumption that geosmin levels in the fish and water are dynamically related as described by the bioconcentration factor, a strong and dynamic relation between geosmin concentrations in water and fish is expected. Geosmin levels in the fish should then be a (delayed) reflection of the levels in the water. However, under aquaculture conditions, concentrations in water and fish are generally weakly correlated (reviewed by Azaria and van Rijn, 2018; Houle et al., 2010; Schrader et al., 2010). In a study by Petersen et al. (2011) correlation between geosmin concentrations in the water and in the fish (rainbow trout) was reasonably good $\left(R^{2}=0.66\right)$. Yet the bioconcentration factor of approximately 60 that can be deduced from Figure 1 in Petersen et al. (2011) is much lower than the dynamic bioconcentration factor (BCF) of 228 that can be calculated from Howgate (2004) for comparable rainbow trout (ca. 300 g, lipid content 5.6\%, water temperature $10-14$ ${ }^{\circ} \mathrm{C}$ ). Possibly geosmin in rainbow trout and culture water never reached equilibrium due to fluctuating geosmin concentrations in the water as reported by Petersen et al. (2011). It has indeed been questioned whether equilibrium assumptions can be made for chemical exposure in RAS (Hathurusingha and Davey, 2014). It seems more likely that geosmin uptake under aquaculture conditions is lower than predicted by theoretical rate constants and this is exactly what was also observed in our geosmin exposure experiment with rainbow trout (Chapter 2). The much lower bioconcentration explains the recommendation by Petersen et al. (2011) that geosmin levels in pond water should be kept below $10 \mathrm{ng} / \mathrm{l}$ to avoid off-flavours. At first this threshold for geosmin in the water seems rather high because with a BCF of 228 this would result in an estimated equilibrium concentration in the fish of $2.3 \mu / \mathrm{kg}$, well above the sensory detection limit of $0.9 \mu / \mathrm{kg}$ for rainbow trout reported by Robertson et al. (2005). However, with a BCF of $60,10 \mathrm{ng} / \mathrm{l}$ geosmin in the water leads to an equilibrium concentration in the fish of $0.6 \mu / \mathrm{kg}$, safely below this sensory threshold.

Assuming a dynamic relation between geosmin in water and fish, the levels in fish just before harvest should be determined only by the fish's recent exposure to geosmin. The complete exposure history should be less relevant. Again, this seems not to be the case under aquaculture conditions. Various studies on the development of off-flavours in fish raised in recirculating aquaculture systems (RAS) showed a continuous build-up of geosmin in the fish, seemingly independent of the concentrations in the water (e.g. Lindholm-Lehto et al., 2020). Several studies report large variations in geosmin levels in fish from the same rearing system where comparable levels should be expected because fish were exposed to the same levels of geosmin in the water (e.g. Schrader et al., 2010; Petersen et al., 2011; Zimba et al., 2012) while variations in characteristics of the fish were probably small (e.g. species, size, lipid content). These examples illustrate the general lack of understanding of the relation between geosmin 
in water and fish under aquaculture conditions as well as the importance of this relation for managing off-flavours. It appears that geosmin bioconcentration does not entirely follow the general model for the bioconcentration of moderately lipophilic compounds. In Chapter 2 we indeed showed that in a stagnant system, i.e., with a fixed total amount of geosmin present, uptake in rainbow trout does not entirely reflect the concurring decline in the water. Part of the geosmin in the system 'disappeared' and we consider biotransformation of geosmin by the fish a plausible explanation for this observation. Also our study on the effect of an increased water flow rate over depuration tanks for European eel (Chapter 4) points in the direction of geosmin biotransformation. Whether biotransformation indeed can explain the lower than expected in geosmin levels in fish versus water ratio observed under aquaculture conditions requires further study.

Research into geosmin dynamics in RAS is limited to a few studies (e.g. Lukassen et al., 2019; Podduturi et al., 2020) and consequently our understanding is limited. Within a RAS different compartments can be distinguished that may act as geosmin sources, reservoirs or sinks, depending on the processes taking place in each compartment. Relevant compartments may include biofilms, water, particulate matter (solids suspended in the water), fish and system components. Potentially relevant processes include production, degradation, bioconcentration, volatilization, sorption, fish harvesting, fish stocking, particle filtration and water exchange. Biofilms contain high geosmin levels compared to the water suggesting they are a primary source (e.g. Houle et al., 2010). Biofilms seem to act as temporary reservoir because geosmin levels do not differ in the in- and outflowing water of biofilters until they are manipulated (Podduturi et al., 2020). Apparently cells first need to disintegrate before geosmin is released to the water (Jüttner and Watson, 2007). At the same time, biofilms could also act as sinks as geosmin biodegraders seem to be present in various part of a RAS including the nitrifying trickling filter (Azaria et al., 2017). Biofilms, organic sludge (Gutmann and van Rijn, 2009) and possibly plastics within the system (tank walls, liners, piping) may act as (temporary) sinks through sorption of geosmin. Also the fish are a major sink as their body lipids provide a large amount of material for which geosmin has a high affinity. The size of the fish compartment varies over time due to fish growth, harvesting and restocking. Large amounts of geosmin are removed from the system when fish are harvested. Part of this geosmin may return if the effluent of depuration systems is used as renewal water for the RAS. Growth dilution affects geosmin levels in fish but not the absolute amount present. Fish tanks have been found to act as net geosmin producers, although outflowing water had only slightly higher geosmin concentrations than the inflowing water (Podduturi et al., 2020). Geosmin production in the fish tanks is not necessarily surprising and could take place in e.g. biofilms on tank walls. However, considering that geosmin released to the tank water in the direct vicinity of a large amount of fish would be quickly taken up in the fish, net geosmin 
production in fish tanks is surprising. Possibly part of the geosmin is associated to particles and therefore not available for uptake. The high water flow rate over the fish tanks may also partly prevent direct uptake. Since bioconcentration is reversible, fish may at some point also act as secondary geosmin source when geosmin levels in the water decline. Also contaminated fish newly introduced in a system may act as geosmin source and contaminate those fish that are already present. Biotransformation of geosmin would make the fish act as sinks and remove geosmin from the system, although it cannot be excluded that the excreted metabolites could be transformed into geosmin again by bacteria (Legler et al., 2002). Since geosmin is relatively volatile, it may be removed by air stripping, for example in gas exchangers installed in the system to remove excess carbon dioxide or in ventilated trickling filters. Detection of geosmin in the air vented from a trickling filter confirmed removal by air-stripping (Podduturi et al., 2020). Geosmin adsorbed to suspended sludge (Guttman and van Rijn, 2009) or present in intact cells of suspended pieces of biofilm may be removed from the system by particle filtration (e.g. drum filters) (Podduturi et al., 2020). The water in the system acts as reservoir but certainly also as medium by which geosmin is exchanged between the different compartments. Water exchange will contribute to the geosmin balance over a RAS: the intake water may contain geosmin and geosmin may be removed via discharge water. Possibly a large part of the geosmin in the water compartment is associated to particles rather than freely dissolved molecules (Durrer et al., 1999; Guttman and van Rijn, 2009). Therefore, it then seems likely that only part of the geosmin in water is available for uptake by the fish. Lower geosmin bioavailability than expected based on total concentration measurements may explain reports of poor associations between geosmin in water and fish as well as unexpectedly low geosmin uptake in fish. In case dynamic partitioning between freely dissolved and a particle bound geosmin occurs, also particle bound geosmin is available for uptake in fish. This will depend on the total mass balance of suitable substrates in the system for a moderately lipophilic compound such as geosmin. Further adding to this unclear situation is that it is not always reported if water samples were filtered before geosmin analysis or not, i.e., in- or exclude particle bound geosmin.

Clearly, the dynamics of geosmin in a RAS are complex and largely not understood. So far limited attempts have been made to establish these dynamics and the relative importance of each of the compartments, processes and their interactions. Research is complicated because geosmin concentration measurements of in- and outflowing water of RAS compartments only reflect the net results of production and removal processes. The poorly understood relation between geosmin concentrations in water and fish makes it difficult to predict the magnitude of off-flavour issues on the basis of geosmin concentrations in the water. It also makes it unclear what background levels of geosmin can be permitted in the water before off-flavour issues arise. Such a threshold concentration is needed as target for measures that aim to 
prevent geosmin exposure of fish. Water treatments are generally engineered such that their removal capacity is sufficient to counteract the production of the targeted compound while allowing a certain background concentration. Clearly the knowledge for a similar engineering approach for geosmin control is lacking. Geosmin dynamics in aquaculture systems need to be elucidated to allow for the design of proper off-flavour management.

\section{Main strategies for off-flavour mitigation}

Despite the current knowledge gaps regarding the geosmin dynamics in aquaculture systems, it is evident that elevated geosmin exposure levels result in increased bioconcentration which then requires longer depuration times. Therefore, any reduction of exposure and bioconcentration is worth pursuing. As already outlined in the General introduction to this thesis, three main strategies to break the chain of events leading to off-flavoured fish can be distinguished:

1) Prevention of geosmin production;

2) Removal of geosmin from the water;

3) Removal of geosmin from the fish.

For each strategy available methods, their state of the art and perspectives are discussed below.

\subsection{Strategy I: Prevention of geosmin production}

\section{Microbial geosmin production}

Prevention of microbial production of geosmin and other off-flavour causing chemicals is ultimately the best strategy as it targets the problem at its very source. Methods that prevent geosmin production have not been developed to this date, probably because research efforts have only recently been directed towards prevention (Azaria and van Rijn, 2018). Aquaculture production systems that are prone to off-flavour issues, such as recirculating aquaculture systems (RAS) and ponds, rely on microbiological processes for their water quality management. These systems consequently harbour diverse microbial communities (Rurangwa and Verdegem, 2015). The farm survey mentioned in the General introduction already suggested that if looked for, geosmin will be detected in most RAS and the farm survey by Lukassen et al. (2017) confirmed this. This may not be surprising given the wide range of microbiota capable of geosmin production while only a low abundance of producers is required for detectable geosmin levels in fish farm water (Lukassen, 2017). It seems that the presence of geosmin producers in RAS is unavoidable. Geosmin off-flavours in farmed fish, i.e., bioconcentration to levels above human sensory detection limits, then is a matter of the level of geosmin production rather than the presence of geosmin producers. When the 
presence of geosmin producers in aquaculture systems is indeed unavoidable, prevention seems best addressed by creating unfavourable conditions for geosmin production. Conditions affecting geosmin production have been studied both in fish culture systems and in pure bacterial cultures and include effects of e.g. phosphate, nitrate, carbon sources and trace metals. Mechanistic explanations for observed effects are lacking (reviewed by Azaria and van Rijn, 2018). Within RAS geosmin production is assumed to take place at aerobic/anoxic sites rich in organic matter (Azaria and van Rijn, 2018) and various studies confirmed this (reviewed by Azaria and van Rijn, 2018; Podduturi et al., 2020). Interestingly, geosmin presence seems not only determined by, but also affects the microbial community structure (Azaria et al., 2019). Insufficient information on the backgrounds of microbial geosmin synthesis is currently available to formulate practical measures that would limit geosmin production in aquaculture systems. It is, however, to be expected that the research field will advance rapidly with the development of a molecular method for the detection and quantification of the presence of a gene involved in geosmin synthesis (GeoA, Auffret et al., 2011). Molecular approaches also can assist in revealing the influence of environmental conditions on geosmin production (e.g. Lukassen, 2017). So far this molecular GeoA tool revealed that large parts of microbial communities in aquaculture systems consist of yet to be identified bacterial phyla (Lukassen, 2017). Despite the significant advancement of the field in recent years, prevention of geosmin production by managing microbiota seems still in its early stages of development.

\section{Design and management of systems}

Fish farmers that are regularly confronted with off-flavoured fish crops are a valuable source of information on the interactions between off-flavour spells and fish culture system design and management. Their practical experiences may be anecdotical and unconfirmed by scientific studies, they certainly can give clues on the dynamics of geosmin spells. For example, Dutch eel farmers using RAS claim they need to depurate their fish longer in the weeks before Christmas (own unpublished data). In this period they typically harvest and sell more fish than usual during the year. Off course it is possible that selling more fish and reaching more consumers results in an increase in complaints about off-flavour. However it is believed that in this period fish are indeed more off-flavoured than during the rest of the year. According to fish farmers the phenomenon is caused by a burst release of geosmin following the larger than usual, stepwise reduction of the standing stock, feed load and nutrient load to the biological filters. These changes of the conditions in the RAS are believed to cause biofilm shedding by the suddenly undernourished biological filters and release of geosmin from this biofilm material to the water. What follows is increased geosmin exposure and uptake by the yet to be harvested fish. From this chain of events it can be deduced that biofilters harbour a significant geosmin reservoir. This is in line with e.g. Houle et al. (2010) who detected high 
levels of geosmin in biofilms from a RAS for Arctic char production. Release of geosmin from biofilms may not take place until it comes loose and cells disintegrate, which seems indeed required to release intercellular geosmin (Jüttner and Watson, 2007). All this leads to awareness among fish farmers to operate RAS as stable as possible to avoid sudden geosmin spells. Indeed, Podduturi et al. (2020) reported burst releases of geosmin direct following biofilter cleaning. Biofilms in biofilters seem to act as geosmin reservoirs and keeping this reservoir small is worth pursuing as geosmin will be released eventually. Maintaining biofilms in aerobic biological filters in RAS as thin as possible, is therefore highly recommendable. A Dutch eel farmer practicing regular removal and washing of the plastic biofilter material from his trickling filter indeed seldomly experienced off-flavour issues. Possibly this practice caused the absence of off-flavours but this was never investigated nor confirmed. Similarly, RAS using moving bed biofilter reactors (MBBR) have been suggested to be less prone to off-flavours than those using trickling filters. The continuous mechanical shear forces on the suspended plastic biofilm carriers in a MBBR may lead to thinner biofilms than the hydraulic shear forces employed on biofilms in trickling filters. Again, systematic investigations establishing a difference in susceptibility to off-flavours between the two types of nitrifying biofilters and corroborating the suggested underlying mechanism is lacking. Since it is clear that biofilms in RAS can harbour geosmin (e.g. Houle et al., 2010; Podduturi et al., 2020) that will eventually end up in the water and thus the fish, Petersen et al., (2011) recommended to regularly remove biofilms from tank walls, piping and other parts of a RAS. These biofilms will then appear as suspended solids in the system water and need to be removed by mechanical filtration as quickly as possible to prevent release of geosmin and a temporary peak in exposure. As clear geosmin peaks have been observed in response to biofilter cleaning (Podduturi et al., 2020), cleaning activities are better not taking place just before scheduled harvests. Further research on off-flavour mitigation through system design and management could be more effective by incorporation of insights and practical experiences of fish farmers.

\section{Recommendations for strategy I}

Considering that prevention is generally the best strategy while research efforts have only been recently directed towards prevention of microbial geosmin production in aquaculture systems, it is clear that more research in this field is highly recommended. A detailed review of the state of the art of this field including specific recommendations for future research have already been provided by Lukassen (2017). In addition to these recommendations it seems worthwhile to gain insight in the rate of geosmin production to enable estimations of total geosmin productions within culture systems. Quantification of geosmin production in fish culture systems is needed for the engineering and design of water treatments that aim to counteract the geosmin production as outlined above. It should be emphasized that partial prevention of geosmin production may already contribute significantly to off-flavour 
mitigation. Any reduction in production probably reduces geosmin exposure and subsequent bioconcentration in the fish. As a result, geosmin levels in the fish are lower at the start of the depuration process, which reduces the time required for off-flavour depuration.

\subsection{Strategy II: Removal of geosmin from the water}

\section{Drinking water versus aquaculture water}

Removal of geosmin from the water targets this compound after microbial production but prior to bioconcentration in fish. As such it partially or maybe even completely prevents geosmin exposure and off-flavours in fish. Geosmin removal by conventional waste water treatment processes like coagulation, chlorination and sedimentation are not effective, but adsorption, oxidation and microbial degradation processes are (Srinivasan and Sorial, 2011). Geosmin removal has been investigated in the context of drinking water production (reviewed by Srinivasan and Sorial, 2011) and aquaculture (reviewed by Azaria and van Rijn, 2018). This distinction in application areas is relevant because large differences between water matrices exist. In drinking water production efforts to remove earthy off-flavours generally treat water with low levels of dissolved organic contaminants, while in fish culture water geosmin is only a minor part of the total amount of organic compounds present. Assuming a dissolved organic matter concentration of $80 \mathrm{mg} C O D / \mathrm{l}$, quite typical for RAS, and a geosmin concentration of $50 \mathrm{ng} / \mathrm{l}$, geosmin contributes less than $0.0002 \%$ to the total organic load on a water treatment facility. This clearly illustrates that the challenge for geosmin removal from fish culture waters lies in selectively targeting minute amounts of geosmin within a complex and rich organic matrix, and this is reflected in the achievements so far.

\section{Oxidation of geosmin}

Ozone

Ozone applications in laboratory scale experiments (Westerhoff et al., 2006) and drinking water plants (Nerenberg et al., 2000) have shown that geosmin dissolved in water can be successfully oxidized by ozone treatment. Experiments at fish farms however were largely unsuccessful and this was attributed to competition with other organic compounds (Schrader et al., 2010). Direct removal of geosmin by ozone from fish culture water, generally high in organic matter, thus seems not feasible. Ozone treatments are quite commonly applied in RAS to reduce levels of dissolved organics or for disinfection (Gonçalves and Gagnon, 2011). Since microbial geosmin production capacity is associated with high organic loads (Lukassen, 2017) while ozonation reduces organic loads, ozone treatment may indirectly reduce geosmin production. However, ozonation could also increase geosmin levels in RAS. This was seen in a practical trial on a Dutch eel farm (own unpublished data) which may be explained by ozone induced biofilm disintegration releasing intercellular geosmin to the water (Jüttner and 
Watson, 2007). A similar effect has been observed in drinking water production where water chlorination led to the release of geosmin from disintegrated blue-green algae cells (Ando et al., 1992). The observed increase in geosmin may have been a temporary start-up effect that would have lasted until geosmin reservoirs in biofilms were depleted. Long-term effects were however not established; the farm trial was discontinued because of the increased geosmin levels. Ozone may also increase the bioavailability of organic substrates for microbial geosmin synthesis due to partial oxidation by ozone. Clearly long-term extensive systematic farm surveys are required to elucidate direct and indirect effects of ozonation on geosmin levels in RAS.

\section{Advanced oxidation processes}

Another commonly applied water treatment in RAS is UV irradiation, i.e., photooxidation, not specifically to reduce off-flavours but mainly for disinfection of circulating or intake water (Summerfelt, 2003). UV treatments have, to various extent, been shown to remove geosmin. Conventional (254 nm) UV radiation seems ineffective (e.g. Kutschera et al., 2009), however, Rosenfeldt et al. (2005) reported up to $50 \%$ geosmin removal by direct UV photolysis. Photooxidation is based on the formation of hydroxyl radicals by UV radiation of water molecules. Advanced oxidation processes (AOP) combine UV radiation with ozone or hydrogen peroxide to increase the production of hydroxyl radicals and thereby the effectivity of the treatment. Hydroxyl radicals are highly reactive but also largely non-specific oxidants. Several studies showed a large potential for geosmin removal by AOP under laboratory conditions and in clean water, i.e., in the absence of radical scavengers (reviewed in Klausen and Gronberg, 2010). Since removal efficiencies are strongly affected by the presence of radical scavengers next to the target compound (Kutschera et al., 2009; Klausen and Gronberg, 2010) the effectivity of the treatment of fish culture water is questionable. The study by Klausen and Gronberg (2010) testing geosmin removal by $\mathrm{AOP}\left(\mathrm{UV} / \mathrm{O}_{3}\right.$ and $\mathrm{UV} / \mathrm{H}_{2} \mathrm{O}_{2}$ ) of spiked water from a recirculating aquaculture system is therefore of great interest. They successfully removed geosmin with AOP but, due to competition effects, at a much lower rate compared to previous studies in demineralized water. As a result the energy requirement is much higher and this limits practical feasibility. The authors therefore recommend pre-treatment to remove background organics and minimize competition effects. The study was done in water from a recirculating aquaculture system (RAS) with low water renewal (1\%/d) but the authors do not report the levels of dissolved organic compounds. Therefore it is hard to judge to what extent their findings are representative for other RAS. Again it is the nonspecific nature of the water treatment that limits the effective removal of geosmin from fish culture water rich in organic matter. The study by Nam-koong et al. (2016) is therefore of particular interest because they showed that geosmin was removed from RAS water by ultrasonically induced cavitation with little effect of the background water matrix. Unfortunately, the energy 
requirement of the process is high and until energy efficiency has been improved the authors consider the technology uneconomical for application in commercial scale RAS.

It seems clear that geosmin removal from aquaculture water by oxidation processes is largely limited by high background levels of organic matter and therefore not practically feasible.

\section{Adsorption}

The lipophilic nature of geosmin allows for its removal from the water by adsorbents. Activated carbon is an effective adsorbent of geosmin and granular activated carbon (GAC) and powdered activated carbon (PAC) treatments have been shown to be capable of geosmin removal from raw intake water of drinking water plants (Lalezary et al., 1986; Cook et al., 2001; Cook and Newcombe, 2004; Srinivasan and Sorial, 2011). Geosmin competes with other organic compounds of comparable molecular weights for adsorption sites on the activated carbon, while larger organic molecules can block access to adsorption sites. This leads to reduced geosmin removal efficiencies when other organic compounds are present. Dissolved organic carbon levels as low as 3-10 mg/l led to reduced geosmin removal efficiencies (Cook and Newcombe, 2004; Cook et al., 2001; Drikas et al., 2009). Considering that background levels of dissolved organic carbon fish culture are generally high (e.g. Yamin et al., 2017) most of the adsorption sites in activated carbon filters will not be taken by geosmin. This will lead to low geosmin removal efficiencies, the need for large filters to achieve relevant reductions of geosmin levels and the need for frequent replacement of the carbon. Clogging of activated carbon filters with organic solids poses an operational risk.

Cyclodextrin, a synthesized hydrophobic polymer, is considered to have significant potential for sorption of geosmin from water for drinking water production and aquaculture (Gutierrez et al., 2013; Mamba et al., 2007). Sorption experiments were however conducted in water with no other organic compounds than geosmin and 2-methylisoborneol (MIB) and results do represent geosmin sorption under competition. The potential of cyclodextrin for geosmin removal from aquaculture systems thus remains to be established.

Removal of geosmin from aquaculture water by adsorption of geosmin to zeolite was tested with promising results (Wee et al., 2014). Competition for adsorption sites is limited because the larger organic molecules present in aquaculture water are mainly adsorbed onto the external surfaces whereas geosmin utilizes the internal sites of zeolite. The same study also showed promising results for geosmin adsorption onto zeolite followed by UV-A photodegradation. The photodegradation was catalysed by $\mathrm{TiO}_{2}$ coating of the zeolite. Despite successful laboratory trials, practical applications at fish farms have not been developed yet (Van Hoestenberghe, pers. comm.).

Geosmin removal from fish culture water by sorbents with relatively unspecific affinities for organic molecules does not seem feasible unless background levels of competing dissolved 
organics are low or significantly reduced by pre-treatments (Klausen and Gronborg, 2010). However, strong reduction dissolved organic matter levels is not realistic for intensive aquaculture production systems. Geosmin removal by a-selective sorbents seems only feasible from relatively clean water like the water in depuration systems. This was shown by Burr et al. (2015): geosmin was removed from the inflowing water of a flow-through depuration tank using a granular activated carbon GAC filter and this led to faster depuration of off-flavours from Atlantic salmon. For more selective sorbents like cyclodextrin and zeolite practical feasibility remains uncertain until applications at fish farms have been developed and tested.

\section{Biodegradation}

Bacterial strains capable of geosmin biodegradation under aerobic or anaerobic conditions have been isolated from sand filters in drinking water plants as well as aquaculture systems (reviewed by Azaria and van Rijn, 2018). Removal of geosmin can be attributed to a combination of sorption to e.g. sludge, bioflocs or activated carbon and actual biodegradation. Development of dedicated bioreactors for geosmin biodegradation has started only recently and to date, full-scale systems that may be implemented in commercial aquaculture systems are not available. However, given the recent technological advancements, dedicated biofiltration within RAS may become a feasible method for geosmin removal according to Azaria and van Rijn (2018). Interestingly, geosmin biodegradation was recently linked to denitrification (Azaria et al., 2019). This is surprising since denitrification reactors have also been reported to act as geosmin producers within RAS (Podduturi et al., 2020). It seems that both geosmin production and degradation can take place. The magnitude of each process then determines whether the reactor is a net producer or consumer of geosmin. It would be interesting to investigate to what extent unintended geosmin removal already occurs in denitrification reactors in RAS, how this could be promoted and how the balance between production and degradation can be shifted towards net degradation. Given that denitrification is an established process in RAS, dual functioning reactors could accelerate the development of removal of off-flavour causing chemicals.

\section{Recommendations for Strategy II}

Removal of geosmin from fish culture water by a-selective processes, e.g. ozonation, advanced oxidation or sorption are hampered by competitive effects of the water matrix. This makes them either ineffective or increases energy demands to levels beyond practical feasibility. Ultrasonically induced cavitation seems an effective geosmin removal process on which the water matrix has less impact but at its current level of development the energy demand of the process is also too high (Nam-koong et al., 2016). Further research into these areas seems hardly worth pursuing except when the focus shifts from fish culture systems to depuration 
systems where background levels of organic compounds are much lower than in regular fish culture water. With less limiting effects of the water matrix in depuration systems, geosmin may be effectively removed by a-selective methods. These treatments provide an alternative for removing geosmin by increasing the water flow rate over depuration tanks to promote geosmin excretion (Davidson et al., 2014; Davidson et al., 2020). In fact, when water use needs to be limited, treatment loops removing geosmin are preferable.

Geosmin biodegradation in bioreactors in RAS seems promising, especially considering that research into this area is fairly recent. Development towards practical application may accelerate when geosmin biodegradation can be combined with denitrification processes (Azaria et al., 2018), as the application of denitrification reactors is already established within fish culture systems. Similar to prevention of geosmin production, partial prevention of geosmin bioconcentration in the fish through geosmin removal from the water is also worth pursuing as it will shorten the required depuration time.

\subsection{Strategy III: Removal of geosmin from the fish}

Removal of off-flavour causing chemicals from the fish prior to harvest utilizes the reversibility of the bioconcentration process. The steady state equilibrium concentrations in fish and water re-establish once the fish are placed in water free of these compounds, resulting in a net flux from the fish to the water. To remove the off-flavours from the fish, this so called off-flavour depuration process needs to be continued until all off-flavour causing chemicals in the fish have been eliminated to levels below their human sensory detection limits. This procedure is currently the main remedy against off-flavour applied by the aquaculture industry. The offflavour depuration process is however not always reliable; its results can be variable and unpredictable and off-flavoured fish continue to enter the market. In addition, the process can significantly increase costs of production. As outlined in the General introduction, it seems that the aquaculture industry optimized its off-flavour depuration processes towards minimal operational costs, water use, energy use and biomass loss rather than optimal removal of offflavour chemicals from fish. This seems like a missed opportunity because Howgate's (2004) theoretical framework for geosmin bioconcentration by fish and knowledge of the physiology underlying bioconcentration allow for deducing measures that potentially improve the elimination of off-flavour chemicals from fish. Two basic mechanisms to speed-up geosmin excretion and thereby reduce the required depuration time were deduced: 1 . measures aimed at increasing the rate at which geosmin is excreted by the fish, and 2. measures aimed at increasing the rate at which excreted geosmin is removed from the direct environment of the fish. 


\section{Increasing the geosmin excretion rate}

Under the assumption that geosmin bioconcentration is a mere partitioning process over water and lipid compartments, excretion in geosmin free water can be described as exponential decay (Howgate, 2004, eq. 3 in the General introduction). Various depuration experiments in clean water show that geosmin decline over time is indeed adequately described by exponential decay (reviewed by Howgate, 2004 up to 2000; Robertson et al., 2005; Davidson et al., 2014; Lindholm-Lehto et al., 2019).

The equation describing geosmin excretion in clean water as exponential decay shows that the time required to reach a certain target concentration in the fish only depends on the geosmin concentration in the fish at the start of the depuration process and the rate of excretion. Robertson et al. (2005) indeed reported that depuration times in their experiment were directly related to the initial geosmin levels in the fish. This leaves the excretion rate as the only factor to manipulate the depuration time. The excretion rate constant $k_{2}$ depends on the maximum chemical uptake efficiency of the gill, the gill ventilation rate, the lipid volume and the lipophilic nature of the chemical as expressed by its octanol/water partition coefficient (Gobas and Mackay, 1987 in Howgate, 2004). For a given fish contaminated with geosmin, the lipid volume and the lipophilic nature of the chemical are fixed. For rainbow trout, Gobas and Mackay (1987) calculated a maximum chemical uptake efficiency of the gill of 0.54 for moderately lipophilic chemicals, i.e., logKow 3-6 (in Howgate, 2004). Since diffusion barriers are defined by gill morphology (Erickson and McKim, 1990) maximum uptake efficiencies probably vary with fish size and species. However, for a fish of a given size and species, it is quite reasonable to assume that the maximum chemical uptake efficiency of the gill is a fixed value, although temperature may have some effect (Howgate, 2004). This leaves gill ventilation rate as only factor to manipulate the passive geosmin excretion rate. Gill ventilation rate is inversely related to arterial oxygen levels in fish (e.g. Randall, 1982). Factors affecting oxygen demand and oxygen availability then seem to be the main tools to manipulate the excretion rate. From a physiological point of view this is not surprising since the fish gill's characteristics that allow for the efficient uptake of oxygen also favour the exchange of xenobiotic lipophilic chemicals (McKim and Erickson, 1991).

\section{Oxygen availability}

Effects of oxygen availability have been investigated in relation to uptake of chemicals rather than excretion. Considering that uptake and excretion are essentially the same passive diffusion processes over the water/blood barrier in the fish gill, be it in different directions, it is reasonable to assume that effects on uptake also apply to excretion. The mathematical background of the uptake and excretion rate constants for moderately lipophilic chemicals seem to confirm this. Both depend equally on uptake efficiency and gill ventilation. The only 
difference between the uptake and excretion rate constants is that uptake depends on de total fish volume while excretion depends on the lipid volume in the fish and logKow (Gobas and Mackay, 1987 in Howgate, 2004). Uptake of endrin (logKow 4.80) increased with increasing gill ventilation rate caused by decreasing oxygen availability (McKim and Goeden, 1982). Based on this it can be hypothesised that reducing water oxygen levels enhance geosmin excretion, but this has not been investigated. The rainbow trout in the study by McKim and Goeden (1982) increased their gill ventilation rate more than fourfold when oxygen levels dropped from $100 \%$ to $30 \%$ saturation. Assuming a similar effect for geosmin and equal maximum uptake efficiency at the different oxygen levels, the mathematical equations for the uptake and excretion rate constants imply a fourfold increase of both rate constants following this drop in oxygen saturation. Fish farmers will understandably be reluctant to drop oxygen to sublethal levels and risk losing their valuable fish crops just before harvest. However, reducing oxygen to still safe levels of e.g. 50-60\% saturation probably still significantly increases geosmin excretion. Considering that managing depuration systems at lower oxygen levels is technically within easy reach for fish farms that already employ sophisticated systems for measurement and control of oxygen levels, this measure certainly deserves to be investigated. Operating depuration systems at reduced oxygen levels seems much more promising than increasing the water temperature to enhance geosmin excretion. In this thesis the effect of temperature was investigated in experiments with European eel (Chapter 4) and Atlantic salmon (Chapter 5 ) and none of the experiments led to the detection of significant temperature effects. Geosmin excretion has been postulated to increase with temperature through the temperature effect on oxygen availability and demand. Fish increase their gill ventilation rate as temperature increases to compensate for the decrease in oxygen solubility in water while physiological oxygen demand increases (Howgate, 2004; Neely, 1979). Fish in our experiments testing temperature were not fed and the increase in physiological oxygen demand due to temperature increase may have therefore been rather small (Saravanan et al., 2013). At the same time, temperature treatments not always led to large contrasts in dissolved oxygen concentrations. The effect on gill ventilation might then have been too small to sort detectable effects on geosmin excretion. Unfortunately gill ventilation rate was not measured to confirm this. Both experiments tested temperature effects in conjunction with other treatments: exercise in case of European eel and water flow rate in case of Atlantic salmon. For both species we detected significant effects of these treatments and this possibly prevented the detection of smaller temperature effects. Temperature effects on geosmin depuration seem not reported in scientific literature but for MIB increased excretion with increasing temperature was found (Johnsen et al., 1996; Dionigi et al., 2000), which is in line with Howgate (2004). All in all we do not rule out that temperature affects geosmin excretion as postulated by Howgate (2004), but it seems that among the measures 
that can be taken to speed-up geosmin excretion, the potential impact of temperature increase is rather small.

\section{Oxygen demand}

European eel that were forced to swim (Chapter 3) showed faster geosmin excretion and consumed more oxygen than freely swimming control fish. Gill ventilation rates were unfortunately not measured but the higher oxygen consumption of the exercised fish confirms that increasing oxygen demand indeed promotes geosmin excretion. Nile tilapia that were fed during off-flavour depuration excreted geosmin faster than the unfed controls (Chapter 6). The feeding effect was attributed mainly to increased oxygen demand in fed fish (Jobling, 1981), but we did not record oxygen consumption nor gill ventilation rate to corroborate this. Only the slightly lower mean oxygen saturation in the tanks with fed fish may be a reflection of increased oxygen consumption.

Uptake (e.g. Brinkmann et al., 2014; Blewett et al., 2013; Yang et al., 2000) and excretion (Yang et al., 2000) of lipophilic chemicals by fish have been positively related to their oxygen consumption. The physiological changes that enable fish to increase oxygen transfer across the gills to handle increased oxygen demands have a similar effect on the exchange of lipophilic chemicals across the gills (McKim and Erickson, 1991; Brauner et al., 1994; Yang et al., 2000; Blewett et al., 2013). These physiological changes include an increase in cardiac output, which leads to a rise in blood pressure, higher perfusion of secondary gill lamellae, a more even lamellar blood flow and more rigid lamellae (Randall and Daxboeck, 1982; Randall et al., 1967). Uptake (water to blood) of lipophilic compounds is limited by the delivery of compounds at the outside gill surface, i.e., the water flow over the gills. Blood flow at the other side of the blood/water interface in the gills does not limit uptake (Schmieder and Weber, 1992). Blood and water flow limitations seem not been investigated for the excretion of moderately lipophilic compounds across the gills. The positive effect of increased gill ventilation on excretion suggests water flow limitation of excretion, but the effect may be difficult to distinguish from increase in blood flow that will coincide with increased gill ventilation (Randall et al., 1967). It is clear that excretion (blood to water) requires delivery of the compound at the inside of the gill surface by the blood. This requires the mobilisation of compound from the lipid compartments in the fish's body followed by transport via the circulatory system to the gills. It seems reasonable to assume that delivery at the inside of the gill surface increases with increased tissue and gill perfusion, cardiac output and blood pressure, i.e., physiological changes observed when oxygen demand increases. This will only enhance excretion when delivery at the inside of the gill is a limiting factor. Our observation that increased excretion coincides with increased blood lipid levels (Chapter 6) suggests that transport and delivery pose some limitation to geosmin excretion by Nile tilapia. In blood moderately lipophilic compounds are bound to lipoproteins (Spindler-Vomachka et al., 1984) 
and specific plasma transporter proteins (Schmieder and Henry, 1988). This makes it highly likely that the plasma lipid fraction, including lipoproteins is involved in geosmin transport via the circulatory system. Considering that transport of geosmin from peripheral tissues to the gills requires the exchange of geosmin between tissue and blood lipid compartments, it is quite plausible that a larger blood lipid compartment leads to increased geosmin delivery in the gills and faster excretion. The contrast in blood lipid level in this experiment was installed through either starving or feeding the fish. Therefore, it is also possible that the faster excretion that we observed in the fed fish with higher blood lipid is (partly) caused by the feeding induced increase in oxygen demand (Jobling, 1981). The experiment did not allow for distinguishing effects of increased blood lipid and oxygen demand.

\section{Biotransformation}

Earlier, it was proposed that fish have no need for a xenobiotic metabolizing system as absorbed xenobiotics could diffuse through the gills into an infinite volume of water (Brodie and Maickel, 1962 in Clarke et al., 1991). This hypothesis was clearly unsupportable since the majority of xenobiotics is lipophilic and thus partitions into body lipids rather than diffusing into the surrounding water (Clarke et al., 1991). Nowadays it is clear that biotransformation of xenobiotics is present in all major groups of organisms. Also in aquatic species it is a significant phenomenon which directly affects the fate and effects of absorbed xenobiotics (Lech and Bend, 1980). Xenobiotic metabolism is divided into three phases. In phase I xenobiotics are modified by addition of reactive or polar groups by enzymes such as cytochrome P540 oxidases. In phase II the modified or parent xenobiotics are made more water soluble by conjugation to polar compounds and thus easier to excrete. In vivo studies have demonstrated that xenobiotic conjugation to glucuronic acid (glucuronidation), is quantitatively the most important pathway for elimination of many xenobiotics in fish (Clarke et al., 1991). In phase III conjugated xenobiotics are recognized by cellular efflux transporters and pumped out of the cells and over epithelial barriers such as of gills and the intestinal tract.

Biotransformation of off-flavour causing chemicals is believed to be absent in fish (Howgate, 2004). For MIB phase I biotransformation is reported to be absent in channel catfish based on cytochrome P450 activity measurements (phase I) and the absence of MIB metabolites in plasma (Schlenk et al., 2000). Phase I metabolism is however not required for geosmin and MIB biotransformation because both compounds already contain hydroxyl groups to which phase II metabolism can bind conjugates. Clearly the evidence basis for excluding geosmin biotransformation is narrow. Especially when considering that xenobiotic metabolism pathways have very low substrate specificity and almost any non-polar (lipophilic) compound can be metabolized (Jakoby and Ziegler, 1990), it seems rather unlikely that phase II biotransformation of geosmin is completely absent in fish. 
This thesis provided indirect evidence for the presence of geosmin biotransformation in European eel, rainbow trout and Atlantic salmon. In Chapter 2 we showed that in a stagnant system, i.e., with a fixed total amount of geosmin present, uptake in rainbow trout does not entirely reflect the concurring decline in the water. Part of the geosmin in the system 'disappeared' and we consider biotransformation of geosmin by the fish a plausible explanation for this observation. Geosmin conjugates would not be detected when analyzing samples for the parent compound. We showed that eels (Chapter 4) eliminate geosmin from their bodies surprisingly independent of the water renewal rate of the depuration tanks, while eels are known for their active biotransformation system. Although being eliminated from the fish, geosmin hardly appeared and certainly did not accumulate in the water of the depuration tanks. These observations may be explained by geosmin being eliminated from fish as metabolite rather than the parent compound and geosmin biotransformation thus seemed indicated. Also in Atlantic salmon (Chapter 5) the effect of the water renewal rate of depuration tank on geosmin excretion was smaller than predicted and this may be explained by biotransformation of part of the geosmin in the salmon. Large species differences in biotransformation capacity exist (Nichols et al., 2006) and eel are among the fish with a high phase I and phase II biotransformation capacity (Braunbeck and Völkl, 1991; de Boer and Hagel, 1994; Van der Oost et al., 1994).

Biotransformation can be a determinant factor for bioconcentration of chemicals in fish and will result in lower levels in the fish than predicted based on their lipophilicity (Lech and Bend, 1980; Kleinow et al., 1987). In addition, biotransformation of chemicals to forms that can be actively excreted can have a large effect on the compartmentalization of the chemical within the fish (Lech and Bend, 1980). This is exactly what we observed in geosmin exposed rainbow trout (Chapter 2). In these rainbow trout lipid normalized geosmin levels in the liver immediately after exposure started were $\sim 1.5$ times higher than in the rest of the body, which we attribute to the high perfusion of the liver (reviewed by Streit, 1998). Towards the end of the exposure period the lipid normalized geosmin level of the liver had declined to 0.5 times the level in the rest of the body. We attributed this to induced biotransformation in the liver, known for its high biotransformation capacity. Because of the potential impact of biotransformation it is essential to establish the presence and magnitude of geosmin biotransformation across fish species to fully understand the bioconcentration process.

\section{Increasing the geosmin removal rate from depuration tanks}

The second basic mechanism to speed-up geosmin depuration involves measures aimed at the rate at which excreted geosmin is removed from the direct environment of the fish. These measures keep geosmin concentrations in the water surrounding the fish low. Note that optimal exponential decay of the geosmin concentration in this fish only occurs at constant zero geosmin in the water, i.e., there is instant and total removal of excreted geosmin. In artificial aquatic environments with high fish densities, compounds excreted by fish can 
accumulate to significant levels in the water, depending on the amounts excreted and removal rate from the tank, e.g. by a continuous water flow over the tank (Schram et al., 2009). This means that excreted geosmin probably accumulates in the water of industrial off-flavour depuration systems and that the assumption of zero geosmin in the water is violated. Excreted geosmin may then be re-absorbed by the fish, effectively reducing the net excretion and increasing the depuration time required to bring the concentrations in the fish below human sensory detection limits. The decline of the chemical concentration in the fish during excretion then not only depends on the initial geosmin concentration in the fish and the excretion rate constant but also on the uptake rate constant, the fish density (biomass per water volume) and the rate of geosmin removal from the depuration tank by e.g. tank water renewal. Other geosmin sources may be present in a depuration system next to geosmin excretion by the fish (e.g,. Petersen et al., 2011) and these will also affect geosmin levels in the water and thereby net excretion rates. Assuming no other means of geosmin removal from the depuration tank than the outflowing water, the water flow rate over a depuration tank is an important factor controlling the depuration time of fish with given geosmin levels, uptake and excretion rate constants. A strong effect of water flow rate over the depuration tank was confirmed by model predictions (Chapters 4 and 5). However, the predicted effects were absent in European eel (Chapter 4) and less strong than predicted in Atlantic salmon (Chapter 5). We considered geosmin biotransformation by the fish a plausible explanation for these observations but have no data to corroborate this. The experiment with Atlantic salmon tested combined effects of water flow rate over the depuration tank and temperature (Chapter 5). Increased water flow rate was predicted to enhance geosmin excretion by removing geosmin from the direct environment of the fish. Increased temperature was predicted to enhance geosmin excretion through an increase in gill ventilation rate. We hypothesized that these two measures would interact because increased gill ventilation not only increases chemical excretion, it has an equal effect on chemical uptake (Gobas and Mackay, 1987). Considering that increased excretion also increases geosmin accumulation around the fish, a parallel increase of reabsorption of excreted geosmin seems likely. It then appears that increasing the rate of geosmin excretion by the fish needs to be accompanied by measures that increase the removal of geosmin away from the fish to sort an optimal effect on net geosmin excretion. Without measures that remove geosmin away from the fish, the increased excretion largely results in an increased recycling of geosmin over the fish rather than increased net excretion. Model predictions indeed showed this interaction effect but it was not evident from the experiment with Atlantic Salmon (Chapter 5), probably because the contrast in temperature treatments and subsequent difference in excretion rates was too small.

Increased removal of geosmin from the direct environment of the fish may certainly affect geosmin excretion by fish. The effects however seem species specific and smaller than predicted based on the lipophilicity of geosmin. 


\section{Recommendations for Strategy III}

Based on the current theoretical framework for geosmin bioconcentration two basic mechanisms to enhance geosmin excretion can be distinguished: 1 . Increasing the rate of excretion and 2. Increasing the rate of removal from the direct environment from the fish. Model prediction showed that these mechanisms interact such that increased geosmin excretion from the fish is most effective when combined with increased geosmin removal away from the fish. Although this interaction was not evident in our experiments (Chapter 5), further investigations into interaction effects are recommended because they potentially have a strong effect on the effectivity of depuration.

Reducing dissolved oxygen levels in depuration systems is possibly a very effective and technically easily achieved method to increase geosmin excretion rates through increasing gill ventilation rates of fish. Because experimental evidence is lacking, future experimental research in this area is highly recommended.

The extent to which increased removal of geosmin from the depuration tank promotes geosmin excretion seems species specific, possibly due to species differences in the contribution of biotransformation to geosmin elimination. As far as currently investigated the effect is smaller than to be expected based on the lipophilicity of geosmin. The optimal water flow rate over depuration tank, i.e., the minimal flow at which no geosmin accumulation occurs requires further investigations. Ideally, geosmin levels in depuration tanks are monitored to prevent both too low flows and suboptimal depuration as well as wasting water by installing higher flows than necessary to control geosmin levels.

This thesis delivered indirect evidence for geosmin biotransformation in rainbow trout (Chapter 2), European eel (Chapter 4) and Atlantic salmon (Chapter 5), including important effects on its bioconcentration. If geosmin biotransformation indeed occurs, overall bioconcentration prediction is more complex than the simple partitioning process over water and lipid compartments according to current consensus. The approach towards improving the off-flavour depuration process then needs to be refocused. Biotransformation and the subsequent excretion of metabolites instead of the parent compound reduce the potential impact of re-absorption of excreted geosmin on the net geosmin excretion from the fish. This may render measures that are aimed at prevention of re-absorption of excreted geosmin less effective (mechanism 2) simply because the need to remove geosmin away from the fish is smaller. This was seen in our experiments with European eel (Chapter 4) and Atlantic salmon (Chapter 5). If present, enzymatic biotransformation can most likely be induced and enhanced and this opens new opportunities for increasing geosmin elimination from the fish next to promoting excretion via the gills (mechanism 1). Geosmin biotransformation during the depuration process can reduce depuration time through additional removal of geosmin from tissues. It certainly would be preferable to enhance biotransformation during the culture period in which fish build up geosmin in their tissues as this leads to lower geosmin in the fish 
at the start of the depuration process. Clearly, the presence and magnitude of geosmin biotransformation in relevant fish species needs to be established to understand its effect on bioconcentration and optimize off-flavour depuration. The presence of especially phase II metabolism can be investigated via exposure to easy to conjugate and detect model compounds. The relative importance of the biotransformation process and its pathways can be investigated by perturbations of biotransformation through specific inhibitors. In rainbow trout salicylamide is a known inhibitor of the glucuronide formation (Lech, 1974). Comparing bioconcentration of e.g. geosmin in fish treated with salicylamide to untreated fish, can reveal the relevance of phase II metabolism of geosmin in this fish as well as its relative importance to geosmin bioconcentration. Detection of geosmin metabolites would provide direct evidence for geosmin biotransformation.

The observed variation in geosmin levels in fish with the same exposure history (e.g. Petersen et al., 2011) suggests considerable individual variation in geosmin bioconcentration within species. This could mean that individual fish respond differently to measures aimed at improving off-flavour depuration processes. To further elucidate variation in bioconcentration, it is recommended to address the response of individual fish to experimental treatments rather than groups through pooled samples. It would be of great interest to investigate whether within species variation in bioconcentration results from variation in biotransformation capacity and whether this has a genetic basis. In that case breeding programs selecting for high biotransformation capacity provides another opportunity to reduce geosmin bioconcentration in farm fish.

\subsection{Modeling geosmin bioconcentration}

\section{Theoretical framework}

Mathematical models that predict the development over time of geosmin concentrations in fish in response to exposure to waterborne geosmin are very useful tools for research into and management of off-flavours. As outlined in Chapter 2, Howgate (2004) provided a theoretical framework for the bioconcentration of geosmin and MIB in fish based on the general fish bioconcentration model for moderately lipophilic compounds (reviewed in Arnot and Gobas, 2006). In Howgate's (2004) model for geosmin, bioconcentration is governed by passive concentration driven uptake and excretion via the gills while faecal egestion, metabolic biotransformation and growth dilution were excluded. This resulted in an equation describing the development over time of the chemical concentration in the fish $\left(C_{F(t)}\right)$ in response to a stable chemical concentration in the water $\left(C_{W}\right)$ and an equation that describes the depuration of the chemical from the fish as exponential decay where $C_{F(t=0)}$ is the initial chemical concentration in the fish (eq. 2 and 3 in the General introduction). 


\section{The validity of the theoretical framework}

The theoretical framework, i.e., the model proposed by Howgate (2004) to describe the uptake and excretion of geosmin by fish could not adequately describe the experimental uptake of geosmin in rainbow trout (Chapter 2). This was clear from the start because the experiment was conducted in a stagnant system in which the assumption of constant geosmin in the water is violated due to uptake. We therefore extended the model to account for this effect as described in Chapter 2. The observed geosmin concentrations in the water and fish were adequately described by this extended model, but only because we deviated from the theoretical framework by adding a term for biotransformation to the model. The study revealed that rainbow trout bioconcentrates waterborne geosmin, but less than predicted based on theoretical rate constants and assuming passive distribution based on lipophilicity only. The study also showed that geosmin distribution is not entirely governed by the lipid content of tissues, indicating that the bioconcentration process is more complex than mere partitioning over water and lipid compartments.

During off-flavour depuration geosmin excretion may lead to accumulation in the water and the assumption of zero geosmin in the water that is required for optimal exponential decay is then violated. The extent to which geosmin accumulates depends on the water exchange rate of the depuration tank. To account for the effect of variable geosmin levels in the water under in the influence of the water flow rate, we extended the bioconcentration model by adding an equation that describes the variation of the geosmin concentration in the water as a function of chemical uptake and excretion by the fish, fish density and chemical outflow via the tank effluent (Chapter 4). This extended model for depuration in flow-through systems predicted strong effects of the water flow rate on geosmin elimination. Surprisingly this was not observed in European eel (Chapter 4) and only to some extent in Atlantic salmon (Chapter 5). It seems that the eel did not excrete any parent compound and the salmon only some. Even in the treatments with stagnant water (no flow) geosmin in the salmon continued to decline over time while the model predicted that a steady state equilibrium with the water would be quickly reached. This indicates that removal of geosmin from the direct environment of the fish is not essential for its elimination from fish. The differences between model predictions and experimental data indicate that the theoretical framework does not account for all processes affecting geosmin bioconcentration in fish.

A predictive model for geosmin and MIB uptake in fish has been published by Hathurusingha and Davey (2014). These authors questioned whether equilibrium assumptions can be made for the uptake of geosmin in fish farmed in RAS. They consequently developed a transient state (as opposed to steady-state) model based on the general fish bioconcentration model for moderately lipophilic chemicals (Arnot and Gobas, 2006). The model includes a term for 
biotransformation, which is parameterized with a relatively small rate constant which is not specific for geosmin (Gobas, 1993 in Hathurusingha and Davey, 2014). The interesting aspect of the model is that it predicts the accumulation of geosmin in the fish over time as it grows to marketable size. The model fits well to experimental data of Petersen et al. (2011), but only because the parameterization of uptake and excretion rate constants deviates from the theoretical rate constants Howgate (2004) provides for rainbow trout. This indicates once more that geosmin bioconcentration differs from what is generally predicted for moderately lipophilic compounds.

The observations in Chapters 2, 4 and 5 of this thesis challenge the theoretical framework for geosmin bioconcentration as proposed by Howgate (2004) on the following points: 1 . The observations cannot be explained by considering geosmin bioconcentration as 'only' a passive partitioning process between water and lipid compartments. It is clear that also other processes take place. Biotransformation of geosmin by the fish could be one of these processes as it provides a plausible explanation for our observations. The additional processes need to be identified and quantified before they can incorporated in mathematical bioconcentration models. 2 . The distribution of geosmin is not entirely governed by the lipid content of tissues and organs. This mainly affects the distribution of geosmin within the fish over edible (fillets) and inedible parts of the fish. It may also be indicative for biotransformation. 3. Bioconcentration in vivo is lower than theoretical uptake and excretion rate constants predict and the theoretical rate constants may thus be overestimations of true values. Experiments quantifying these rate constants are needed. Once these aspects have been elucidated, the development of mathematical predictive models can be readdressed.

\section{Predicting the required depuration time}

Even though geosmin bioconcentration of geosmin appears to differ from the general bioconcentration model for moderately lipophilic chemicals, the depuration of geosmin from fish can still be adequately described by exponential decay (Chapter 4), also in case the assumption of zero geosmin in the water is violated. Note that a significant rate constant estimated from experimental data then represents the net result of all known and unknown processes affecting geosmin elimination from the fish. This probably makes the estimated rate constant specific for the experimental setting rather than generic, which is still appropriate for e.g. investigating treatment effects. When other processes such as biotransformation or uptake affect the depuration process, the excretion rate constant $k_{2}$ in the exponential decay equation should be substituted by a more generic rate constant for net the elimination, e.g. $k_{T}$. The equation for exponential decay of geosmin in the fish during depuration can be used to calculate the time required to depurate fish until the human sensory detection limit (SDL) is reached. For this purpose it is convenient to substitute the geosmin concentration in the 
fish at a certain time point $\left(C_{F(t)}\right)$ for the targeted geosmin concentration, i.e., the human sensory detection limit $\left(C_{S D L}\right)$.

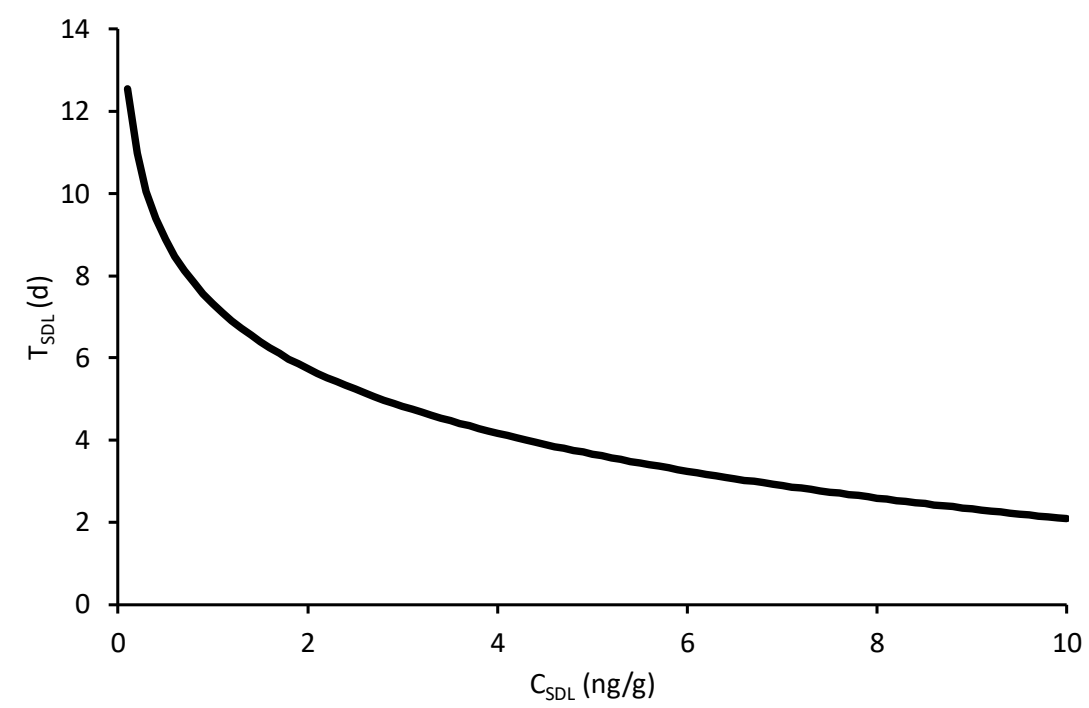

Fig 1. Required depuration time $T_{S D L}(d)$ as function of the human sensory detection limit for geosmin in fish $C_{S D L}(\mu \mathrm{g} / \mathrm{kg})$. Total elimination rate constant $k_{T}=0.441 / \mathrm{d}$. Geosmin concentration at the start of the depuration process $\mathrm{C}_{\mathrm{F}(\mathrm{t}=0)}=25 \mu \mathrm{g} / \mathrm{kg}$.

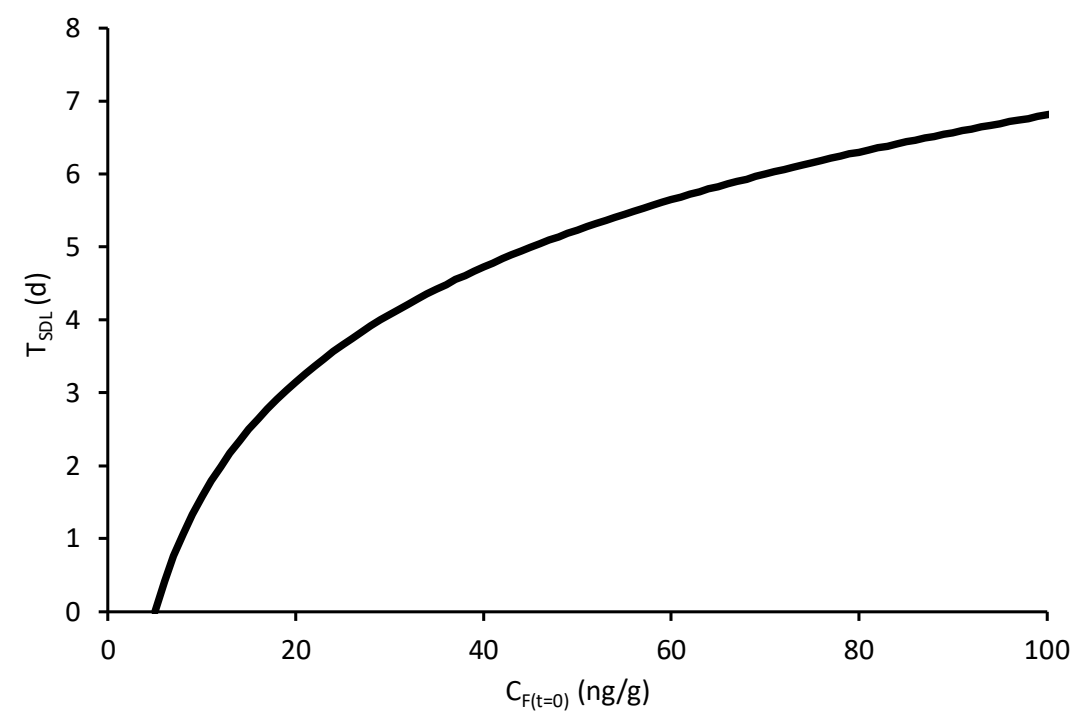

Fig 2. Required depuration time $T_{S D L}(d)$ as function of the geosmin concentration at the start of the depuration process $C_{F(t=0)}(\mu \mathrm{g} / \mathrm{kg})$. The human sensory detection limit for geosmin in fish $C_{S D L}=5 \mu \mathrm{g} / \mathrm{kg}$. Total elimination rate constant $k_{T}=0.441 / \mathrm{d}$. 


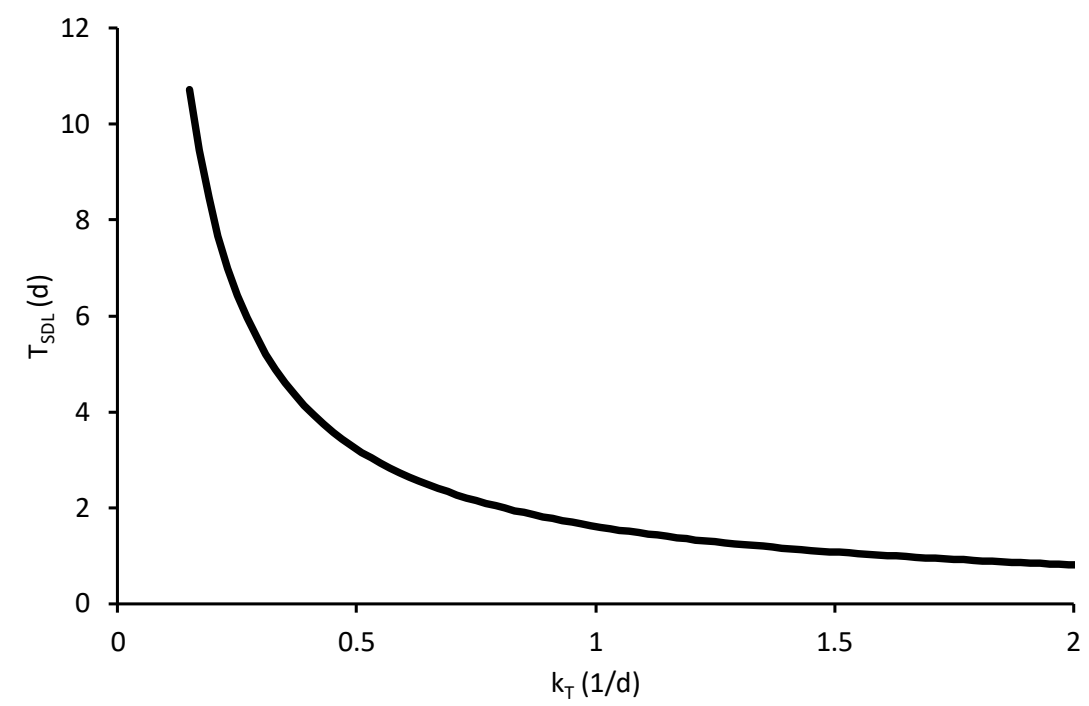

Fig 3. Required depuration time $T_{S D L}(d)$ as function of the total elimination rate constant $k_{T}$ $(1 / \mathrm{d})$. The geosmin concentration at the start of the depuration process $C_{F(t=0)}=25 \mu \mathrm{g} / \mathrm{kg}$. The human sensory detection limit for geosmin in fish $\mathrm{CSDL}_{\mathrm{SL}}=5 \mu \mathrm{g} / \mathrm{kg}$.

The equation can then be rewritten into an equation for the time required to reach the sensory detection limit $\left(T_{S D L}\right)$ as a function of the geosmin concentration in the fish at the start of the depuration process $\left(C_{F(t=0)}\right)$, the targeted concentration $C_{S D L}$ and the total elimination rate constant $\left(k_{T}\right)$ as follows:

$T_{S D L}=\frac{1}{k_{T}} \operatorname{Ln} C_{F(t=0)}-\frac{1}{k_{T}} \operatorname{Ln} C_{S D L}$

Note that this equation assumes the water to remain free of geosmin throughout the depuration process. This equation allows for exploration of the effects of initial geosmin levels in the fish, sensory detection limits and elimination rate on required depuration time. A reasonable estimate for the elimination rate constant should be available, e.g. from experimental data. Figures 1 to 3 illustrate the effects of the geosmin concentrations at the start of the depuration process, the targeted concentration and the total elimination rate constant. It then appears that for a given initial geosmin level in the fish and total elimination rate constant, the required depuration time increases exponentially as the sensory detection limit (the targeted concentration) decreases (Fig. 1). This shows that successful depuration is more difficult for fish species with low sensory thresholds and for more critical human consumers. It also appears that for a given sensory detection limit and total elimination rate constant, the required depuration time shows a In-linear increase with the initial geosmin concentration in the fish (Fig. 2). This underlines the importance of preventing geosmin bioconcentration as much as possible during fish growth to market weight. The required 
depuration time decreases exponentially with increasing total elimination rate (Fig 3 ). This underlines the potential effect of increasing the elimination rate to minimize depuration time.

\subsection{Additional recommendations for future research}

Geosmin analysis

The methods for geosmin analysis in water and tissue samples used in this thesis were internally validated according to NEN7777 (anonymous, 2011) specifications. The extended measurement uncertainty was determined at $28 \%$ for samples with a low geosmin spike and $26 \%$ for samples with a high geosmin spike. The extended measurement uncertainty quantifies the deviation of the results of concentration measurements from true concentrations in samples. The true value of a geosmin concentration lies within the range of the measured concentration \pm half the extended measurement uncertainty. For example, if a sample analysis results in a geosmin concentration of $25 \mathrm{ng} / \mathrm{g}$, the true concentration lies in the range of $21.5-28.5 \mathrm{ng} / \mathrm{g}$. The consistent addition to all samples of an internal standard (D5-geosmin) with identical behaviour as the analyte provided quality assurance. The quality characteristics of our methods for geosmin analysis are in line with other mass spectrometry methods for other organic compounds employed in our laboratory. Although the analytical quality certainly is acceptable according to NEN7777, it is clear that uncertainty and thus potential variability around the measurements is higher than for example the mass of a fish measured on a balance. Clearly, one should not expect that determining the geosmin concentration in a fish and the mass of the fish are equally accurate. This means that the resolution of the geosmin concentration measurement, i.e., the ability to detect differences, is lower. It is then more difficult to detect small treatment effects, especially when background levels of geosmin are low. Experimental designs should take this into account by aiming for high background geosmin levels and treatment effects that are larger than half of the extended measurement uncertainty. In this thesis we attributed the absence of significant treatment effects in a few cases to analytical variability rather than actual absence of the effect, e.g. in case of the geosmin elimination from muscle tissue by fed and starved Nile tilapia (Chapter 6), but also the absence temperature effects on geosmin excretion by European eel (Chapter 3) and Atlantic salmon (Chapter 5). Clearly further improvement of analytical quality is needed to investigate the more subtle aspects of geosmin bioconcentration but also e.g. microbial geosmin production and geosmin removal from water. Fortunately progress is to be expected with the advancement of analytical equipment. The recent commissioning of a new triple quadrupole mass spectrometer in our laboratory and the following switch to MS/MS have led to a reduction of the repeatability of geosmin analysis from 9.8 to $4 \%$. The repeatability according to NEN7777 (anonymous, 2011) is defined here as the deviation among the results of eight repeated analyses of the same sample. 
Unfortunately costs per sample are high for geosmin analysis in water and tissues and this may limit the number of samples that can be analyzed within a research project. Research may then be restricted to relatively simple experimental designs with few replicates, treatment groups, tissue samples or sampling points in time. Fish samples may be pooled and limited to whole fish or fillets to reduce the number of samples, while geosmin analysis in multiple tissues of individual fish would lead to more rapid advancement of the research field. Also the considerable individual within species variation in geosmin bioconcentration that probably exists, remains undetected in pooled samples. Clearly the high costs per sample hamper progress of research on geosmin off-flavours in fish. Unfortunately cost reduction is unlikely. The costs per sample are high because the sample preparation and analysis is complex, labour intensive and requires a well-equipped laboratory and highly skilled staff. The relatively low demand for geosmin analysis hinders the development of lower costs routine analyses.

High costs per sample also restrict access of fish farmers to geosmin analysis in samples from their farms. As a result, data on geosmin levels in commercially operated aquaculture systems are scarce. The complexity of the method makes that considerable time passes, often days, between sample collection and availability of the measurement results, while commercial operations may look for more real-time information. This leads to another recommendation for future research: the development of quick and cheap methods for geosmin analysis in water and fish that can be applied at the farm and does not require extensive laboratory facilities. Obviously such methods would give less accurate results but for indicative tests this is acceptable. Aquaculture operations confronted with off-flavour issues would certainly benefit from the availability of a "geosmin test-kit". This would allow for semi real-time monitoring of geosmin levels and prediction of geosmin spells. Also, it would aid the management of off-flavour depuration processes. Insight in off-flavour intensity at the start of the process would allow for predicting to some extent the required depuration time while progress towards sufficient off-flavour elimination can be monitored. Use of semi-quantitative sensory analytical tools is probably within easiest reach. Sensory analysis may be applied to both water and fish samples. Water samples may require a concentration step using for example a passive sampler for which geosmin has a high affinity. The development and installation of on-farm sensory test panels is highly recommended.

\section{2-methylisoborneol (MIB)}

Earthy/musty off-flavours in fish are predominantly caused by geosmin and 2methylisoborneol (MIB). Most studies on off-flavour simultaneously address both chemicals. This thesis however focused on geosmin, a decision based on the much better results of the internal validation of the analytical method obtained for geosmin. The two chemicals have 
comparable lipophilic properties and it is therefore likely that the findings of this thesis also apply to MIB. However, some aspects of bioconcentration may vary between the two chemicals with potentially large effects on off-flavour management. For example the presence and role of biotransformation may differ, and this should be verified in future studies.

\subsection{Concluding remarks}

The experimental work conducted in this thesis leads to the following conclusions regarding the bioconcentration of geosmin in fish:

- Rainbow trout bioconcentrates waterborne geosmin, but in vivo bioconcentration is less than the general fish bioconcentration model for moderately lipophilic compounds predicts based on theoretical rate constants.

- Geosmin distribution within the body of rainbow trout and Nile tilapia is not exclusively governed by the lipid content of tissues/organs.

- Geosmin depuration from European eel is not affected by the water renewal rate of depuration tanks.

- Geosmin depuration from Atlantic salmon is enhanced by increased water renewal rate of depuration tanks.

- Geosmin elimination from European eel seems does not follow the generally accepted passive diffusion mechanism for excretion of lipophilic chemicals. We assume that geosmin biotransformation by the eel is probable.

- Exercise (swimming) enhances geosmin excretion by European eel and reduces the time required to depurate off-flavours from fish.

- Fed Nile tilapia eliminate geosmin faster from their ovaries compared to starved fish.

- The rate of geosmin elimination from muscle tissue and ovary is similar in Nile tilapia.

This thesis shows that there is more to geosmin bioconcentration in fish than passive partitioning over water and lipid compartments. The physiology underlying the bioconcentration process remains to be fully elucidated. Yet this thesis presents various measures for the optimization of off-flavour depuration processes that can be readily adopted by the aquaculture industry. 
Appendices 


\section{References}

Ando, A., Miwa, M., Kajino, M., Tatsumi, S., 1992. Removal of musty-odorous compounds in water and retained in algal cells through water purification processes. Water Science and Technology 25(2), 299-306.

Anonymous, 2011. NEN7777 Environment and food - Performance characteristics of measurement methods.

Arnot, J.A., Gobas, F.A., 2006. A review of bioconcentration factor (BCF) and bioaccumulation factor (BAF) assessments for organic chemicals in aquatic organisms. Environmental Reviews 14(4), 257-297.

Aschner, M., 1969. Off-flavors in carp from fish ponds in the coastal plain and the Galil. Bamidgeh 19, 23-25.

Auffret, M., Pilote, A., Proulx, É., Proulx, D., Vandenberg, G., Villemur, R., 2011. Establishment of a real-time PCR method for quantification of geosmin-producing Streptomyces spp. in recirculating aquaculture systems. Water research 45(20), 6753-6762.

Azaria, S., Nir, S., van Rijn, J., 2017. Combined adsorption and degradation of the off-flavor compound 2methylisoborneol in sludge derived from a recirculating aquaculture system. Chemosphere 169, 69-77.

Azaria, S., Post, A.F., van Rijn, J., 2020. Changes in the Bacterial Community Structure of Denitrifying Sludge from a Recirculating Aquaculture System (RAS) After Geosmin and 2-Methylisoborneol Enrichment. Current Microbiology 77(3), 353-360.

Azaria, S., van Rijn, J., 2018. Off-flavor compounds in recirculating aquaculture systems (RAS): Production and removal processes. Aquacultural Engineering 83, 57-64.

Blewett, T.A., Robertson, L.M., MacLatchy, D.L., Wood, C., 2013. Impact of environmental oxygen, exercise, salinity and metabolic rate on the uptake and tissue-specific distribution of $17 \alpha$-ethynylestradiol in the euryhaline teleost Fundulus heteroclitus. Aquatic Toxicology 138-139, 43-51.

Bligh, E.G., Dyer, W. J., 1959. A rapid method of total lipid extraction and purification. Canadian Journal of Biochemistry and Physiology 37(8), 911-917.

Brauner, C.J., Randall, D.J., Neuman, J.F., Thurston, R.V., 1994. The effect of exposure to 1,2,4,5tetrachlorobenzene and the relationship between toxicant and oxygen uptake in rainbow trout (Oncorhynchus mykiss) during exercise. Environmental toxicology and chemistry 13 (11), 1813-1820.

Braunbeck, T., Völkl, A., 1991. Induction of biotransformation in the liver of eel (Anguilla anguilla L.) by sublethal exposure to dinitro-o-cresol: an ultrastructural and biochemical study. Ecotoxicology and environmental safety $21(2), 109-127$.

Brett, J.R., 1964 The respiratory metabolism and swimming performance of young sockeye salmon J. Fish. Res. Board. Can. 21, 1183-1226.

Brett, J.R., Glass, N.R., 1973. Metabolic rates and critical swimming speeds of sockeye salmon (Oncorhynchus nerka) in relation to size and temperature J. Fish. Res. Board. Can. 30, 379-387.

Brinkmann, M., Eichbaum, K., Kammann, U., Hudjetz, S., Cofalla, C., Buchinger, S., Reifferscheid, G., Schuttrumpf, H., Preuss, T., Hollert, H., 2014. Physiologically-based toxicokinetic models help identifying the key factors affecting contaminant uptake during flood events. Aquatic toxicology 152, 38-46.

Burgerhout, E., Tudorrache, C., Brittijn, S.A., Palstra, A.P., Dirks, R.P., van den Thillart, G.E.E.J.M., 2013. Schooling reduces energy consumption in swimming male European eels, Anguilla anguilla L. J. Exp. Mar. Biol. Ecol. 448, $66-71$.

Burr, G.S., Wolters, W.R., Schrader, K.K., Summerfelt, S.T., 2012. Impact of depuration of earthy-musty off-flavors on fillet quality of Atlantic salmon, Salmo salar, cultured in a recirculating aquaculture system. Aquacultural Engineering 50, 28-36.

Chater, K.F., 2015. The smell of the soil. Microbiology Today, 66. 
Clark, K.E., Gobas, A.P.C., Mackay, D., 1990. Model of the organic chemical uptake and clearance by fish from food and water. Environmental Science and Technology 24 1203-1213.

Clarke, D.J., George, S.G., Burchell, B., 1991. Glucuronidation in fish. Aquatic Toxicology 20, 35-56.

Cook, D., Newcombe, G., 2004. Can we predict the removal of MIB and geosmin with PAC by using water quality parameters? Water Science and Technology: Water Supply 4(4), 221-226.

Cook, D., Newcombe, G., Sztajnbok, P., 2001. The application of powdered activated carbon for MIB and geosmin removal: predicting PAC doses in four raw waters. Water Research 35(5), 1325-1333.

Darriet P., Pons M., Lamy S., Dubourdieu D., 2000. Identification and quantification of geosmin, an earthy odorant contaminating wines. J. Agric. Food Chem. 48, 4835-4838.

Davidson, J., Schrader, K., Ruan, E., Swift, B., Aalhus, J., Juarez, M., Wolters, W., Burr, G., Good, C., Summerfelt, S.T., 2014. Evaluation of depuration procedures to mitigate the off-flavor compounds geosmin and 2methylisoborneol from Atlantic salmon Salmo salar raised to market-size in recirculating aquaculture systems. Aquacultural engineering 61, 27-34.

Davidson, J., Grimm, C., Summerfelt, S., Fischer, G. and Good, C., 2020. Depuration system flushing rate affects geosmin removal from market-size Atlantic salmon Salmo salar. Aquacultural Engineering 90, 102-104.

De Boer, J., 1988. Chlorobiphenyls in bound and non-bound lipids of fishes; comparison of different extraction methods. Chemosphere 17, 1803-1810.

De Boer, J., van der Valk, F., Kerkhoff, M.A.T., Hagel, P., Brinkman, U.A.Th., 1994. An 8-year study on the elimination of PCBs and other organochlorine compounds from eel (Anguilla anguilla) under natural conditions. Environ. Sci. Technol. 28 (13), 2242-2248.

De Boer, J., Hagel, P., 1994. Spatial differences and temporal trends of chlorobiphenyls in yellow eel (Anguilla anguilla) from inland waters of the Netherlands. Science of the Total Environment 141(1-3), 155-174.

Dickschat, J.S., Bode, H.B., Mahmud, T., Müller, R., Schulz, S., 2005. A novel type of geosmin biosynthesis in myxobacteria. The Journal of organic chemistry 70(13), 5174-5182.

Dionigi, C.P., 1993. Physiological strategies to control geosmin synthesis in channel catfish aquaculture systems. ACS symposium series.

Dionigi, C.P., Johnsen, P.B., Vinyard, B.T., 2000. The recovery of flavor quality by channel catfish. North American Journal of Aquaculture 62(3), 189-194.

Durrer, M., Zimmermann, U., Jüttner, F., 1999. Dissolved and particle-bound geosmin in a mesotrophic lake (Lake Zürich): spatial and seasonal distribution and the effect of grazers. Water Research 33(17), 3628-3636.

Eding, E.H., van Weerd, J.H., 1999. Grundlagen, aufbau und management von kreislaufanlagen, DLGVerlagsgesellschaft-GmbH, Frankfurt, Germany

Engle, C.R., Pounds, G.L., Van der Ploeg, M., 1995. The cost of off-flavor. Journal of the World Aquaculture Society 26(3), 297-306.

Erickson, R.J., McKim, J.M., 1990. A model for exchange of organic chemicals at fish gills: flow and diffusion limitations. Aquatic toxicology 18(4), 175-197.

Figueiredo-Silva, A., Saravanan, S., Schrama, J., Panserat, S., Kaushik, S., Geurden, I., 2013. A comparative study of the metabolic response in rainbow trout and Nile tilapia to changes in dietary macronutrient composition. British Journal of Nutrition 109(5), 816-826.

Gonçalves, A.A., Gagnon, G.A., 2011. Ozone application in recirculating aquaculture system: an overview. Ozone: Science \& Engineering 33(5), 345-367. 
Hathurusingha, P.I., Davey, K.R., 2014. A predictive model for taste taint accumulation in Recirculating Aquaculture Systems (RAS) farmed-fish-demonstrated with geosmin (GSM) and 2-methylisoborneol (MIB). Ecological modelling 291, 242-249.

Jandacek, R.J., Tso, P., 2001. Factors affecting the storage and excretion of toxic lipophilic xenobiotics. Lipids 36(12), 1289-1305.

Jankowska, B., Kwiatkowska, A., Kolman, R., 2002. A comparison of certain characteristics of meat of the Siberian sturgeon (Acipenser baeri Brandt) and that of its hybrid with the green sturgeon (A. medirostris Ayres). Electronic journal of the Polish agricultural universities, Fisheries 5 (1).

Jobling, M., 1981. The influences of feeding on the metabolic rate of fishes: a short review. Journal of fish biology 18(4), 385-400.

From, J., Hørlyck, V., 1984. Sites of uptake of geosmin, a cause of earthy-flavor in rainbow trout (Salmo gairdneri). Canadian Journal of Fisheries and Aquatic Sciences 41, 1224-1226.

Gerber, N.N., Lechevalier, H.A., 1965. Geosmin, an earthy-smelling substance isolated from actinomycetes. Applied microbiology 13(6), 935-938.

Gobas, F.A.P.C., MacKay, D., 1987. Dynamics of hydrophobic organic chemical bioconcentration in fish. Environmental Toxicology and Chemistry 6, 495-504.

Guttman, L., van Rijn, J., 2009. 2-Methylisoborneol and geosmin uptake by organic sludge derived from a recirculating aquaculture system. Water research 43(2), 474-480.

Ho, L., Hoefel, D., Bock, F., Saint, C.P., Newcombe, G., 2007. Biodegradation rates of 2-methylisoborneol (MIB) and geosmin through sand filters and in bioreactors. Chemosphere 66(11), 2210-2218.

Houle, S., Schrader, K.K., Le François, N.R., Comeau, Y., Kharoune, M., Summerfelt, S.T., Savoie, A., Vandenberg, G.W., 2011. Geosmin causes off-flavour in arctic charr in recirculating aquaculture systems. Aquaculture Research 42(3), 360-365.

Howgate, P., 2004. Tainting of farmed fish by geosmin and 2-methyl-iso-borneol: a review of sensory aspects and of uptake/depuration. Aquaculture 234(1-4), 155-181.

Hughes, G.M., Albers, C. Muster, D., Gotz, K.H., 1983. Respiration of the carp, Cyprinus carpio L, at 10 and $20^{\circ} \mathrm{C}$ and the effects of hypoxia. J. Fish. Biol.22, 613-628.

Jakoby, W.B., Ziegler, D.M., 1990. The enzymes of detoxification. The journal of biological chemistry 265 (34), 20715-20718.

Jeleń, H.H., Majcher, M., Zawirska-Wojtasiak, R., Wiewiórowska, M., Wasowicz, E.R.W.I.N., 2003. Determination of geosmin, 2-methylisoborneol, and a musty-earthy odor in wheat grain by SPME-GC-MS, profiling volatiles, and sensory analysis. Journal of Agricultural and food Chemistry 51(24), 7079-7085.

Johnsen, P.B., Lloyd, S.W., Vinyard, B.T., Dionigi, C.P., 1996. Effects of Temperature on the Uptake and Depuration of 2-Methylisoborneol (MIB) in Channel Catfish Ictalurus punctatus. Journal of the World Aquaculture Society 27(1), 15-20.

Jüttner, F., Watson, S.B., 2007. Biochemical and ecological control of geosmin and 2-methylisoborneol in source waters. Applied and environmental microbiology 73(14), 4395-4406.

Klausen, M.M., Grønborg, O., 2010. Pilot scale testing of advanced oxidation processes for degradation of geosmin and MIB in recirculated aquaculture. Water Science and Technology: Water Supply 10(2), 217-225.

Kleinow, K.M., Melancon, M.J., Lech, J.J., 1987. Biotransformation and induction: Implications for toxicity, bioaccumulation and monitoring of environmental xenobiotics in fish. Environmental health perspectives 71, 105-119. 
Krishnani, K. K., P. Ravichandran, Ayyappa, S., 2008. Microbially derived off-flavor from geosmin and 2methylisoborneol: sources and remediation, Reviews of Environmental Contamination and Toxicology 194, 1-27.

Kutschera, K., Börnick, H., Worch, E., 2009. Photoinitiated oxidation of geosmin and 2-methylisoborneol by irradiation with $254 \mathrm{~nm}$ and $185 \mathrm{~nm}$ UV light. Water Research 43(8), 2224-2232.

Lalezary, S., Pirbazari, M., McGuire, M.J., 1986. Evaluating Activated Carbons for Removing Low Concentrations of Taste-and Odor-Producing Organics. Journal-American Water Works Association 78(11), 76-82.

Lech, J.J., 1974. Glucuronide formation in rainbow trout - effect of salicyl amide on the acute toxicity, conjudation and excretion of trifluormethyl-4-nitrophenol. Toxicol. Appl. Pharmacol. 24, 114-124.

Lech, J.J., Bend, J.R., 1980. Relationschip between biotransformation and the toxicity and fate of xenobiotic chemicals in fish. Environmental health perspectives 34, 115-131.

Legler, J., Jonas, A., Lahr, J., Vethaak, A.D., Brouwer, A. and Murk, A.J., 2002. Biological measurement of estrogenic activity in urine and bile conjugates with the in vitro ER-CALUX reporter gene assay. Environmental Toxicology and Chemistry: An International Journal 21(3), 473-479.

Liato, V., Aïder, M., 2017. Geosmin as a source of the earthy-musty smell in fruits, vegetables and water: Origins, impact on foods and water, and review of the removing techniques. Chemosphere 181, 9-18.

Lindholm-Lehto, P.C., Vielma, J., Pakkanen, H., Alén, R., 2019. Depuration of geosmin-and 2-methylisoborneolinduced off-flavors in recirculating aquaculture system (RAS) farmed European whitefish Coregonus lavaretus. Journal of food science and technology 56(10), 4585-4594.

Lindholm-Lehto, P., Koskela, J., Kaseva, J., Vielma, J., 2020. Accumulation of Geosmin and 2-methylisoborneol in European Whitefish Coregonus Lavaretus and Rainbow Trout Oncorhynchus Mykiss in RAS. Fishes 5(2), 13.

Love, R.M., 1998. Biochemical dynamics and the quality of fresh and frozen fish. In: Hall, G.M. (Ed.), Fish Processing Technology. Chapman \& Hall, London, 1-31.

Lukassen, M.B., 2017. Off-Flavour Producing Bacteria in Aquaculture. Doctoral dissertation, Ph. D. Thesis, Aalborg University, Aalborg, Denmark.

Lukassen, M.B., Podduturi, R., Rohaan, B., Jørgensen, N.O., Nielsen, J.L., 2019. Dynamics of geosmin-producing bacteria in a full-scale saltwater recirculated aquaculture system. Aquaculture 500, 170-177.

Lukassen, M.B., Saunders, A.M., Sindilariu, P.D., Nielsen, J.L., 2017. Quantification of novel geosmin-producing bacteria in aquaculture systems. Aquaculture 479, 304-310.

Mamba, B.B., Krause, R.W., Malefetse, T.J., Mhlanga, S.D., Sithole, S.P., Salipira, K.L., Nxumalo, E.N., 2007. Removal of geosmin and 2-methylisorboneol (2-MIB) in water from Zuikerbosch Treatment Plant (Rand Water) using â-cyclodextrin polyurethanes. Water SA 33(2).

McGill, A.S., Hardy, R., Burt, J.R. Gunstone, F.D., 1974. Hept-cis-4-enal and its contribution to the off-flavour in cold stored cod. Journal of the Science of Food and Agriculture 25(12), 1477-1489.

McKim, J.M., Erickson, R.J., 1991. Environmental impacts on the physiological mechanisms controlling xenobiotic transfer across fish gills. Physiological zoology 64(1), 39-67.

McKim, J.M., Goeden, H.M., 1982. A direct measure of the uptake efficiency of a xenobiotic chemical across the gills of brook trout (Salvelinus fontinalis) under normoxic and hypoxic conditions. Comparative Biochemistry and Physiology Part C: Comparative Pharmacology 72(1), 65-74.

McKim, J., Schmieder, P., Veith, G., 1985. Absorption dynamics of organic chemical transport across trout gills as related to octanol-water partition coefficient. Toxicology and applied pharmacology 77(1), 1-10.

Motohiro, T., 1983. Tainted fish caused by petroleum compounds-A review. Water Science and Technology 15(67), 75-83. 
Mottram, D.S., 1998. Chemical tainting of foods. International journal of food science \& technology 33(1), $19-29$.

Nakajima, M., Ogura, T., Kusama, Y., Iwabuchi, N., Imawaka, T., Araki, A., Sasaki, T., Hirose, E., Sunairi, M., 1996. Inhibitory effects of odor substances, geosmin and 2-methylisoborneol, on early development of sea urchins. Water Research 30(10), 2508-2511.

Nam-Koong, H., Schroeder, J.P., Petrick, G., Schulz, C., 2016. Removal of the off-flavor compounds geosmin and 2-methylisoborneol from recirculating aquaculture system water by ultrasonically induced cavitation. Aquacultural Engineering 70, 73-80.

Neely, W.B., 1979. Estimating rate constants for the uptake and clearance of chemicals by fish. Environmental science \& technology 13(12), 1506-1510.

Nerenberg, R., Rittmann, B.E., Soucie, W.J., 2000. Ozone/biofiltration for removing MIB and geosmin. JournalAmerican Water Works Association 92(12), 85-95.

Nichols, J.W., McKim, J.M., Andersen, M.E., Gargas, M.L., Clewell III, H.J., Erickson, R.J., 1990. A physiologically based toxicokinetic model for the uptake and disposition of waterborne organic chemicals in fish. Toxicology and applied pharmacology 106(3), 433-447.

Nichols, J., Erhardt, S., Dyer, S., James, M., Moore, M., Plotzke, K., Segner, H., Schultz, I., Thomas, K., Vasiluk, L., Weisbrod, A., 2007. Use of In Vitro Absorption, Distribution, Metabolism, and Excretion (ADME) Data in Bioaccumulation Assessments for Fish. Human and Ecological Risk Assessment: An International Journal 13(6), 1164-1191.

Nichols, J.W., Schultz, I.R., Fitzsimmons, P.N., 2006. In vitro-in vivo extrapolation of quantitative hepatic biotransformation data for fish: I. A review of methods, and strategies for incorporating intrinsic clearance estimates into chemical kinetic models. Aquatic toxicology 78(1), 74-90.

OECD, 2012. Test No. 305: Bioaccumulation in Fish: Aqueous and Dietary Exposure, OECD Guidelines for the Testing of Chemicals, Section 3, OECD Publishing.

Ovissipour, M., Al-Qadiri, H.M., Lu, X., Hu, Y., Ross, C.F., Van Eenennaam, J.P., Doroshov, S.I., Rasco B., 2015. The effect of white sturgeon (Acipenser transmontanus) ovarian fat deposition on caviar yield and nutritional quality: introducing image processing method for sturgeon ovary fat determination. Int Aquat Res 7, 263272.

Paasivirta, J., Knuutinen, J., Tarhanen, J., Kuokkanen, T., Surma-Aho, K., Paukku, R., Kääriäinen, H., Lahtiperä, M., Veijanen, A., 1983. Potential off-flavour compounds from chloro-bleaching of pulp and chlorodisinfection of water. Water Science and Technology 15(6-7), 97-104.

Palstra, A.P., Mes' D., Kusters, K., Roques, J.A.C., Flik, G., Kloet, K., Blonk, R.J.W., 2015. Forced sustained swimming exercise at optimal speed enhances growth of yellowtail kingfish (Seriola lalandi). Frontiers Physiology 5, 506.

Persson, P.E., 1980. Sensory properties and analysis of two muddy odour compounds, geosmin and 2methylisoborneol, in water and fish. Water Research 14(8), 1113-1118.

Persson, P.E., 1995. 19th Century and early 20th century studies on aquatic off-flavours-a historical review. Water Science and Technology 31(11), 9-13.

Petersen, M.A., Hyldig, G., Strobel, B.W., Henriksen, N.H., Jørgensen, N.O., 2011. Chemical and sensory quantification of geosmin and 2-methylisoborneol in rainbow trout (Oncorhynchus mykiss) from recirculated aquacultures in relation to concentrations in basin water. Journal of agricultural and food chemistry 59(23), 12561-12568.

Podduturi, R., Petersen, M.A., Vestergaard, M., Jørgensen, N.O., 2020. Geosmin fluctuations and potential hotspots for elevated levels in recirculated aquaculture system (RAS): A case study from pikeperch (Stizostedion lucioperca) production in Denmark. Aquaculture 514, 734501.

Puckett, K.J., Dill, L.M., 1984. Cost of sustained and burst swimming to juvenile coho salmon (Oncorhynchus kisutch) Can. J. Fish. Aquat. Sci. 41, 1546-1551. 
Randall, D.J., Daxboeck, C., 1982. Cardiovascular changes in the rainbow trout (Salmo gairdneri Richardson) during exercise. Canadian Journal of Zoology 60(5), 1135-1140.

Randall, D. J., Holeton, G. F., Stevens, E. D., 1967. The exchange of oxygen and carbon dioxide across the gills of rainbow trout. J. exp. Biol. 46, 339-348.

Randall, D.J., 1982. The control of respiration and circulation in fish during exercise and hypoxia. J. Exp. Biol. 100, 275-288.

Ridgway, K., Lalljie, S.P.D., Smith, R.M., 2010. Analysis of food taints and off-flavours: a review, Food Additives \& Contaminants: Part A 27(2), 146-168.

Robertson, R. F., Hammond, A., Jauncey, K., Beveridge, M.C.M., Lawton, L.A., 2006. An investigation into the occurrence of geosmin responsible for earthy-musty taints in UK farmed rainbow trout. Aquaculture 259(1), 153-163.

Robertson, R.F., Jauncey, K., Beveridge, M.C.M., Lawton, L.A., 2005. Depuration rates and the sensory threshold concentration of geosmin responsible for earthy-musty taint in rainbow trout, Onchorhynchus mykiss. Aquaculture 245(1-4), 89-99.

Robin, J., Cravedi, J.P., Hillenweck, A., Deshayes, C., Vallod, D., 2006. Off flavor characterization and origin in French trout farming. Aquaculture 260(1-4), 128-138.

Rogers, I.H., 1978. Environmental effects of terpenoid chemicals: a review. Journal of the American Oil Chemists' Society 55(2), A113-A118.

Rosenfeldt, E.J., Melcher, B., Linden, K.G., 2005. UV and UV/H2O2 treatment of methylisoborneol (MIB) and geosmin in water. Journal of Water Supply: Research and Technology-AQUA 54(7), 423-434.

Rurangwa, E., Verdegem, M.C., 2015. Microorganisms in recirculating aquaculture systems and their management. Reviews in aquaculture 7(2), 117-130.

Saravanan, S., Geurden, I., Figueiredo-Silva, A.C., Kaushik, S., Verreth, J., Schrama, J.W., 2013. Voluntary feed intake in rainbow trout is regulated by diet-induced differences in oxygen use. The Journal of nutrition 143(6), 781-787.

Saunders, A.M., Sindilariu, P.D., Nielsen, P.H. and Nielsen, J.L., 2011. Novel Diversity Of Putative Geosminproducing Bacteria in Freshwater Aquaculture. In FEMS.

Schmieder, P.K., Henry T.R., 1988. Plasma-binding of 1-butanol, phenol, nitrobenzene and pentachlorophenol in the rainbow trout and rat - a comparative study. Comparative biochemistry and physiology C pharmacology, toxicology \& endocrinology 91 (2), 413-418.

Schmieder, P.K., Weber, L.J., 1992. Blood and water flow limitations on gill uptake of organic chemicals in the rainbow trout (Onchorynchus mykiss). Aquatic Toxicology 24(1-2), 103-121.

Schlenk, D., DeBusk, B., Perkins, E.J., 2000. 2-Methylisoborneol disposition in three strains of catfish: absence of biotransformation. Fish Physiology and Biochemistry 23(3), 225-232.

Schrader, K.K., Davidson, J.W., Rimando, A.M., Summerfelt, S.T., 2010. Evaluation of ozonation on levels of the off-flavor compounds geosmin and 2-methylisoborneol in water and rainbow trout Oncorhynchus mykiss from recirculating aquaculture systems. Aquacultural engineering 43(2), 46-50

Schram, E., Pedrero, Z., Cámara, C., Van Der Heul, J.W., Luten, J.B., 2008. Enrichment of African catfish with functional selenium originating from garlic. Aquaculture Research 39(8), 850-860.

Schram, E., Schelvis-Smit, R.A.A.M., Van der Heul, J.W., Luten, J.B., 2010. Enrichment of the African catfish Clarias gariepinus (Burchell) with functional selenium originating from garlic: effect of enrichment period and depuration on total selenium level and sensory properties. Aquaculture Research 41 (6), 793-803.

Schram, E., Schrama, J., Kusters, K., Kwadijk, C.J.A.F., Palstra, A., 2016. Effects of exercise and temperature on geosmin excretion by European eel (Anguilla anguilla). Aquaculture 451, 390-395. 
Schram, E., Schrama, J.W., van Kooten, T., Kwadijk, C.J.A.F., Kampen, H., van de Heul, J.W., Verreth, J.A.J., Murk, A.J., 2018. Experimental validation of geosmin uptake in rainbow trout, Oncorhynchus mykiss (Waldbaum) suggests biotransformation. Aquaculture Research 49 (2), 668-675.

Schram, E., van Kooten, T., van de Heul, J. W., Schrama, J. W., Verreth, J. A. J., Murk, A. J., 2017, Geosmin depuration from European eel (Anguilla anguilla) is not affected by the water renewal rate of depuration tanks. Aquaculture Research 48, 4646-4655

Schram, E., Verdegem, M.C.J., Widjaja, R.T.O.B.H., Kloet, C.J., Foss, A., Schelvis-Smit, R., Roth, B., Imsland, A.K., 2009. Impact of increased flow rate on specific growth rate of juvenile turbot (Scophthalmus maximus, Rafinesque 1810). Aquaculture 292 (1-2), 46-52.

Schultz, I.R., Hayton, W.L., 1999. Interspecies scaling of the bioaccumulation of lipophilic xenobiotics in fish: an example using trifluralin. Environmental toxicology and chemistry 18(7), 1440-1449.

Sheridan, M.A., 1988. Lipid dynamics in fish: aspects of absorption, transportation, deposition and mobilization. Comparative Biochemistry and Physiology Part B: Comparative Biochemistry 90 (4), 679-690.

Sijm, D.T.H.M., Opperhuizen, A., 1989. Biotransformation of Organic Chemicals by Fish: Enzyme Activities and Reactions. The handbook of environmental chemistry, 2/2E Reactions and processes, 163-235, Springer Berlin Heidelberg.

Spindler-Vomachka, M.J., Vodicnik, M.J., Lech, J.J., 1984. Transport of 2,4,5,2',4',5'-hexachlorobiphenyl by lipoproteins in vivo. Toxicology and applied pharmacology 74(1), 70-77.

Srinivasan, R., Sorial, G.A., 2011. Treatment of taste and odor causing compounds 2-methyl isoborneol and geosmin in drinking water: A critical review. Journal of Environmental Sciences, 23(1), 1-13.

Streit, B., 1998. Bioaccumulation of contaminants in fish. In: Braunbeck, T., Hinton, D.E., Streit, B. (Eds.), Fish Ecotoxicology (EXS: 86) Birkhauser, Basel, 353-387.

Streit, B., Siré, E.O., 1993. On the role of blood proteins for uptake, distribution, and clearance of waterborne lipophilic xenobiotics by fish: A linear system analysis. Chemosphere 26 (6), 1031-1039.

Suffet, I.H., Corado, A., Chou, D., McGuire, M.J., Butterworth, S., 1996. AWWA taste and odor survey. JournalAmerican Water Works Association 88(4), 168-180.

Summerfelt, S.T., 2003. Ozonation and UV irradiation-an introduction and examples of current applications. Aquacultural engineering 28(1-2), 21-36.

Suurnäkki, S., Gomez-Saez, G.V., Rantala-Ylinen, A., Jokela, J., Fewer,D.P, Sivonen, K., 2015. Identification of geosmin and 2-methylisoborneol in cyanobacteria and molecular detection methods for the producers of these compounds. Water Research 68, 56-66.

Thaysen, A.C., 1936. The Origin of an Earthy or Muddy Taint in Fish: I. The Nature and Isolation of the Taint. Annals of applied Biology 23(1), 99-104.

Tucker, C.S., Van der Ploeg, M., 1999. Managing off-flavor problems in pond-raised catfish. Stoneville, MS: Southern Regional Aquaculture Center.

Tucker, C.S., 2000. Off-flavor problems in aquaculture. Reviews in Fisheries Science 8(1), 45-88.

Vaccaro, A.M., Buffa, G., Messina, C.M., Santulli, A., Mazzola, A., 2005. Fatty acid composition of a cultured sturgeon hybrid (Acipenser naccarii $\times$ A. baerii). Food Chemistry 93 (4), 627-631.

Van den Thillart, G., van Ginneken, V., Körner, F., Heijmans, R., Van Der Linden, R., Gluvers, A., 2004. Endurance swimming of European eel. Journal of Fish Biology 65, 312-318.

Van der Oost, R., Heida, H., Satumalay, K., van Schooten, F.J., Ariese, F., Vermeulen, N.P., 1994. Bioaccumulation, biotransformation and DNA binding of PAHs in feral eel (Anguilla anguilla) exposed to polluted sediments: a field survey. Environmental Toxicology and Chemistry: An International Journal 13(6), 859-870. 
Vallod, D., Cravedi, J.P., Hillenweck, A., Robin, J., 2007. Analysis of the off-flavor risk in carp production in ponds in Dombes and Forez (France). Aquaculture International 15(3-4), 287-298.

Watson, S.B., Brownlee, B., Satchwill, T., Hargesheimer, E.E., 2000. Quantitative analysis of trace levels of geosmin and MIB in source and drinking water using headspace SPME. Water Research 34(10), 2818-2828.

Watson, S.B., 2003. Cyanobacterial and eukaryotic algal odour compounds: signals or by-products? A review of their biological activity, Phycologia 42(4), 332-350.

Wee, L,H., Janssens, N., Vercammen, J., Tamaraschi, L., Thomassen, L.C. J., Martens, J. A., 2015. Stable TiO2 USY zeolite composite coatings for efficient adsorptive and photocatalytic elimination of geosmin from water. J. Mater. Chem. A 3(5), 2258-2264.

Westerhoff, P., Nalinakumari, B., Pei, P., 2006. Kinetics of MIB and geosmin oxidation during ozonation. Ozone: science \& engineering 28(5), 277-286.

Whitfield, F.B., 1998. Microbiology of food taints. International journal of food science \& technology 33(1), 3151.

Whitfield, F.B., 1999. Biological origins of off-flavours in fish and crustaceans. Water science and technology 40(6), 265-272.

Wieser, W. Forstner, H., 1986. Effects of temperature and size on the routine rate of oxygen consumption and on the relative scope for activity in larval cyprinids. J. Comp. Physiol. B 156, 791-796.

Yang, R., Brauner, C., Thurston, V., Neuman, J., Randall, D.J., 2000. Relationships between toxicant transfer kinetic processes and fish oxygen consumption. Aquatic toxicology 48, 95-108.

Yamin, G., Borisover, M., Cohen, E., van Rijn, J., 2017. Accumulation of humic-like and proteinaceous dissolved organic matter in zero-discharge aquaculture systems as revealed by fluorescence EEM spectroscopy. Water research 108, 412-421.

Zimba, P.V., Schrader, K.K., Hyldig, G., Strobel, B.W., Jorgensen, N.O., 2012. Evaluation of geosmin and 2methylisoborneol off-flavour in smoked rainbow trout fillets using instrumental and sensory analyses. Aquaculture Research 43(1), 149-153. 


\section{Summary}

Off-flavour described as 'earthy-musty' is commonly reported in fish raised in land-based aquaculture systems. Off-flavour is attributed to various compounds produced by microbiota in these aquaculture systems of which 2-methylisoborneol (MIB) and geosmin are the most important. Because of their lipophilic nature waterborne geosmin and MIB are bioconcentrated in the lipid tissues of the exposed fish. When bioconcentration leads to levels in the fish above the human sensory detection thresholds, the fish are off-flavoured.

Despite off-flavour in fish is extensively studied and a well-documented problem, satisfactory solutions are lacking. The most promising solution on a short notice is the optimization of the removal of off-flavour chemicals from fish prior to harvest, i.e., the off-flavour depuration process. In this process, fish farmers remove off-flavour chemicals from their fish by using the reversibility of the bioconcentration process. Fish are kept in clean water until levels of the off-flavour chemical have declined below their human sensory detection thresholds. This depuration process however is not always effective nor reliable. Hence, further optimization is needed to prevent market entrance of off-flavoured fish.

The practical objective of this thesis was to improve off-flavour depuration processes, with a focus on geosmin excretion. The current theoretical model for geosmin bioconcentration in fish relies heavily on knowledge on other similarly lipophilic chemicals and a general fish bioaccumulation model. Whether this general model correctly describes geosmin uptake and excretion by fish has not been experimentally validated. Using the current theoretical model as a starting point, it can be deduced that there are two basic mechanisms to speed-up geosmin elimination from the fish and thereby reduce the required depuration time: 1 . measures aimed at the rate at which geosmin is excreted by the fish, and 2. measures aimed at the rate at which excreted geosmin is removed from the direct environment of the fish. The first mechanism centres around gill ventilation rate as excretion from blood to water is believed to be water flow limited. The second mechanism is based on prevention of reabsorption of excreted geosmin and maintaining the concentration gradient between water and fish; the driving force behind excretion. This led to the following objectives of this thesis:

1. To experimentally validate the current theoretical model for the uptake of geosmin in fish.

2. To experimentally validate the hypothesis that geosmin is distributed over tissues based on the lipid content of tissues.

3. To extent the current theoretical model such that it can be applied to systems in which geosmin levels vary due to uptake or excretion and system management. 
4. To predict the effects of measures aimed at increasing the rate at which fish excrete geosmin, and those aimed at increasing the rate at which geosmin is removed from the depuration tank, and their interactions.

5. To experimentally validate the effects of measures aimed at the rate at which fish excrete geosmin, of measures aimed at the rate at which geosmin is removed from the depuration tank, and their interactions.

To test the hypothesis that the theoretical model with calculated uptake and excretion rate constants correctly describes the uptake of geosmin in fish, the bioconcentration of waterborne geosmin in rainbow trout was assessed (Chapter 2). Because the experiment was conducted in stagnant water, geosmin uptake in the fish was predicted to result in a decline of geosmin in the water. The current theoretical model assumes constant geosmin levels in water and was therefore extended such that it accounted for the predicted decline. In the experiment fifty rainbow trout with a mean (SD) weight of 226.6 (29.0) $g$ and lipid content of $6.2(0.6) \%(w / w)$ were exposed to geosmin in static water for $0,2,4,6,8,12,24,36,48$ and $120 \mathrm{~h}$, with one tank containing five fish for each exposure period. Geosmin concentrations were measured in fish tissue and water samples collected over time. With time the geosmin concentration in the fish increased and decreased in the water. However the total absolute amount of geosmin in the system declined over time which could be explained by biotransformation. A biotransformation term was therefore added to the extended model. The observed decrease in lipid normalized geosmin levels in the liver compared to the liverfree carcass is in accordance with the presence of biotransformation. The same study also assessed geosmin and lipid levels of tissues. This made clear that geosmin distribution within rainbow trout is not exclusively governed by the lipid content of tissues. Overall, it was concluded that in vivo geosmin bioconcentration in rainbow trout is slower and the body burden reached is lower than the generally accepted theoretical model predicts.

To increase the rate at which fish excrete geosmin, effects of exercise and temperature were tested in European eel (Chapter 3) and effects of feeding during off-flavour depuration were tested in Nile tilapia (Chapter 6). European eels loaded with geosmin were depurated for $23 \mathrm{~h}$ during which they were subjected to combinations of exercise (spontaneous swimming activity at $0.05 \mathrm{~m} / \mathrm{s}$ or forced swimming at optimal swimming speed of $0.55 \mathrm{~m} / \mathrm{s}$ ) and temperature $\left(15{ }^{\circ} \mathrm{C}\right.$ or $\left.25{ }^{\circ} \mathrm{C}\right)$ treatments. Oxygen consumption was measured during depuration. Whole body geosmin concentrations were measured in samples collected at $t=0$ and $t=23 \mathrm{~h}$ to assess geosmin excretion. Geosmin excretion by European eel was clearly enhanced by exercise, but temperature had no statistically significant effect. Exercise increased oxygen consumption, which in turn showed a positive linear relation with geosmin excretion. These findings support the idea that the physiological responses aimed at increasing oxygen uptake also affect the branchial exchange of lipophilic xenobiotic chemicals 
between the fish and its surroundings. It was concluded that exercise can be used to reduce the time required to depurate off-flavours from fish.

The effect of feeding during off-flavour depuration on the elimination of geosmin from muscle tissue (fillet) and ovaries as a model for caviar was assessed in Nile tilapia (Oreochromis niloticus) (mean (SD) weight of 185 (15.0) g). The experiment had a 2x4 factorial design with feeding level (starved or fed) and depuration time (24, 48, 72 and 96 h) as factors with duplicates for each of the eight treatment combinations. Fish were normally loaded with geosmin prior to the experiment. During off-flavour depuration geosmin levels in fillet and ovary declined over time in both fed and starved tilapia. In fed tilapia geosmin declined faster from the ovaries compared to starved fish. The same trend of a faster decline was observed for the muscle tissue (fillets) of fed tilapia, though only numerically. Because faster geosmin elimination paralleled with high blood lipids, it cannot be ruled out that blood lipids are involved in geosmin transport via the circulatory system and that low blood lipid levels are limiting geosmin elimination in starved fish. No difference in geosmin elimination rate was detected between ovary and muscle tissue in Nile tilapia. It was concluded that off-flavour depuration time is strongly reduced when farmers adopt a practice of feeding Nile tilapia during off-flavour depuration.

To experimentally validate the effect of the rate at which geosmin is removed from the depuration tank on geosmin excretion, different water renewal rates of depuration tanks were tested with European eel loaded with geosmin (Chapter 4). It was hypothesized that increased water renewal rate promotes geosmin excretion by fish. To predict these effects, the theoretical model was further extended with terms that account for effects of tank water renewal rate and systems losses of chemicals. In accordance with the hypothesis, strong effects of the water renewal rate of depuration tanks on geosmin excretion were predicted. These model predictions were validated in a depuration experiment with geosmin loaded European eel $(n=95)$ with a mean (SD) individual weight $134.4(5.0) \mathrm{g}$ and a mean (SD) lipid content 33.7 (2.8)\% (w/w). Fish were depurated for 24,48 or $72 \mathrm{~h}$ at three different tank water renewal rates $(0.3,3.3$ and $331 / \mathrm{d})$. Treatments were installed by three different mean (SD) water flow rates (13.8 (1.3), 143.5 (9.2) and 1511 (80) l/kg fish/d) over 30 I tanks. Surprisingly, the experiment established that geosmin depuration from European eel is not affected by the water renewal rate of depuration tanks. Eels eliminated geosmin from their bodies but unlike the model predicted, this was independent of the water renewal rate of the depuration tanks. Although being eliminated from the fish, geosmin hardly appeared and certainly did not accumulate in the water of the depuration tanks as the model predicted. This observation may be explained by geosmin being eliminated from eel as metabolite rather than the parent compound. Geosmin elimination from eel seems not to occur according to the generally accepted passive diffusion mechanism for excretion of lipophilic chemicals and geosmin 
biotransformation by the eel seems plausible. Clearly geosmin depuration from European eel cannot be enhanced by increasing water renewal rates of depuration tanks.

Based on the findings of Chapter 4, a species specific response was suspected. Hence Chapter 5 also tested the hypothesis that increased water renewal rate of depuration tanks promote geosmin excretion by fish but in another species: Atlantic salmon. In addition Chapter 5 tested the hypothesis that two basic mechanisms to promote geosmin elimination interact such that increased excretion by the fish should be accompanied by increased geosmin removal from the direct environment to sort a maximal effect on net excretion and required depuration time. Two batches of Atlantic salmon ( $n=80$ per batch) with mean (SD) individual weights of 199.1 (42.0) and 202.9 (35.8) g and a mean (SD) lipid content of $3.5(0.6) \%(w / w)$ were loaded with geosmin. Fish were then depurated for $144 \mathrm{~h}$ during which they were subjected to combinations of water exchange (stagnant water or a water exchange rate of $\sim 1200 \mathrm{l} / \mathrm{kg}$ fish/d) and temperature $\left(\sim 11.5\right.$ or $\left.14.5^{\circ} \mathrm{C}\right)$ treatments. Model prediction revealed effects of water exchange, temperature and interactive effects of these two factors on the decline of the geosmin concentration in Atlantic salmon during depuration. Geosmin accumulation in the depuration tank water was predicted but not observed in the experiment. Based on this experiment we could not draw a clear conclusion regarding our interaction hypothesis. Temperature did not affect geosmin elimination from Atlantic salmon. The depuration experiment revealed a significant main effect of water exchange on geosmin elimination from Atlantic salmon, indicating that removal of excreted geosmin from the direct environment of this fish is needed to obtain maximal geosmin elimination from the fish. It then remains plausible that an increased geosmin excretion rate needs to be accompanied by an increased removal of the excreted geosmin from the fish's direct environment to obtain an optimal effect on the net elimination and depuration time.

The main focus of the General discussion is geosmin exposure of fish, including a review of geosmin dynamics in aquaculture systems, and off-flavour mitigation. The state of the art and perspectives of three strategies to mitigate off-flavour in aquaculture are discussed. These include prevention of microbial geosmin production, geosmin removal from the water and geosmin removal from the fish. The General discussion also addresses the modelling of geosmin bioconcentration in light of the finding of this thesis.

This thesis shows that there is more to geosmin bioconcentration in fish than passive partitioning over water and lipid compartments. Geosmin distribution within the body of rainbow trout and Nile tilapia is not exclusively governed by the lipid content of tissues and organs. In rainbow trout in vivo bioconcentration is less than the general fish bioconcentration model predicts, suggesting biotransformation. Based on the same model, the water renewal rate of depuration tanks was predicted to affect geosmin depuration from fish, but this was 
not observed in European eel and only to some extent in Atlantic salmon experiments. Based on this we assume that geosmin biotransformation is probable. Exercise (swimming) enhances geosmin excretion by European eel and Fed Nile tilapia eliminate geosmin faster from their ovaries than starved fish. The physiology underlying the bioconcentration process remains to be fully elucidated. Yet this thesis presents various measures for the optimization of offflavour depuration processes that can be readily adopted by the aquaculture industry. 


\section{Acknowledgements}

This thesis was completed over a period of 11 years and recalling all those that contributed in one way or the other was quite a trip down memory lane. In more or less random order I want to thank the following people for their indispensable help and support.

First of all I want to thank my promotors Tinka Murk, Johan Verreth and Johan Schrama. You three formed a great team. Because it is impossible to be exhaustive, I just mention what first comes to mind. Tinka, thanks for challenging the scientific consensus on geosmin bioconcentration right from the start and noticing that I suffered from a bit of tunnel vision. You introduced some of the more daring explanations for our observations in this thesis. Johan Verreth, thanks for your resolute handling of the administration that comes along with completing a Ph.D. thesis. As soon as I announced that I was going to work on the completion of this thesis, you quickly fixed a date for my defence. Thereby you effectively pushed me beyond a point of no return and set a deadline, something I clearly needed. I also enjoyed our discussions on the propositions, although it is unfortunate we couldn't share our passion for this folklore over a beer (an Affligem 'fris blond' for you). Johan Schrama, the words critical, honest, constructive and available describe your indispensable help probably best. We spoke almost daily during the last month of completing this thesis and you'd call on the days you didn't hear from me. Much appreciated! Where Tinka taught me to take a step back and look at the data from some distance to see what is there, you taught to stay close to what the data told me. I like to think that I ended up in the best mix of these two approaches.

I should mention that the opportunity for this thesis was originally created by Oliver Schneider's acquisition of the AquaVlan project and Henk van der Mheen allowing me to do this thesis as part of my regular work at Wageningen Marine Research within that project. $A$ unique opportunity, but you may both recall that it took time to convince me to accept it. I have to admit that there were times that I regretted I did, but in the end I am grateful.

To start a thesis is one thing, but to finish it while AquaVlan ceased to exist somewhere halfway is something different. I have to thank Geert Wiegertjes for recognizing what I needed and for creating these side conditions, together with Tammo Bult and my promotors.

Analytical chemistry was quite a new world for me. One of the first things I learned was that when it comes to accuracy, measuring geosmin concentrations differs from weighing a fish. Christiaan Kwadijk and Michiel Kotterman thank you for all your work on the optimization the geosmin analysis methods.

Two chapters in this thesis are based on research done within the SpaceTaste project. A big thanks to all members of the SpaceTaste team: Rian Schelvis, Ainhoa Blanco, Angelo Hofman, 
Ewout Blom, Jeppe Lund Nielsen, Mie Bech Lukassen, Paul Daniel Sindilariu, Emmanuel Bonpunt, Didier Leclerq, Jaap van Rijn, Snir Azaria, Fabian Mollet and Rene Remmerswaal. What we forget is the administrative nightmare that somehow came along with this EU project, what remains are the (academic baby) steps Towards off-flavour free finfish aquaculture we made together. Rian took care of the administrative management, allowing me to focus on the research. Ainhoa and Angelo set-up and ran the SpaceTaste experiments at our laboratory in Yerseke. A special thanks for Rene Remmerswaal for joining the project consortium halfway through the project and thereby essentially saving it from termination by the EC. In that context I also thank Reynout Hana of WUR Legal services.

The so-called "VIP project Off-flavour", acquired by Oliver Schneider, provided another opportunity to study off-flavour. We mainly studied the dynamics of off-flavours issues in recirculating aquaculture systems (RAS) and this work is referred to in the Introduction and General Discussion of this thesis. I thank the team Miriam van Eekert, Els Schuman and William Swinkels for our good cooperation. A special thanks to William for talking endlessly about your practical experience as an eel farmer with off-flavours. A very rich source of information indeed!

Have you seen those terribly complex equations? Not my work! A big thanks to Tobias van Kooten for doing math's that I never could have done myself. Thanks to Wiebe Koops and Pieter Vereijken for helping me with some of the statistics. Pieter is responsible for the statistics of chapter 5 . Wiebe for the design and analysis of the exercise experiment (chapter 3): "I don't do consultancies but this experimental design is such an intriguing challenge to get right that I just cannot resist" (or something similar, I deleted the e-mail).

I want to thank MSc. students Harm Kampen and Kasper Custers. Harm thanks for your work on the first geosmin uptake experiment we did. At first we were puzzled by the results but then figured out how to get it right and laid the foundation for the experiment that appears as Chapter 2 in this thesis. Kasper thanks for running the exercise experiment (Chapter 3 ) and Arjan Palstra for supervising Kasper. Arjan, I don't recall who first came up with the idea to use exercise to boost geosmin excretion, it has been too long, but I herewith give you the credits.

Long-time buddies Raymond and Wim, you claimed your roles as paranimphs right from the start. Great that you are still committed 11 years later.

OK, that's it I guess. I hope I made clear that although it is just my name on the cover of this book, there is no way that I could have completed it entirely by myself. Therefore once more a big thanks to all of you! 


\section{About the author}

Edward Schram was born on the $8^{\text {th }}$ of July 1972 in Culemborg, The Netherlands. He grew up in Beetsterzwaag and obtained his high school diploma in 1990 at the Andreas College, Drachten. That same year he started his study Animal Sciences at Wageningen University. He specialized in aquaculture and environmental technology and obtained his MSc. degree in 1996. After a year of travelling, he started working for the Palestinian Agricultural Relief Committees (PARC) with the assignment to set up an African catfish farm in Jericho. He returned to The Netherlands in 1999 to start working at the predecessor of the Netherlands Enterprise Agency (RVO). In 2001 he started working as project leader aquaculture at what is currently Wageningen Marine Research. He worked on various national and international aquaculture projects, both as researcher, project manager and project developer. Fish species he worked with include African catfish, European eel, pikeperch, rainbow trout, Dover sole and turbot. Topics ranged from husbandry systems, water treatment, water quality, feasibility studies and bioeconomics. In 2009 he took the opportunity to start a part-time PhD within the project AquaVlan in collaboration with Wageningen University. After two years the project was terminated due to administrative issues. He managed however to continue working on off-flavour within two newly acquired off-flavour projects as part of his regular work at Wageningen Marine Research. By the end of the last off-flavour project in 2015, sufficient data to complete a PhD thesis had been collected. However, time was lacking because the focus of his work at Wageningen Marine Research had shifted from aquaculture to fisheries research. Nevertheless, three papers on the original off-flavour research were published between 2016 and 2018. Finally he completed his PhD thesis in 2020 during, and to some extent thanks to, the COVID-19 lockdown. 
Training and Supervision Plan (TSP)

\begin{tabular}{|c|c|}
\hline \multicolumn{2}{|c|}{ GENERAL INFORMATION } \\
\hline Name PhD candidate & Edward Schram \\
\hline Project title & Absorption, distribution, metabolism and excretion of geosmin by fish \\
\hline Group & Aquaculture \& Fisheries, Marine Animal Ecology \\
\hline \multicolumn{2}{|l|}{ Supervising team: } \\
\hline Promotors & Prof. Dr J.A.J. Verreth, Prof. Dr A.J. Murk, Dr J.W. Schrama \\
\hline Project term & from 2009 \\
\hline
\end{tabular}

\section{EDUCATION AND TRAINING}

A. The Basic Package

WIAS Introduction Day (waiver)

WIAS course Ethics and Philosophy in Aquatic Life Sciences

Subtotal Basic Package until 2020

\begin{tabular}{|lcc|}
\hline B. Disciplinary Competences & year & credits \\
\hline SPSS vervolg cursus & 2002 & 0.9 \\
Special topics in Ecotoxicology (S131) & 2008 & 0.3 \\
Preparing own PhD research proposal & 2010 & 6.0 \\
Workshop IndusChemFate, Ravenstein, 11-Nov 2010 & 2010 & 0.3 \\
Use of Laboratory Animals 25-1 to 5-2 2010 & 2010 & 3.0 \\
WIAS Advanced statistics course Design of experiments & 2011 & 1.0 \\
SAS basis cursus & 1.4 \\
\hline Subtotal Disciplinary Competences & $\mathbf{1 2 . 9}$ \\
\hline & 2011 \\
\hline C. Professional Competences & year & credits \\
\hline Writing for Academic publication in the veterinary and life sciences & 2009 \\
Persoonlijke effectiviteit training & 1.5 \\
Survival at sea & 0.9 \\
Time management & 0.3 \\
Giving Feedback & 0.3 \\
Project management Essentials & 0.3 \\
\hline Subtotal Professional Competences & 2005 \\
\hline
\end{tabular}

\begin{tabular}{|lcc|}
\hline D. Societal Relevance & year & credits \\
\hline EuroTier, Hannover, Germany, 19 Nov. 2010, communication with society on off flavour & 2010 & 0.3 \\
Dutch Society for Aquaculture, presentation and discussion & 2015 & 0.6 \\
Aquacultuur: magazine of the Dutch Society for Aquaculture, contribution "Grondsmaak deel 1" & 2011 & 1.0 \\
Aquacultuur: magazine of the Dutch Society for Aquaculture, contribution "Grondsmaak deel 2" & 2011 & 1.0 \\
WMR Science Open Day to public, demonstration of scientific techniques & 2019 & 0.4 \\
\hline Subtotal Societal Relevance & $\mathbf{3 . 3}$ \\
\hline
\end{tabular}

\begin{tabular}{|lcc|}
\hline E. Presentation Skills & year & credits \\
\hline Three strategies to prevent off-flavour in farmed fish, Aquaculture Europe, Porto, Portugal, October 5-8, 2010, poster & 2010 & 1.0 \\
Off flavour in aquaculture, Nordic RAS, Helsinki, Finland, October 5-6, 2011, oral & 2011 & 1.0 \\
Optimizing off-flavour depuration from farmed fish, Aquaculture Europe, San Sebastian, Spain, October 14-17, 2014, oral & 2014 & 1.0 \\
Towards optimal off-flavour depuration, Aquaculture Europe, Rotterdam, the Netherlands, October 20-23, 2015, oral & 2015 & 1.0 \\
\hline Subtotal presentations & $\mathbf{4 . 0}$ \\
\hline
\end{tabular}

\begin{tabular}{|c|c|c|}
\hline F. Teaching competences & year & credits \\
\hline MSc thesis supervision 2010 & 2010 & 2.0 \\
\hline Bsc thesis supervision 2012 & 2012 & 0.6 \\
\hline AquaExcel international RAS training course: presentation on off-flavours & 2013 & 1.0 \\
\hline RAS training Singapore & 2015 & 1.2 \\
\hline Training in RAS, workshop presentation, Indonesia & 2016 & 1.2 \\
\hline Subtotal Teaching competences & & 6.0 \\
\hline
\end{tabular}

Education and Training Total 32.8

*One ECTS credit equals a studyload of approximately 28 hours 


\section{Colophon}

The research described in Chapter 2 was carried out in the framework of EU-Interreg IV "AquaVlan", funded by the European Regional Development Fund (ERDF).

The research described in Chapters 3 and 4 was carried out in the framework of BO 12.04 "Verduurzaming Visserij", sub-project BO-12.04-001-028 AquaOptima, funded by the Dutch Ministry of Economic Affairs.

The research described in Chapters 5 and 6 was carried out in the framework of Research for the benefit of specific groups (FP7-SME-2013), project 604956 SpaceTaste - Towards off flavour free finfish aquaculture, funded by the European Commission.

Cover design: Mercedes Benjaminse | Proefschriftmaken.nl

Cover artwork: Isis Schram ART | Instagram: @dark_arts

Lay-out: Edward Schram

Printed by: Proefschriftmaken.nl 
